SUPPORTING INFORMATION

\title{
A Fast and Reliable Screening Setup for Homogeneous Catalysis with Gaseous Reactants at Extreme Temperatures and Pressures
}

\author{
Max Siebert, Golo Storch, and Oliver Trapp
}




\section{Contents}

1 Autoclave Setup $\quad$ S4

1.1 Pictures of the Inert Gas Pressure Line . . . . . . . . . . . . . . . . . . S5

1.2 Pictures of Autoclaves . . . . . . . . . . . . . . . . S8

1.2.1 Autoclaves while Being Cooled . . . . . . . . . . . . . . . S8

1.2.2 Autoclaves at Room Temperature . . . . . . . . . . . . . . . . . . . S10

1.2.3 Autoclaves while Being Heated . . . . . . . . . . . . . . . . . . . S11

1.2.4 Autoclave during on-line Pressure Measurements . . . . . . . . . . . S13

1.2.5 Autoclave during in-situ IR Measurements . . . . . . . . . . . . . . . S14

1.2.6 Autoclave during in-situ IR and on-line Pressure Measurements . . . S16

1.2.7 $10 \mathrm{~mL}$ Autoclave . . . . . . . . . . . . . . . . . . . . . . S18

1.2.8 $15 \mathrm{~mL}$ Autoclave for on-line Pressure Measurements . . . . . . . . . S22

1.2.9 $35 \mathrm{~mL}$ Autoclave . . . . . . . . . . . . . . . . . . . . . . . . S26

1.2.10 $30 \mathrm{~mL}$ Autoclave for in-situ IR Measurements . . . . . . . . . . . . S28

1.2.11 $35 \mathrm{~mL}$ Autoclave for in-situ IR and on-line Pressure Measurements . S31

1.3 Components of the Inert Gas Pressure Line . . . . . . . . . . . . . . . . . . . S34

1.4 Reduced Setup of the Inert Gas Pressure Line . . . . . . . . . . . . . . . . S39

1.5 Components of Autoclaves . . . . . . . . . . . . . . . . . . . . . . S43

$1.5 .110 \mathrm{~mL}$ Autoclave . . . . . . . . . . . . . . . . . . . . S43

1.5.2 $15 \mathrm{~mL}$ Autoclave for on-line Pressure Measurements . . . . . . . . S46

$1.5 .335 \mathrm{~mL}$ Autoclave . . . . . . . . . . . . . . . . . . . . . . S48

1.5.4 $30 \mathrm{~mL}$ Autoclave for in-situ IR Measurements . . . . . . . . . . . . . S50

1.5.5 $35 \mathrm{~mL}$ Autoclave for in-situ IR and on-line Pressure Measurements . S53

1.6 Further Equipment Used . . . . . . . . . . . . . . . . . . . . . . . S56 
2 Applications of Autoclaves $\quad$ S57

2.1 General Procedure for Pressurized Reactions . . . . . . . . . . . . . . . . S57

2.1.1 Workflow for a Reaction at Room Temperature . . . . . . . . . . . . S60

2.1.2 Workflow for a Reaction at High Temperature . . . . . . . . . . . . . S62

2.1.3 Workflow for a Reaction at Low Temperature . . . . . . . . . . . . . . S64

2.1.4 Workflow when using Carbon Dioxide in a Reaction at Higher Temperatures . . . . . . . . . . . . . . . . . . S66

2.2 Documentation of the Work Steps . . . . . . . . . . . . . . . . . . . . S68

3 Asymmetric Hydrogenation $\quad \mathbf{S 7 9}$

3.1 Preliminary Remarks . . . . . . . . . . . . . . . . . . . . . . . . . . . . S79

3.1.1 Solvents and Reagents . . . . . . . . . . . . . . . . . . . S79

3.1 .2 NMR Spectroscopy . . . . . . . . . . . . . . . . . . . . . . . . . . . S79

3.1.3 Pressure Measurement . . . . . . . . . . . . . . . . . . . . S80

3.1 .4 IR Spectroscopy . . . . . . . . . . . . . . . . . . . . . . . . . . S880

3.1 .5 HPLC Analysis . . . . . . . . . . . . . . . . . . . . . . . S80

3.2 Demonstration of the Analytic Techniques in the Asymmetric Hydrogenation of 2-Phenylacrylic Acid . . . . . . . . . . . . . . . . . . . . . . S82

3.3 Asymmetric Hydrogenation of Prochiral $\alpha$-Substituted Acrylic Acids . . . . S86

3.3.1 Hydrogenation of 2-Phenylacrylic Acid . . . . . . . . . . . . . . . S86

3.3.2 Hydrogenation of Dehydronaproxen . . . . . . . . . . . . . . S100

List of Abbreviations $\quad \mathbf{S 1 1 4}$

$\begin{array}{ll}\text { Bibliography } & \text { S116 }\end{array}$ 


\section{Autoclave Setup}

In the following sections, the inert gas pressure line as well as the different types of autoclaves are shown with additional information as for instance technical sketches, naming of the individual parts and application examples. The framed component names are explicitly listed and described again in the sections 1.3, 1.4 and 1.5. 


\subsection{Pictures of the Inert Gas Pressure Line}

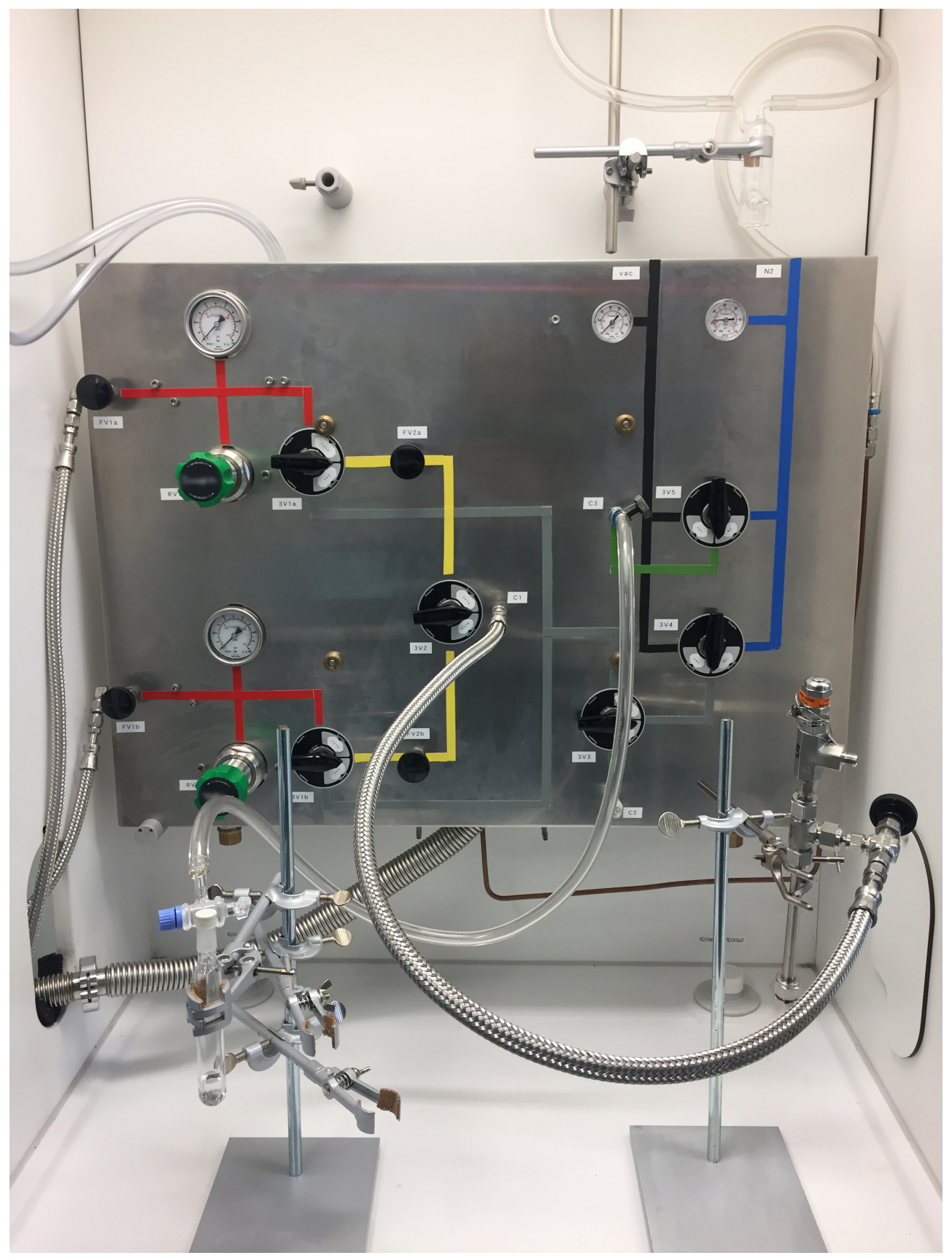

Figure S1.1: Front view of the inert gas pressure line. 


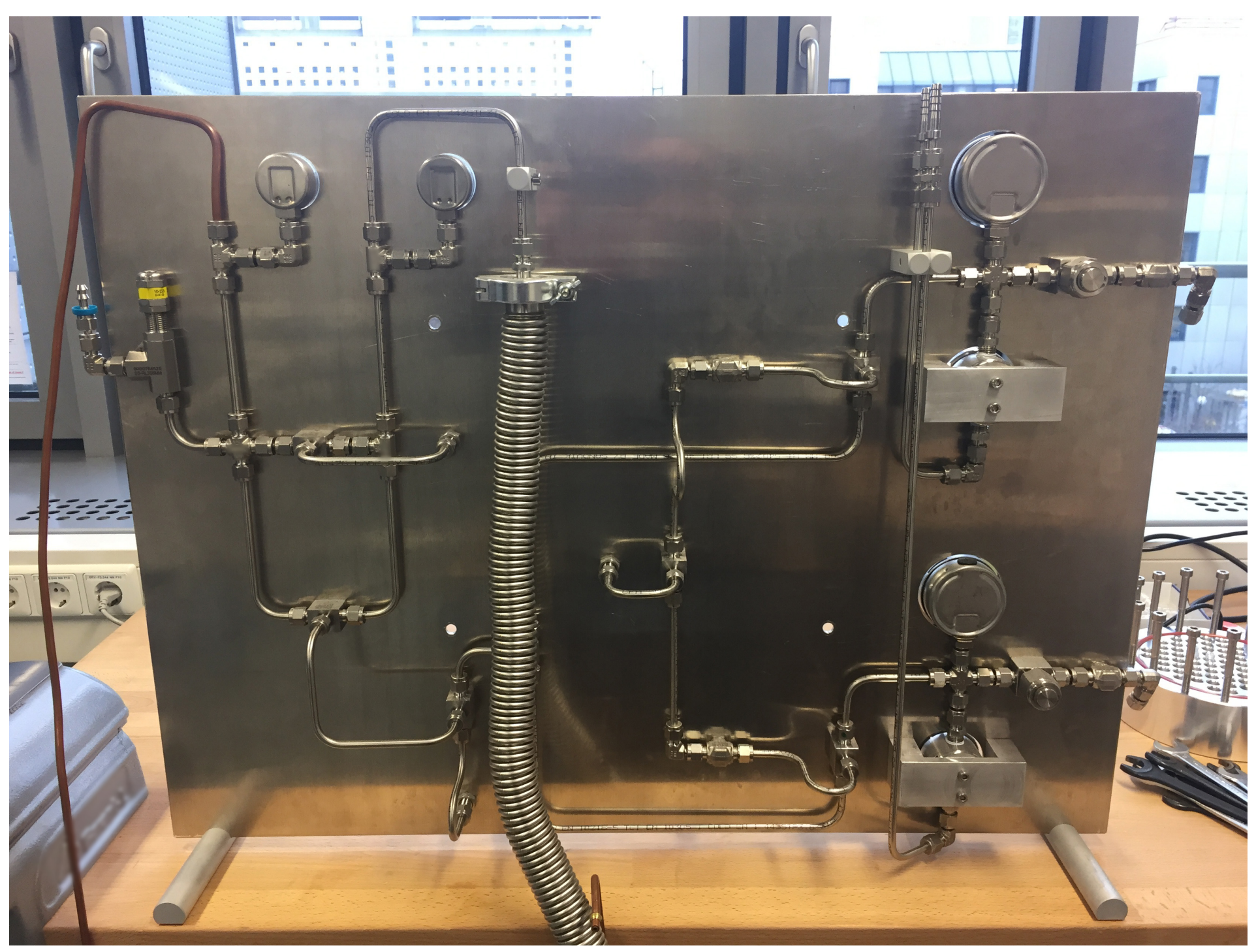




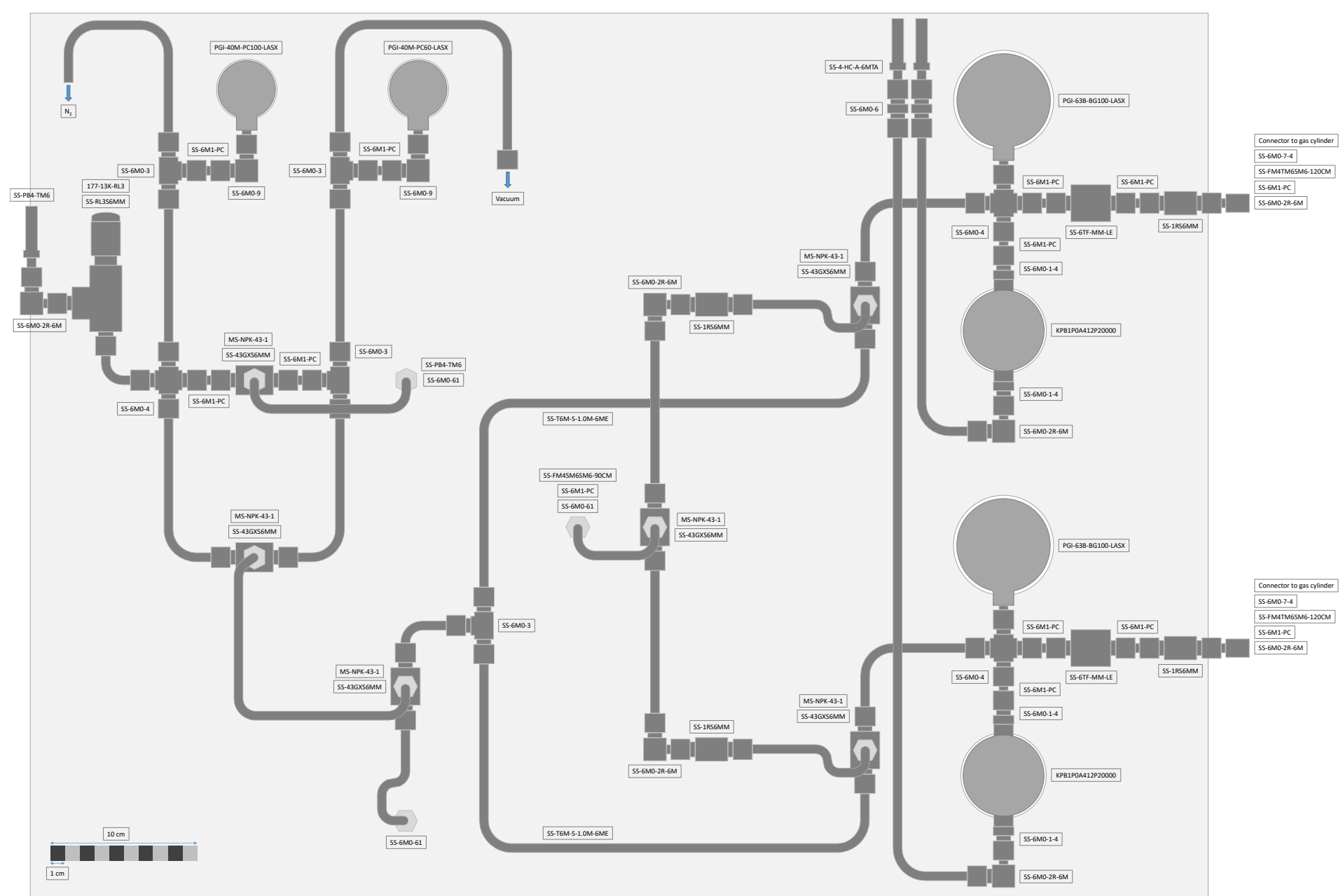

Figure S1.3: Technical sketch of the inert gas pressure line. The graphic can be scaled arbitrarily to better see details and the labels of the individual parts. The scale of the technical drawing is shown in the lower left corner. 


\subsection{Pictures of Autoclaves}

\subsubsection{Autoclaves while Being Cooled}

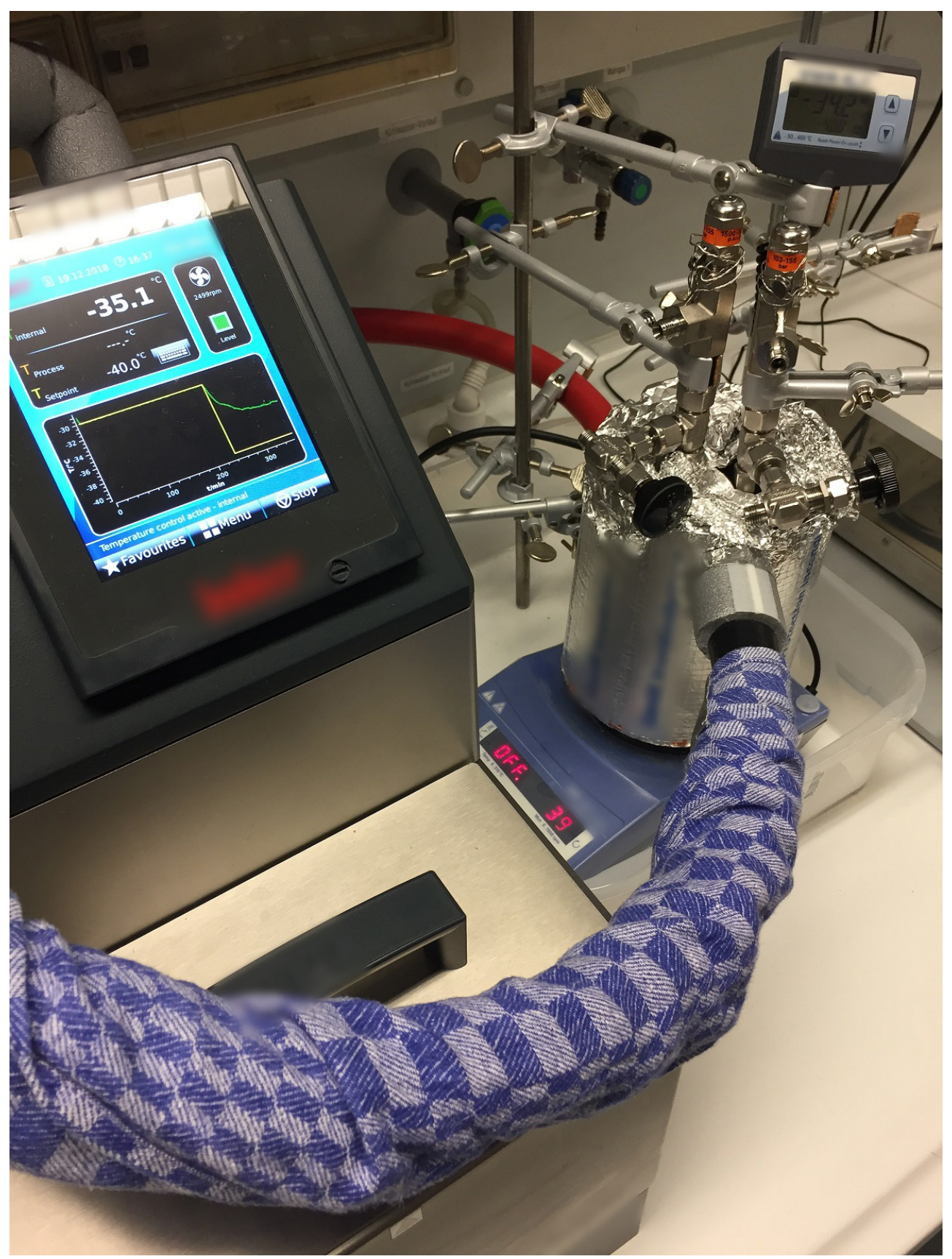

Figure S1.4: View of the cooling setup. 


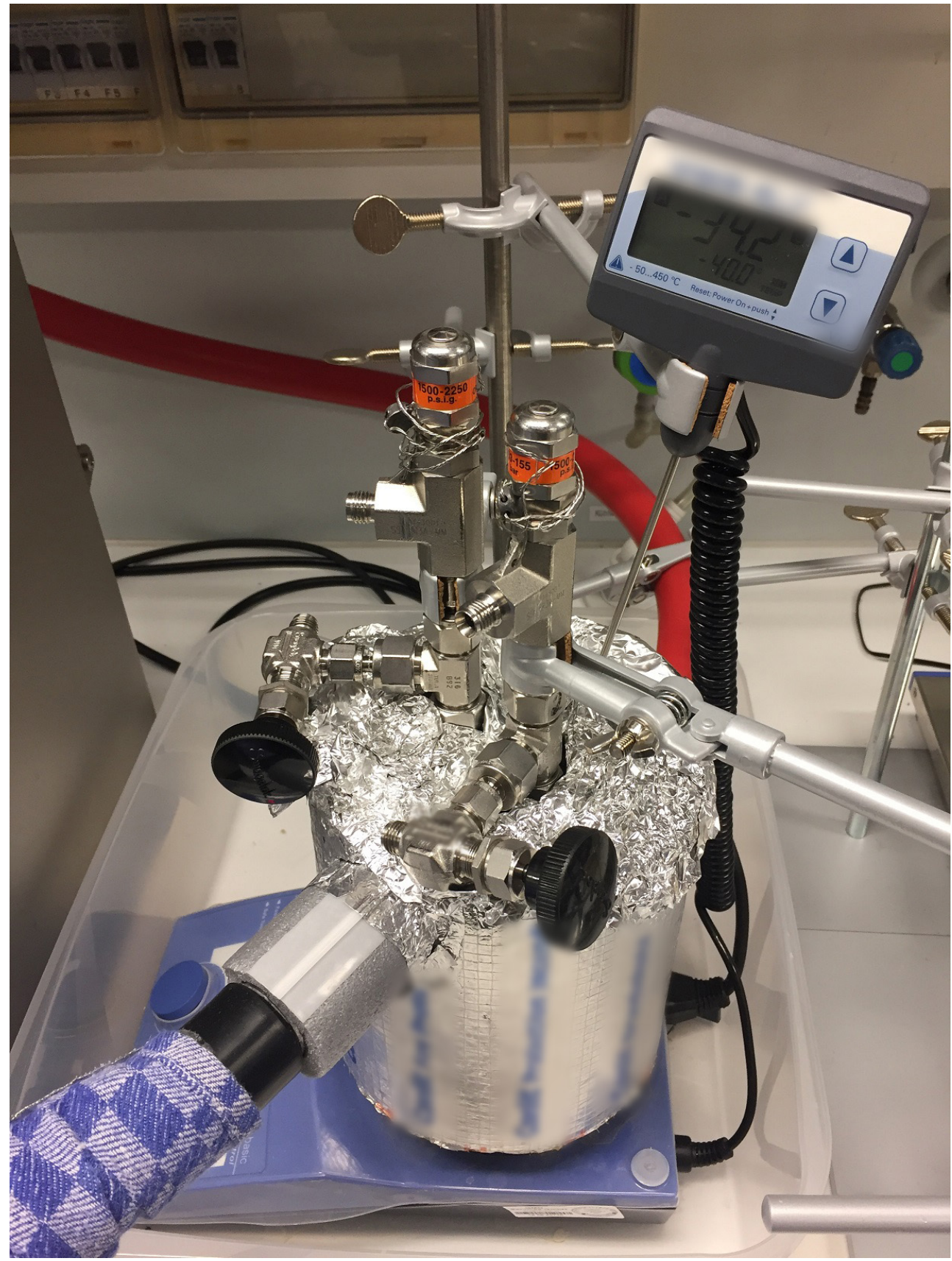

Figure S1.5: View of cooled autoclaves. 


\subsubsection{Autoclaves at Room Temperature}

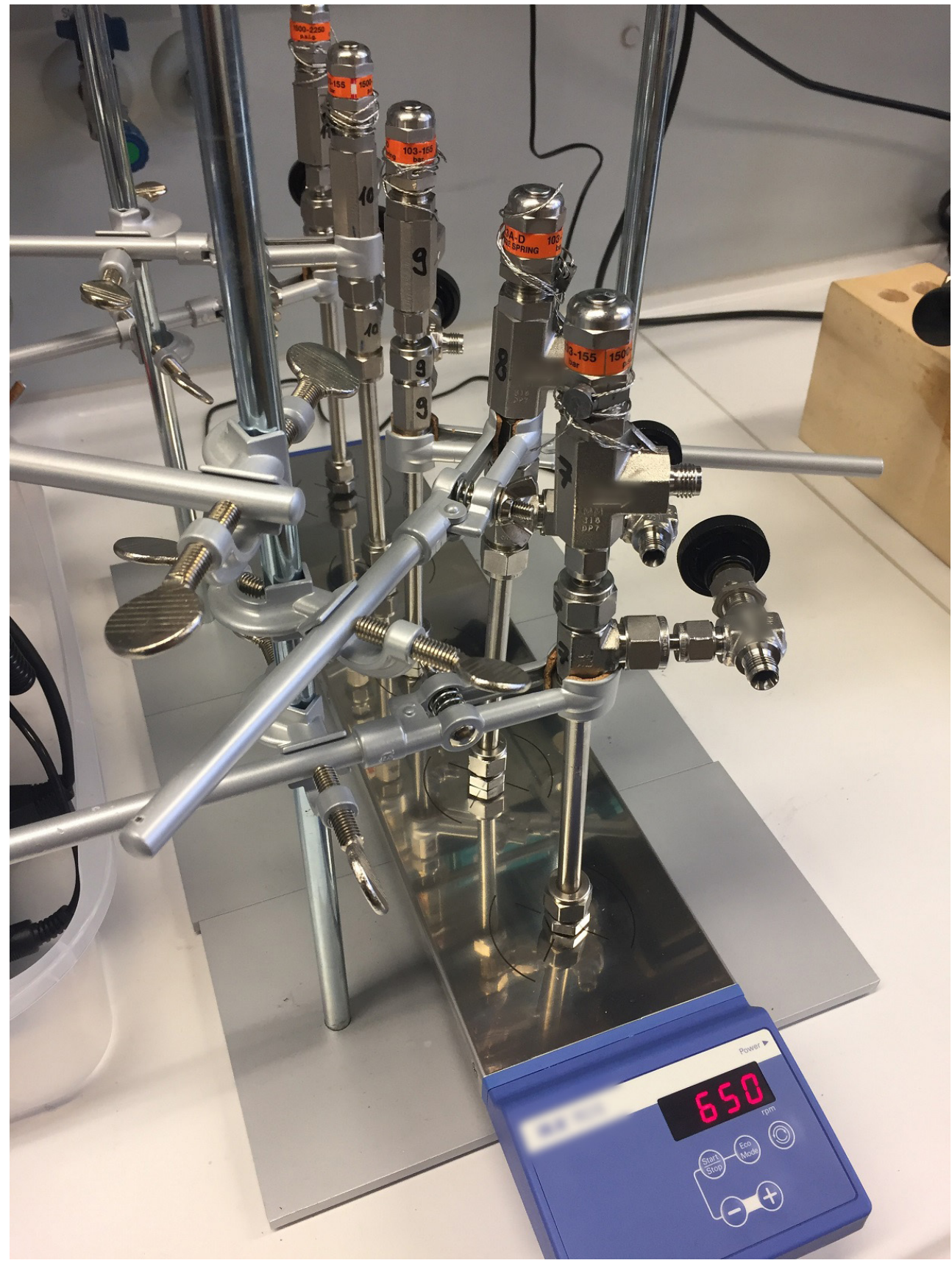

Figure S1.6: View of autoclaves stirring at room temperature. 


\subsubsection{Autoclaves while Being Heated}

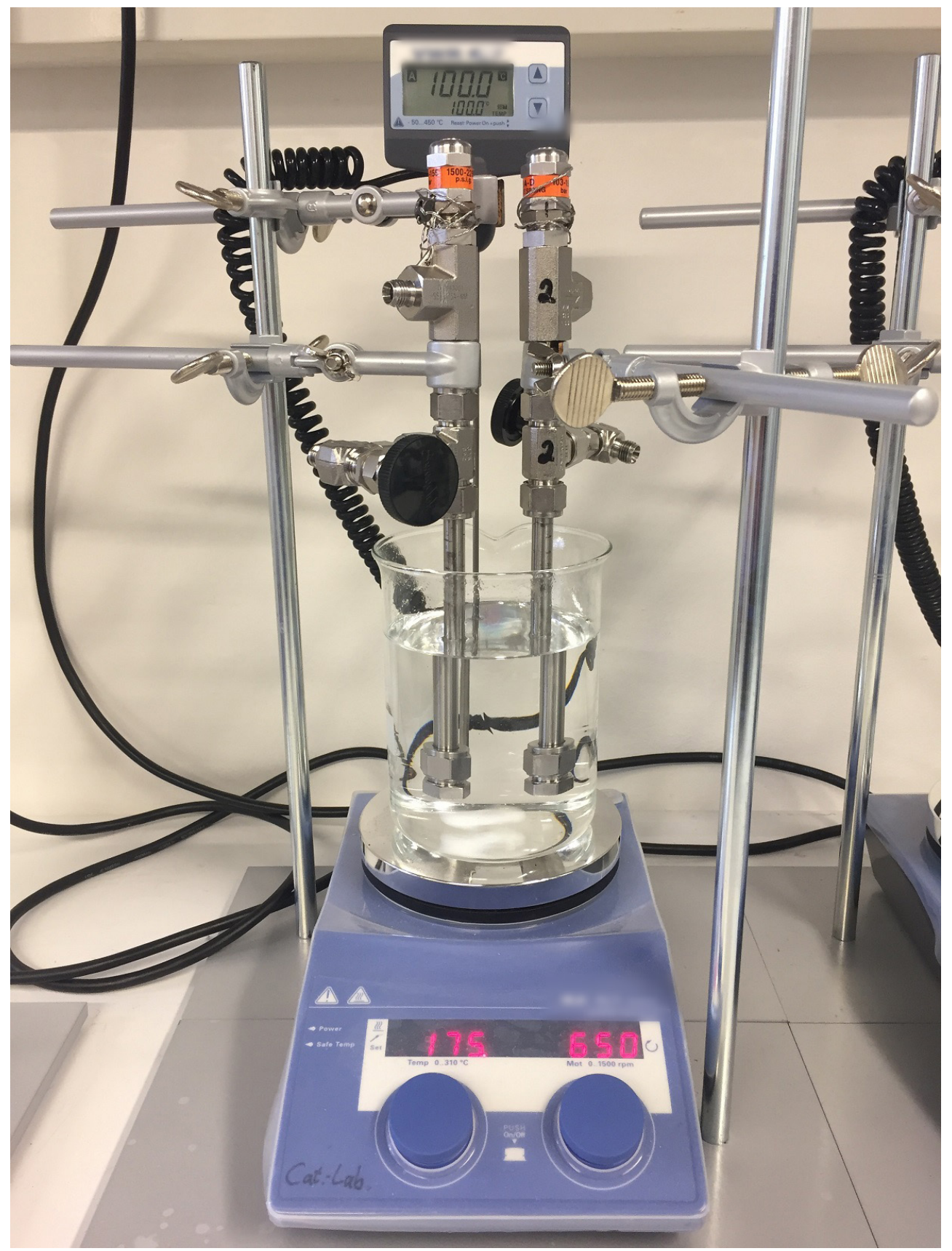

Figure S1.7: View of heated autoclaves. 


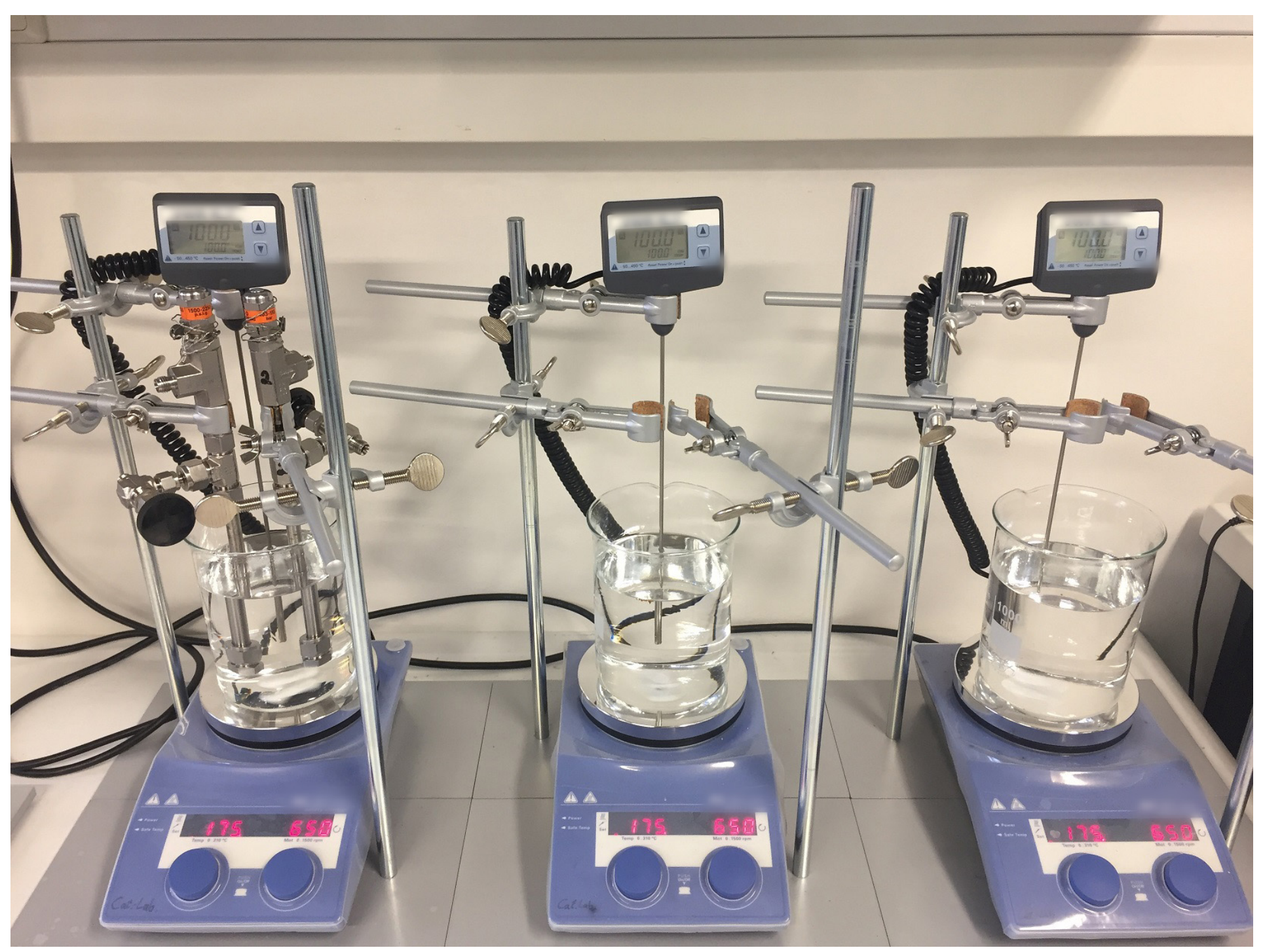




\subsubsection{Autoclave during on-line Pressure Measurements}

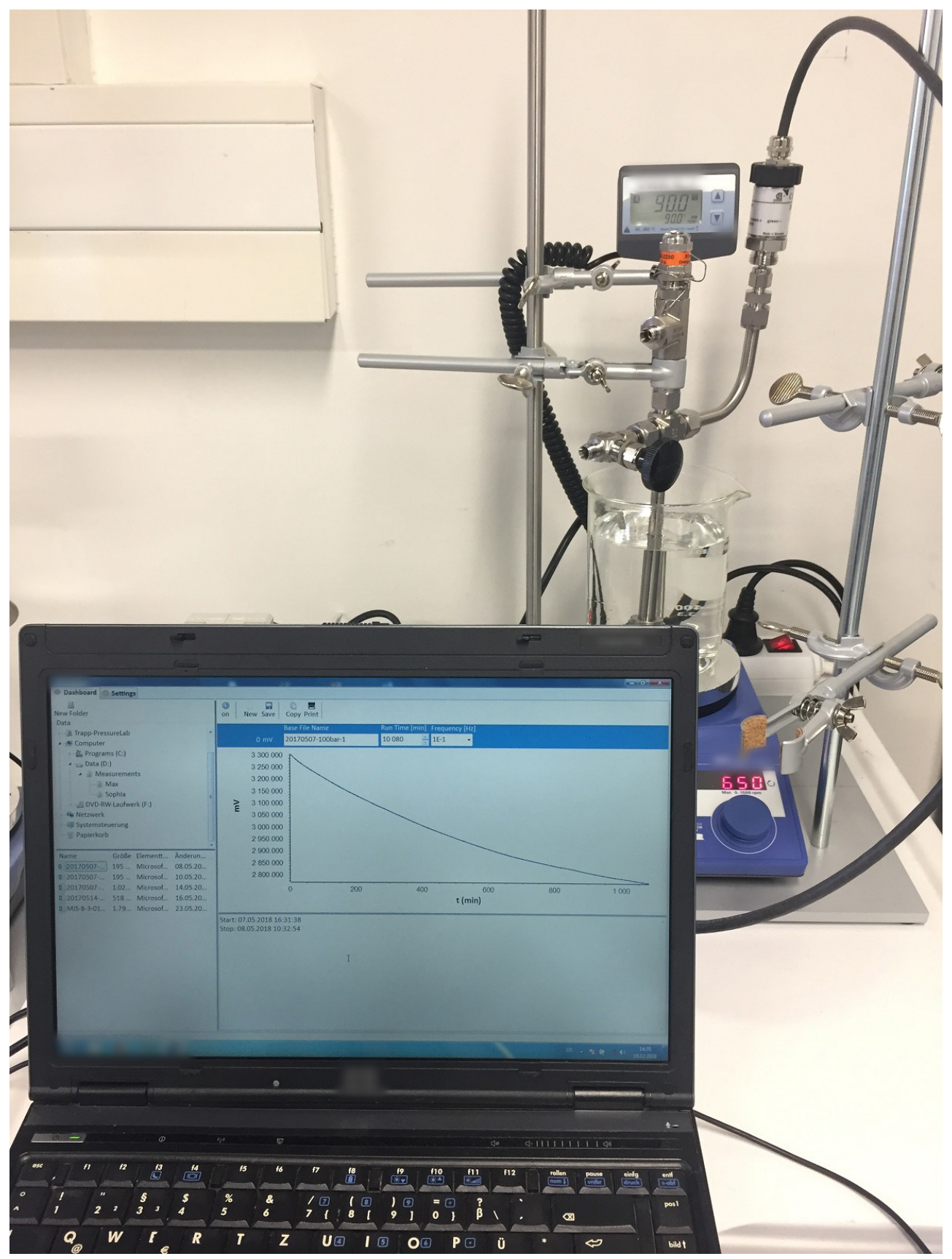

Figure S1.9: View of a heated autoclave during on-line pressure measurements. 


\subsubsection{Autoclave during in-situ IR Measurements}

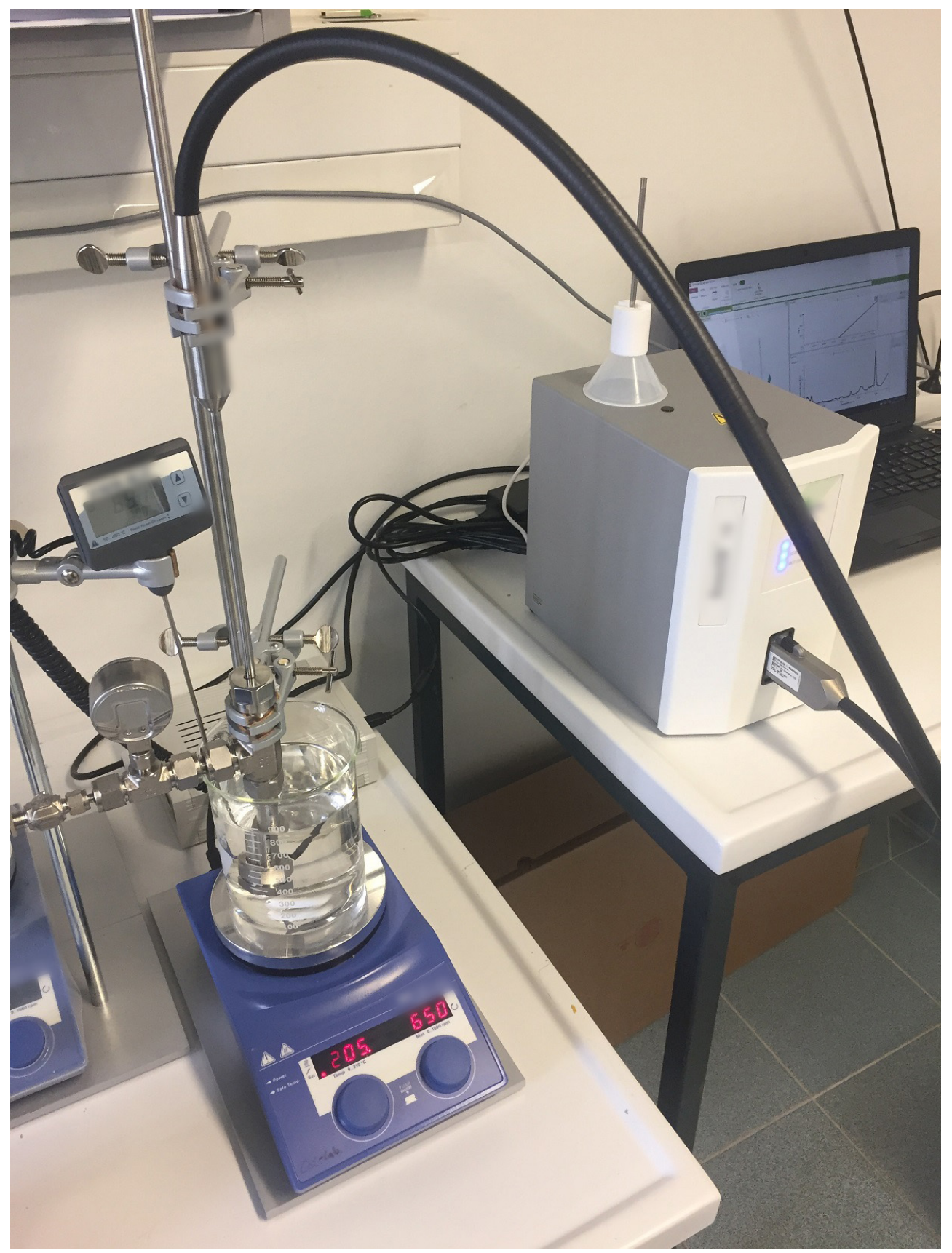

Figure S1.10: View of a heated autoclave during in-situ IR measurements. 


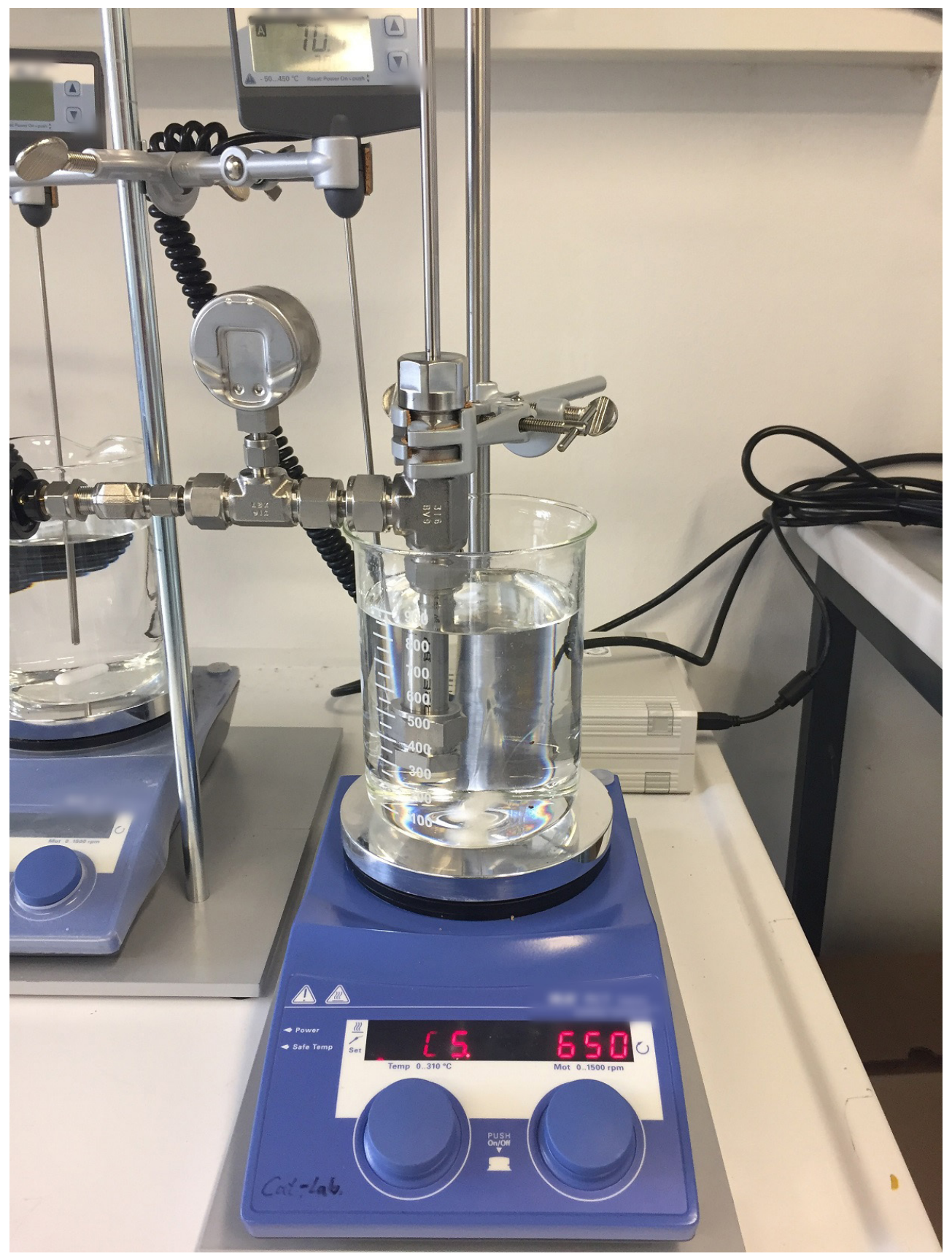

Figure S1.11: View of a heated autoclave during in-situ IR measurements. 


\subsubsection{Autoclave during in-situ IR and on-line Pressure Measurements}

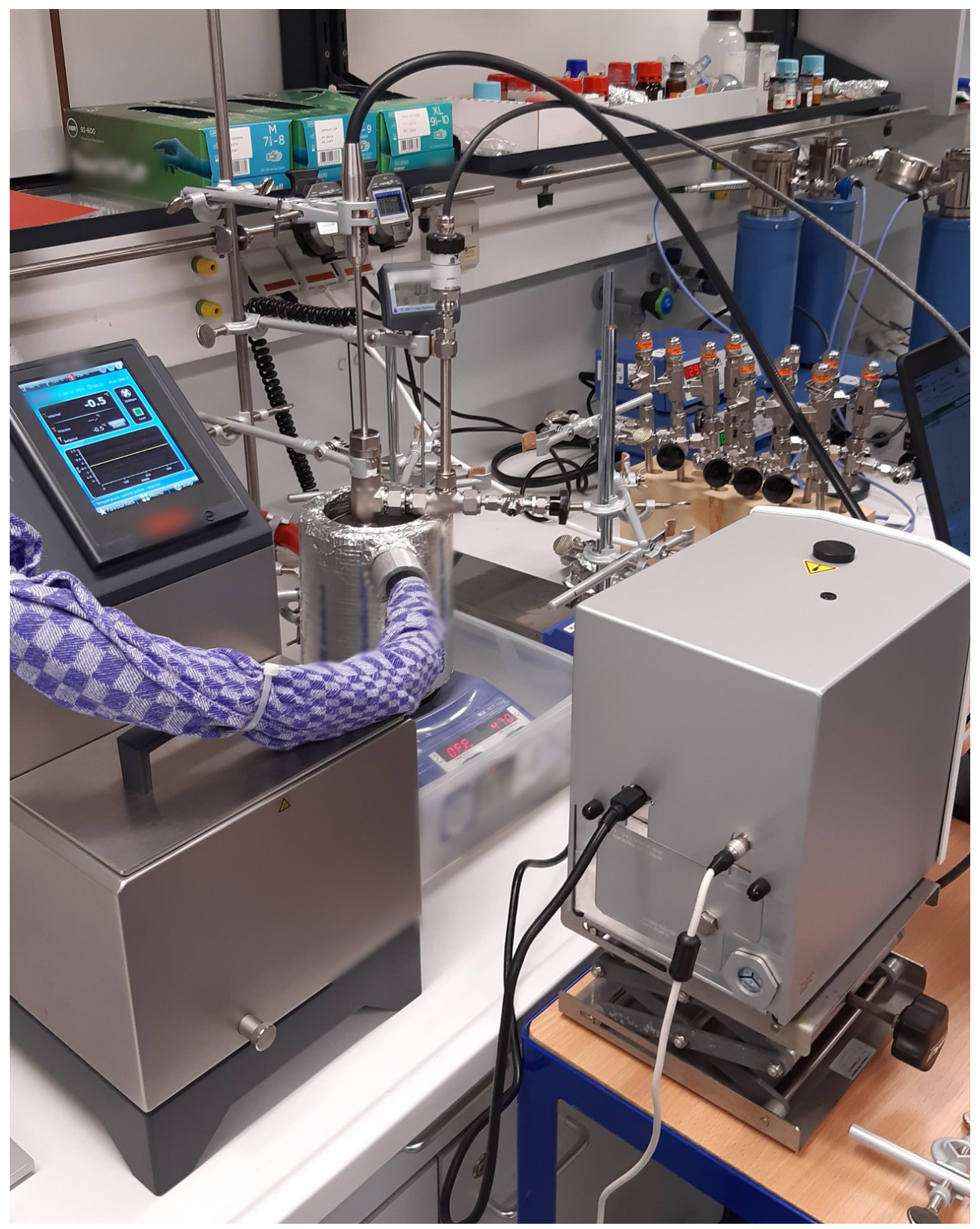

Figure S1.12: View of a cooled autoclave during in-situ IR and on-line pressure measurements. 


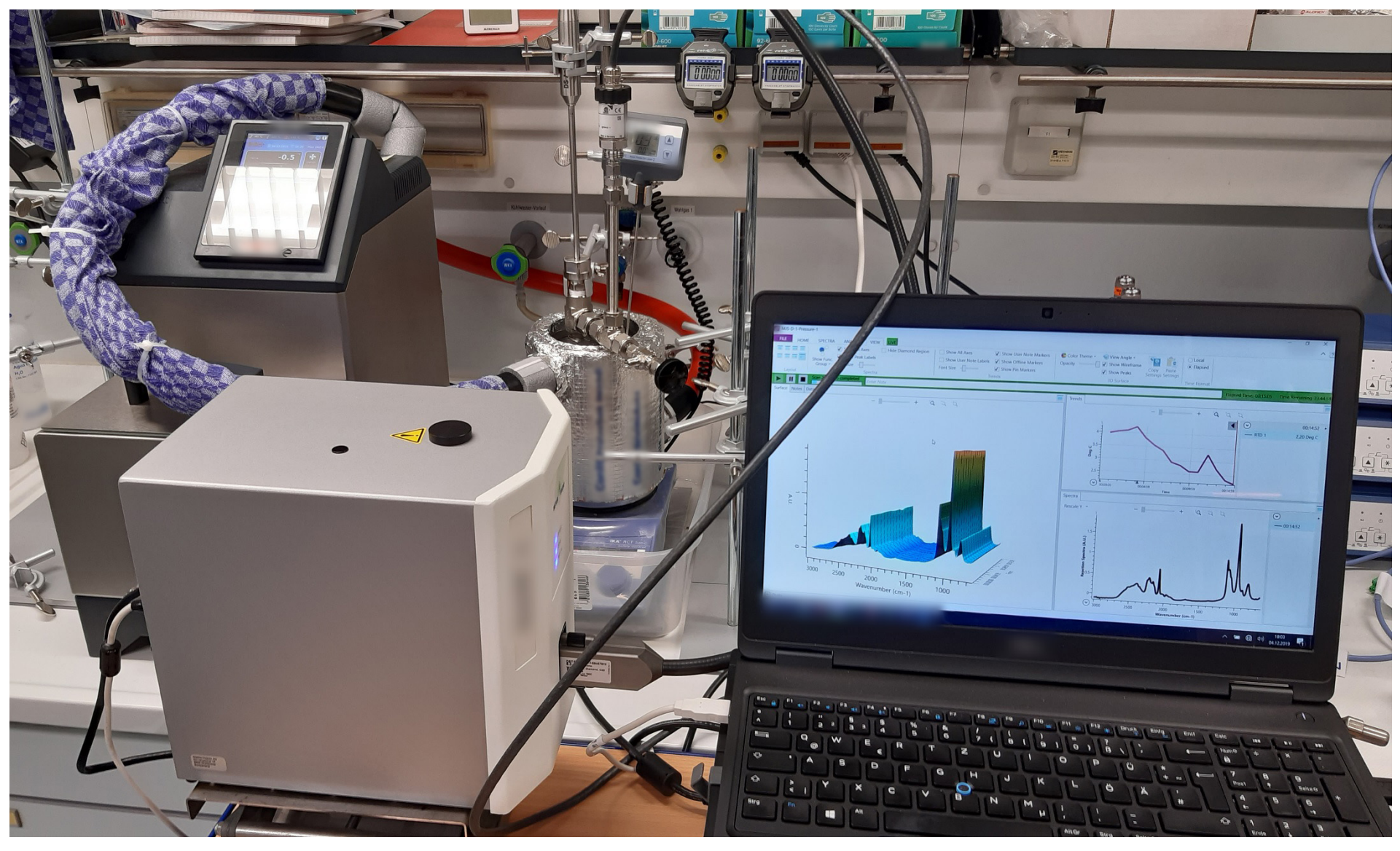

Figure S1.13: View of a cooled autoclave during in-situ IR and on-line pressure measurements. 


\subsection{7 $10 \mathrm{~mL}$ Autoclave}

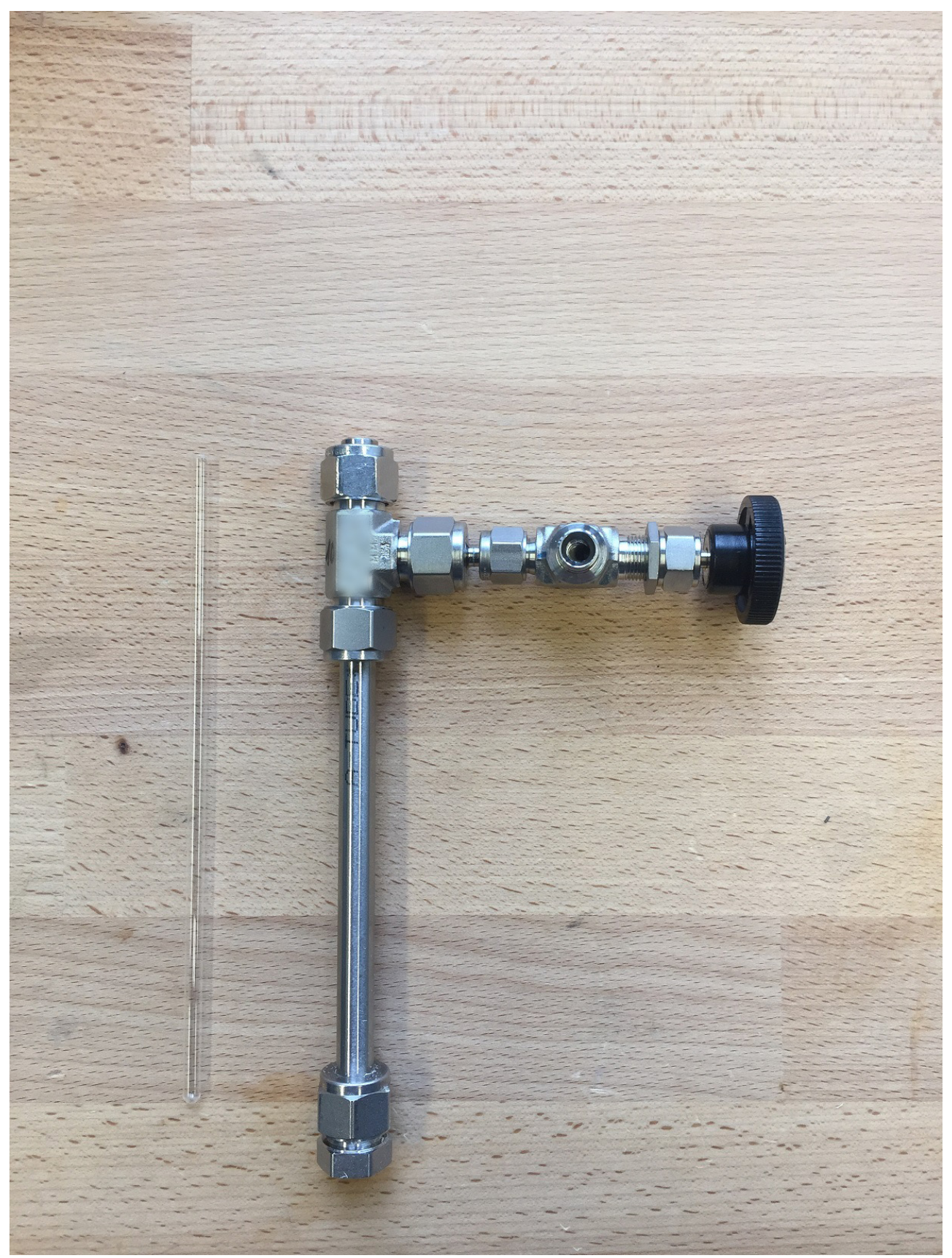

Figure S1.14: View of a $10 \mathrm{~mL}$ autoclave closed with a plug (right) together with a standard $7 \mathrm{in.}$ NMR tube (left). 


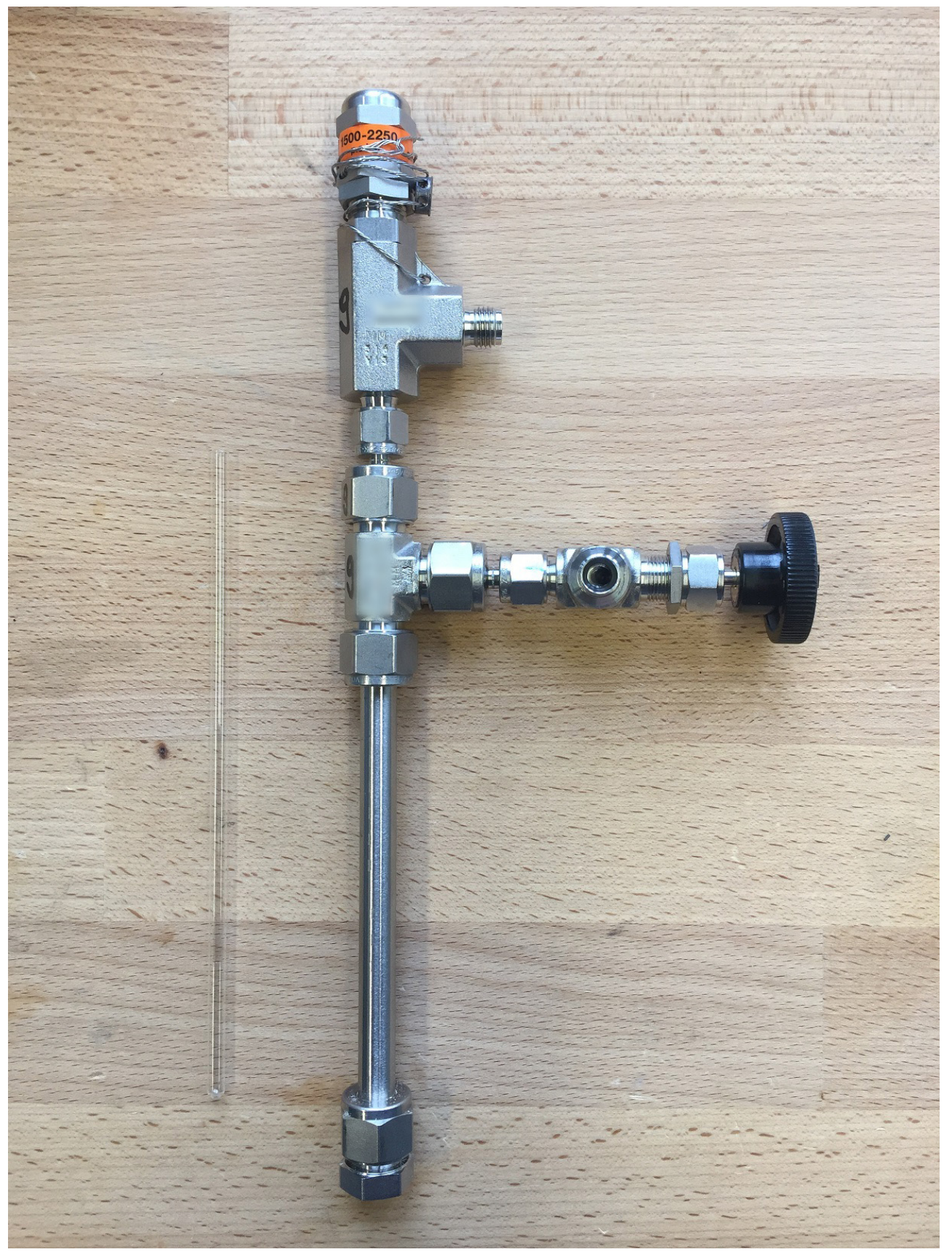

Figure S1.15: View of a $10 \mathrm{~mL}$ autoclave closed with a proportional relief valve (right) together with a standard $7 \mathrm{in}$. NMR tube (left). 


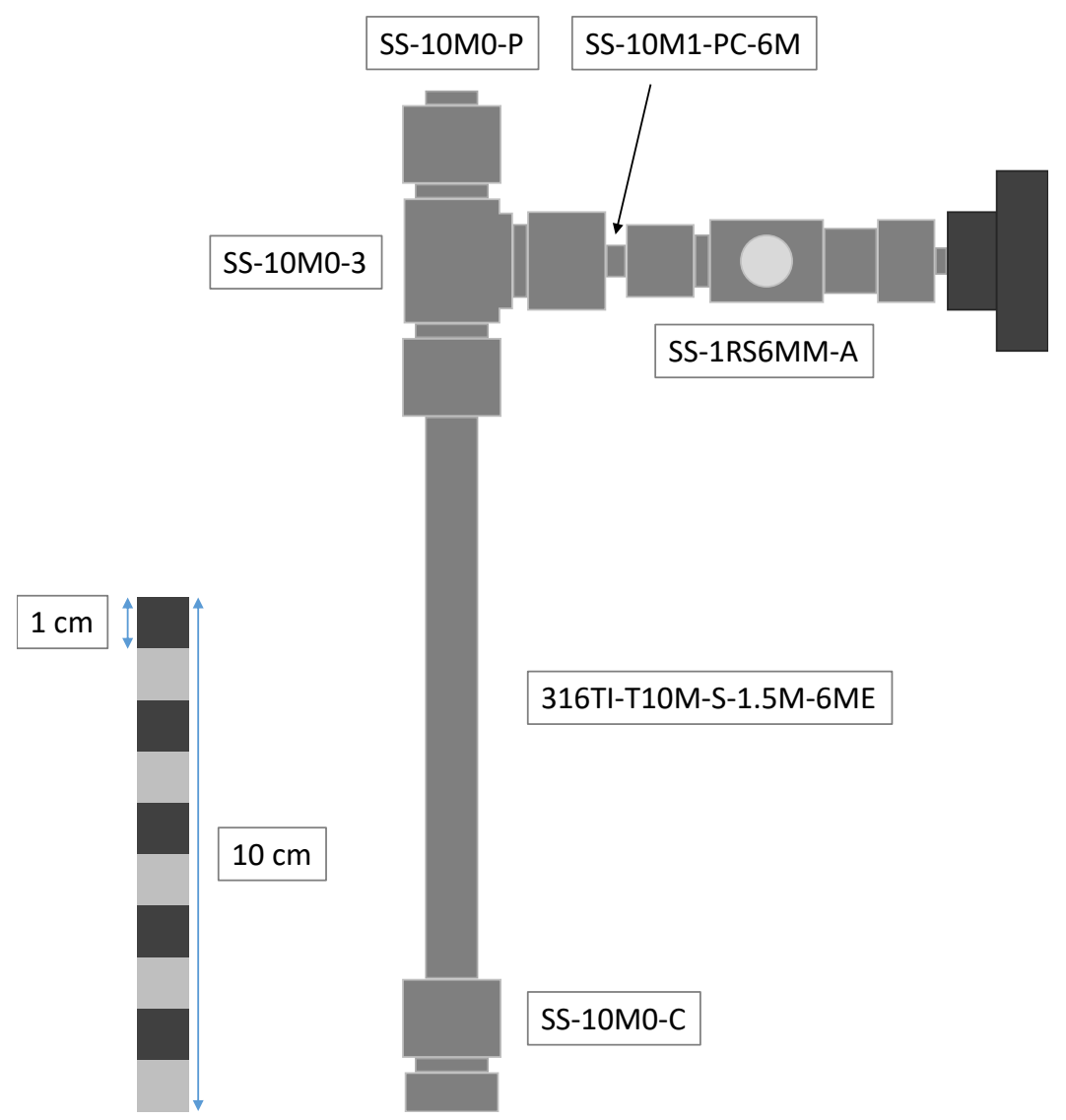

Figure S1.16: Technical sketch of the $10 \mathrm{~mL}$ autoclave closed with a plug. The graphic can be scaled arbitrarily to better see details and the labels of the individual parts. The scale of the technical drawing is shown in the lower left corner. 


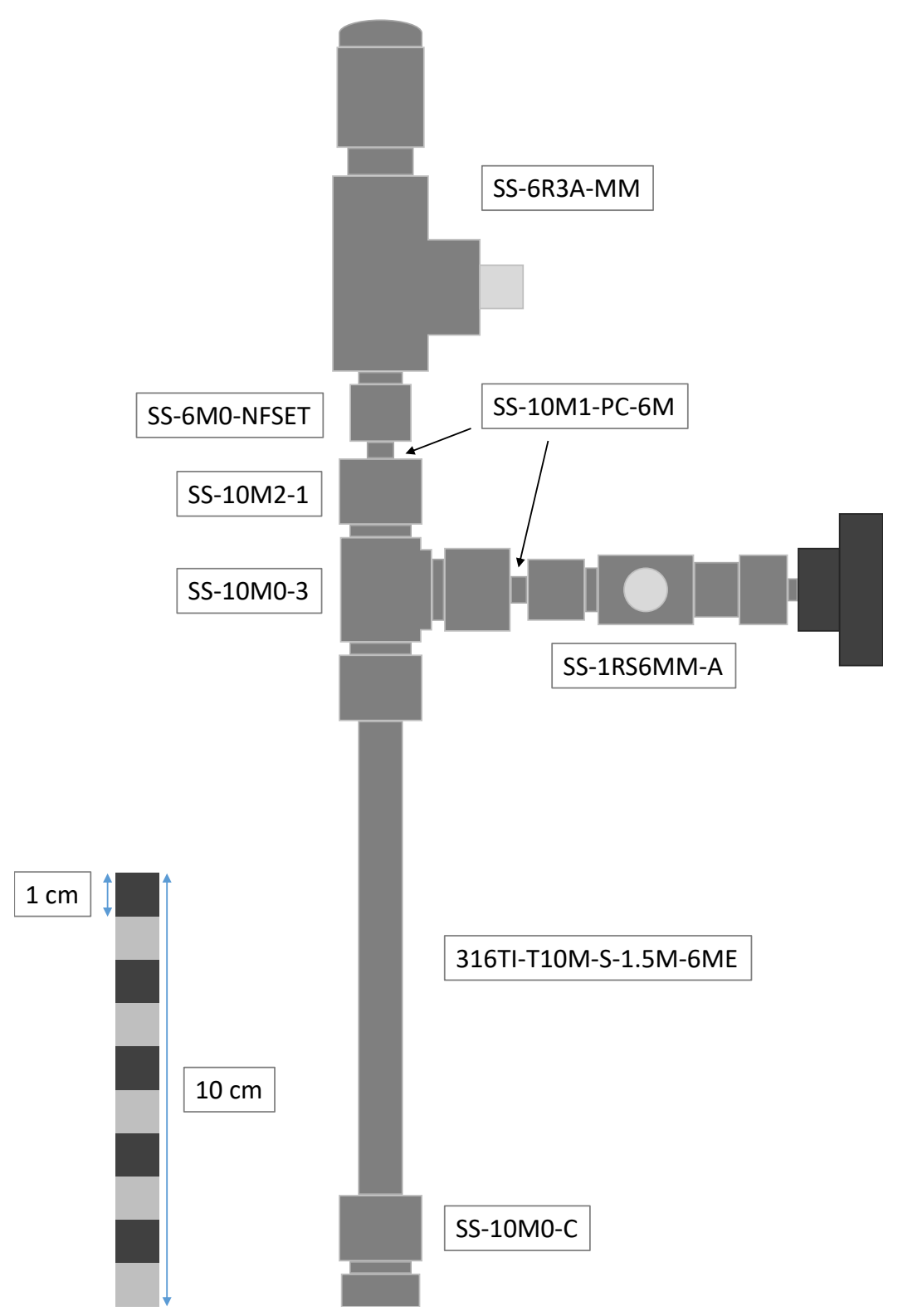

Figure S1.17: Technical sketch of the $10 \mathrm{~mL}$ autoclave closed with a proportional relief valve. The graphic can be scaled arbitrarily to better see details and the labels of the individual parts. The scale of the technical drawing is shown in the lower left corner. 


\subsection{8 $15 \mathrm{~mL}$ Autoclave for on-line Pressure Measurements}

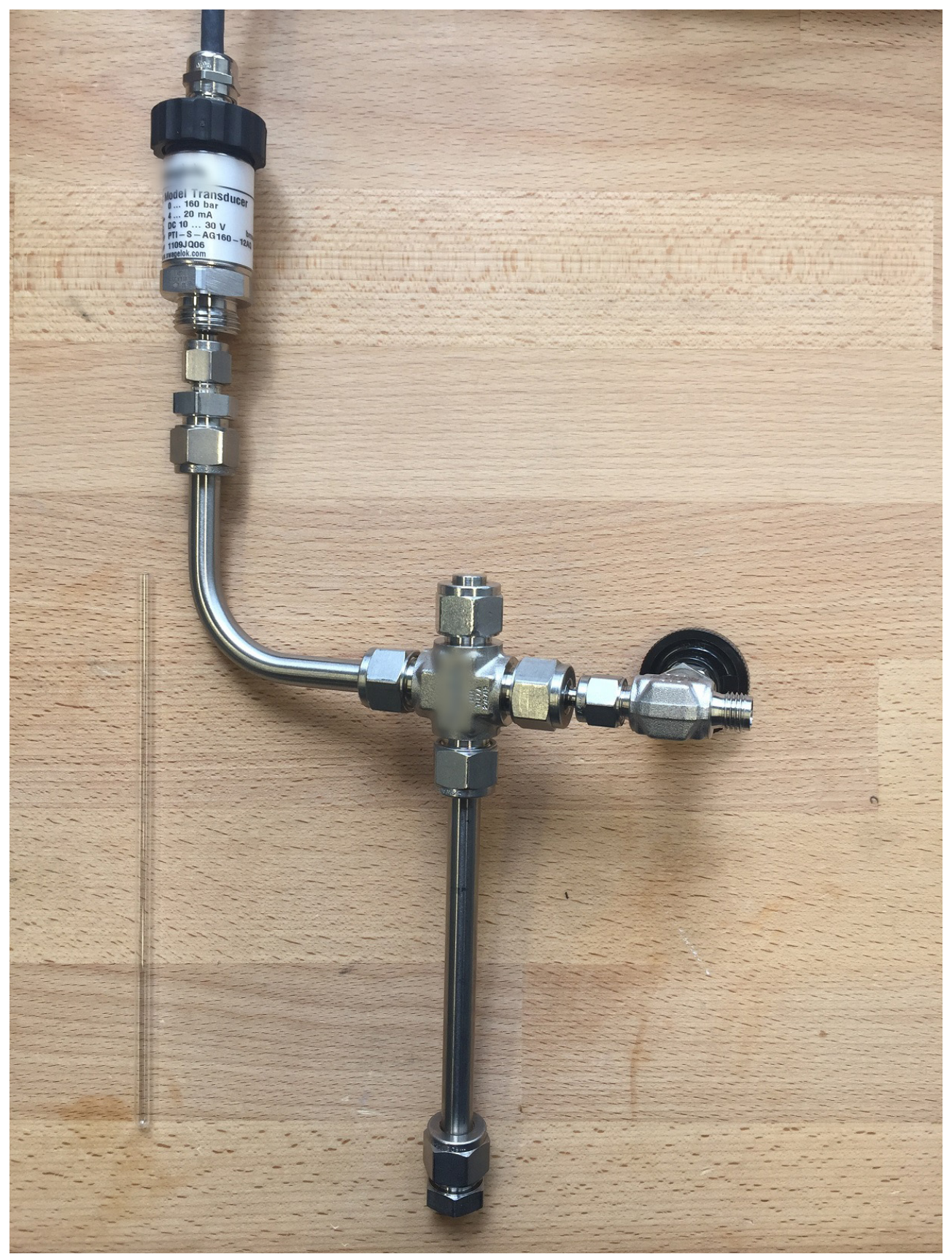

Figure S1.18: View of a $15 \mathrm{~mL}$ autoclave for on-line pressure measurements closed with a plug (right) together with a standard 7 in. NMR tube (left). 


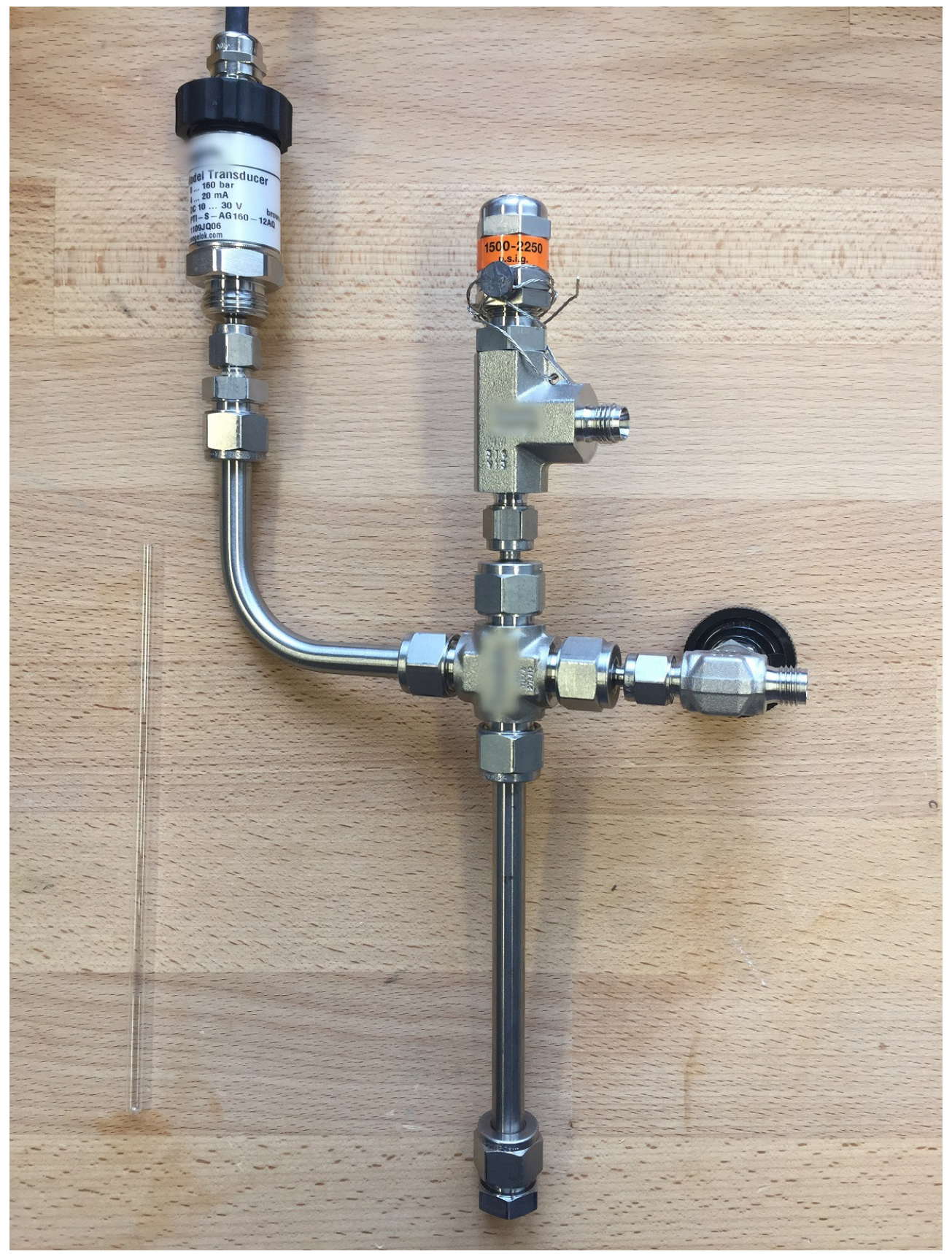

Figure S1.19: View of a $15 \mathrm{~mL}$ autoclave for on-line pressure measurements closed with a proportional relief valve (right) together with a standard 7 in. NMR tube (left) 


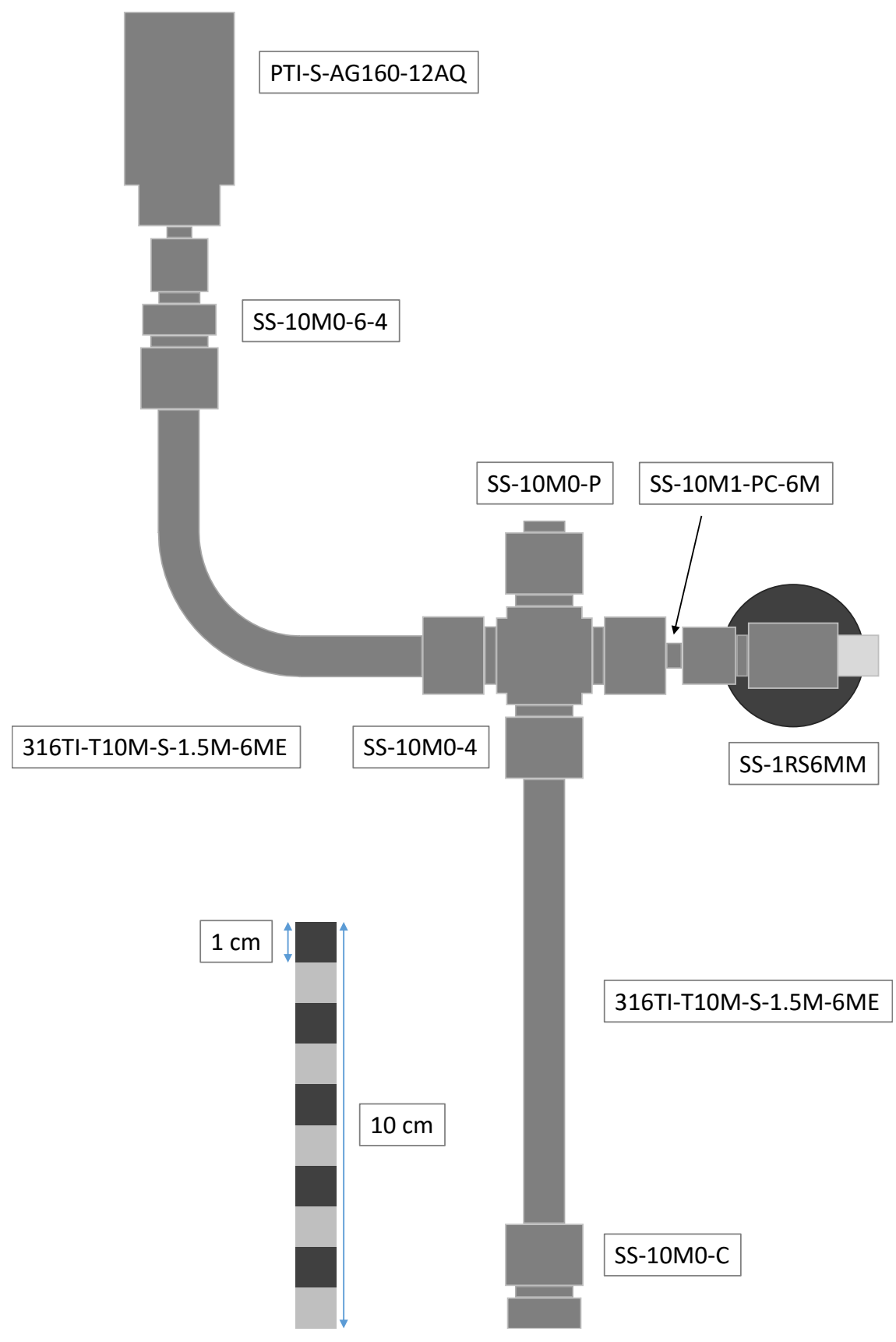

Figure S1.20: Technical sketch of the $15 \mathrm{~mL}$ autoclave for on-line pressure measurements closed with a plug. The graphic can be scaled arbitrarily to better see details and the labels of the individual parts. The scale of the technical drawing is shown in the lower left corner. 


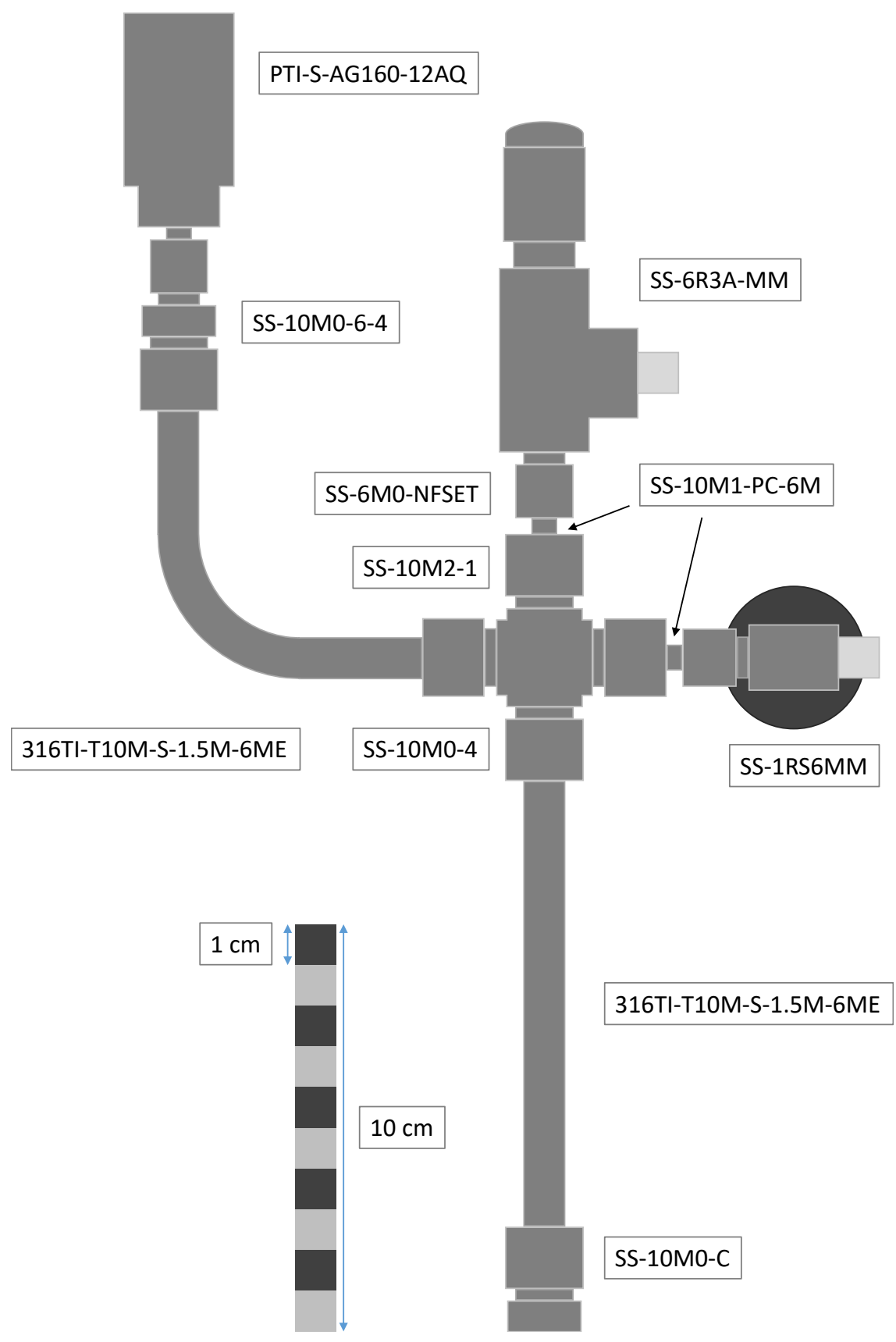

Figure S1.21: Technical sketch of the $15 \mathrm{~mL}$ autoclave for on-line pressure measurements closed with a proportional relief valve. The graphic can be scaled arbitrarily to better see details and the labels of the individual parts. The scale of the technical drawing is shown in the lower left corner. 


\subsection{9 $35 \mathrm{~mL}$ Autoclave}

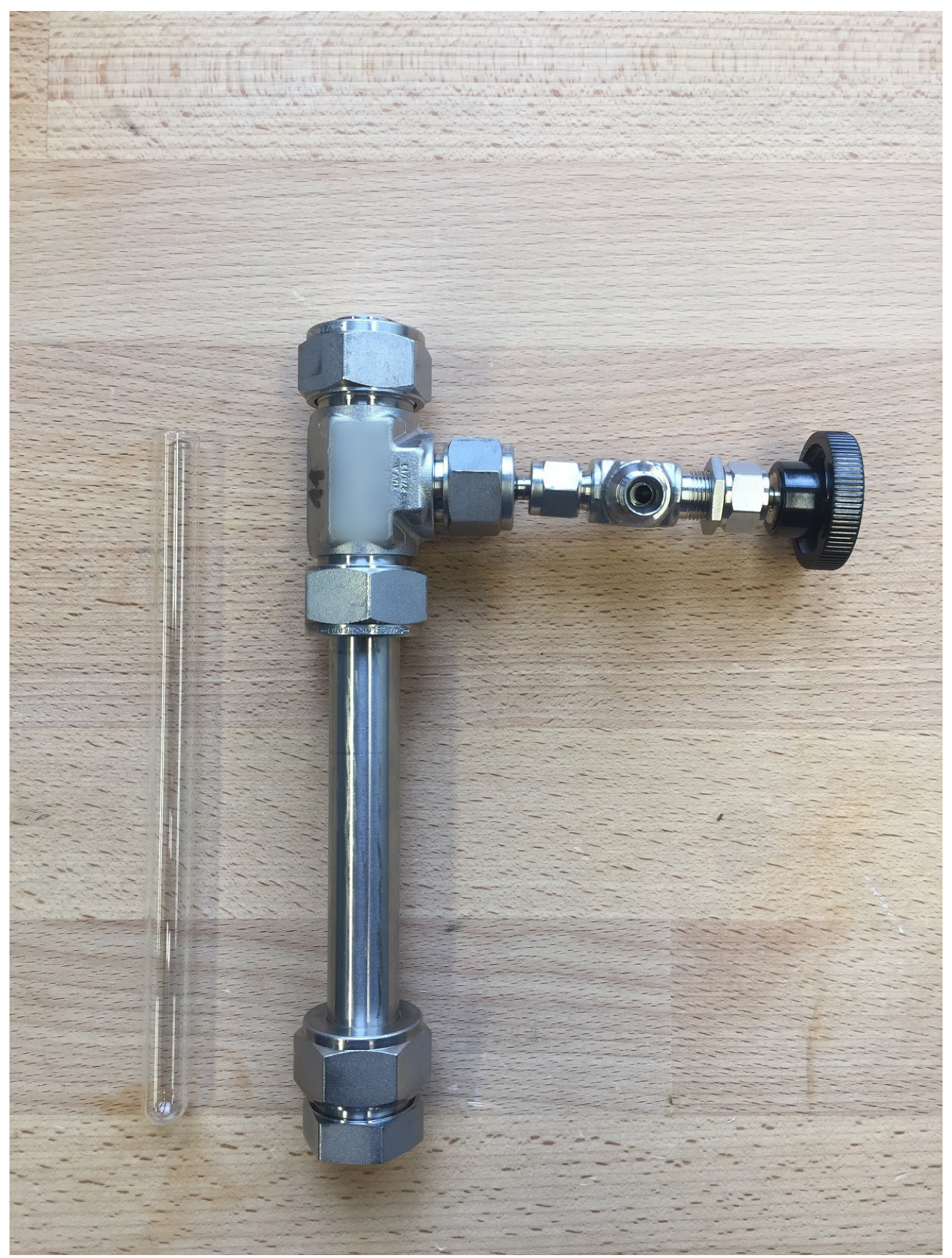

Figure S1.22: View of a $35 \mathrm{~mL}$ autoclave closed with a plug (right) together with a glass inset (left). 


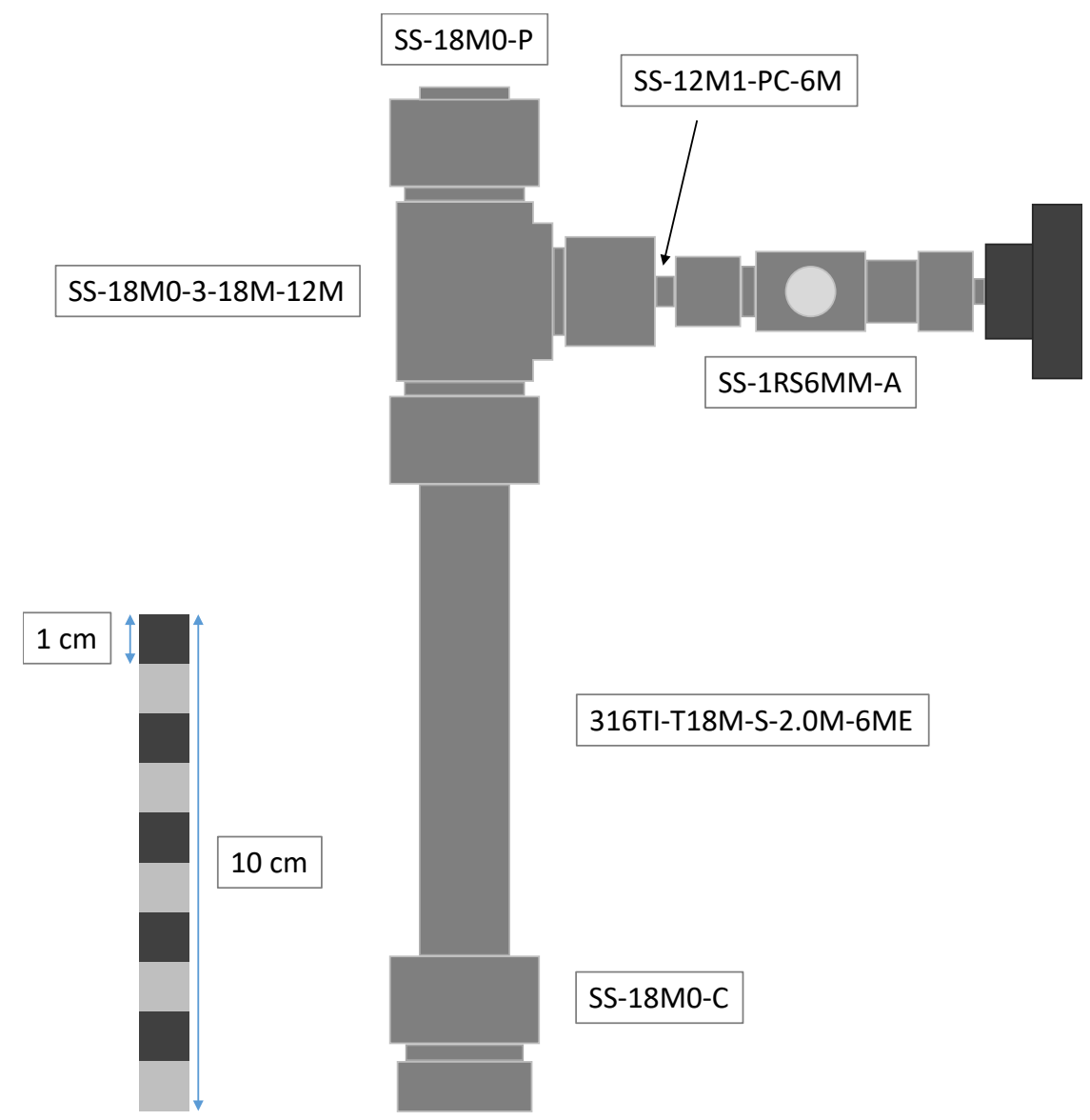

Figure S1.23: Technical sketch of the $35 \mathrm{~mL}$ autoclave closed with a plug. The graphic can be scaled arbitrarily to better see details and the labels of the individual parts. The scale of the technical drawing is shown in the lower left corner. 


\subsubsection{0 $30 \mathrm{~mL}$ Autoclave for in-situ IR Measurements}

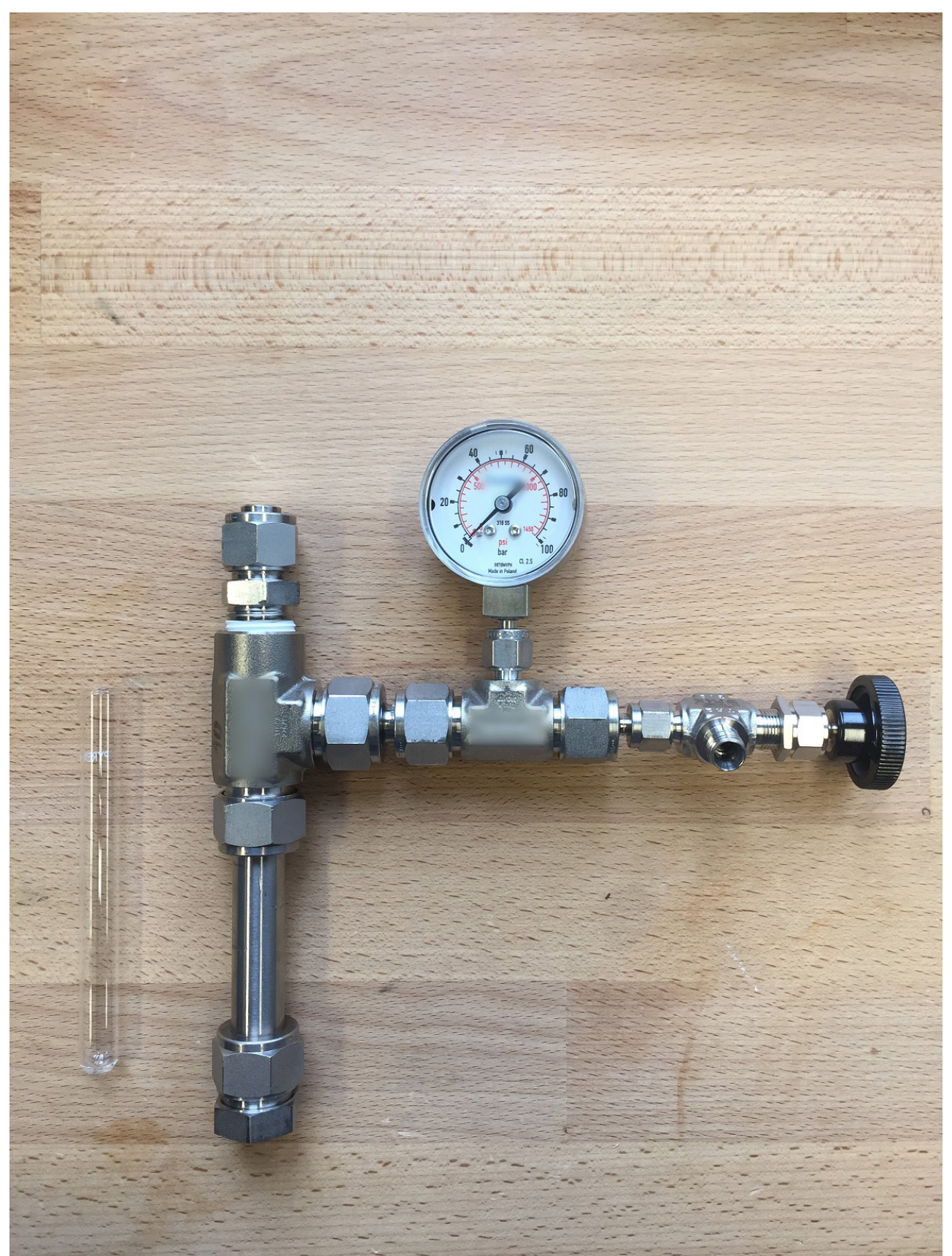

Figure S1.24: View of a $30 \mathrm{~mL}$ autoclave for in-situ IR measurements closed with a tube fitting and a plug (right) together with a glass inset (left). 


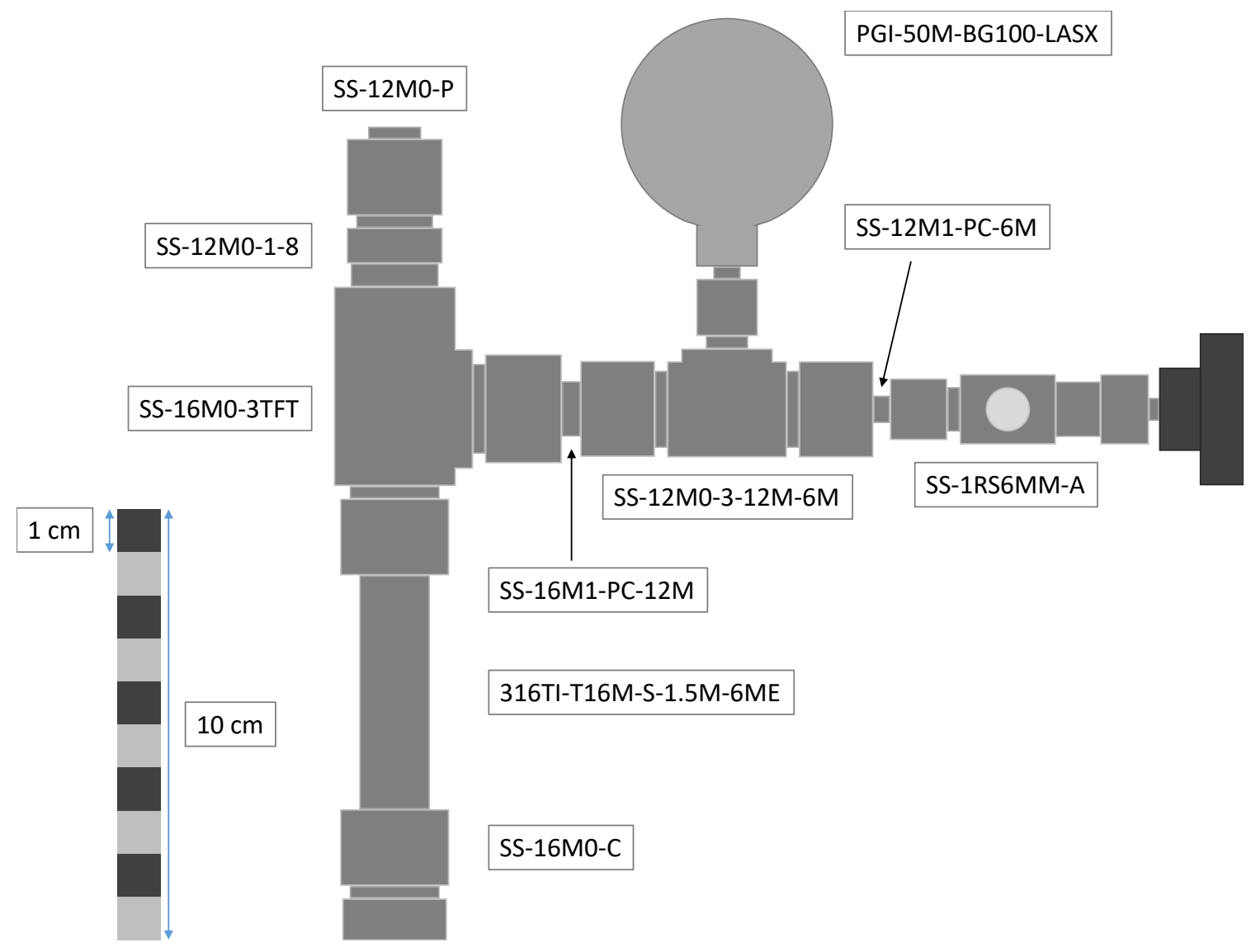

Figure S1.25: Technical sketch of the $30 \mathrm{~mL}$ autoclave for in-situ IR measurements closed with a tube fitting and a plug. The graphic can be scaled arbitrarily to better see details and the labels of the individual parts. The scale of the technical drawing is shown in the lower left corner. 


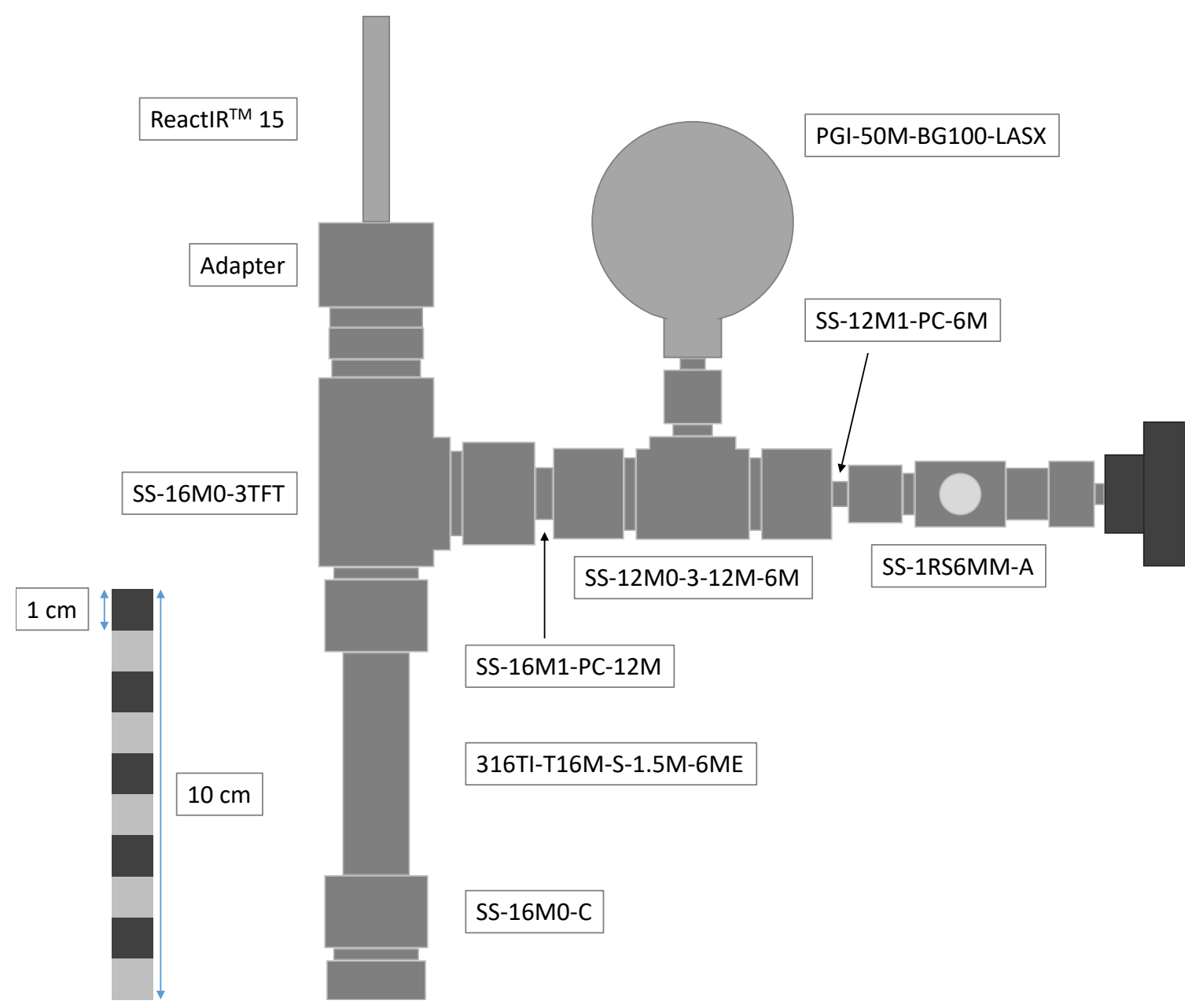

Figure S1.26: Technical sketch of the $30 \mathrm{~mL}$ autoclave for in-situ IR measurements with installed IR probe. The graphic can be scaled arbitrarily to better see details and the labels of the individual parts. The scale of the technical drawing is shown in the lower left corner. 


\subsubsection{1 $35 \mathrm{~mL}$ Autoclave for in-situ IR and on-line Pressure Measurements}

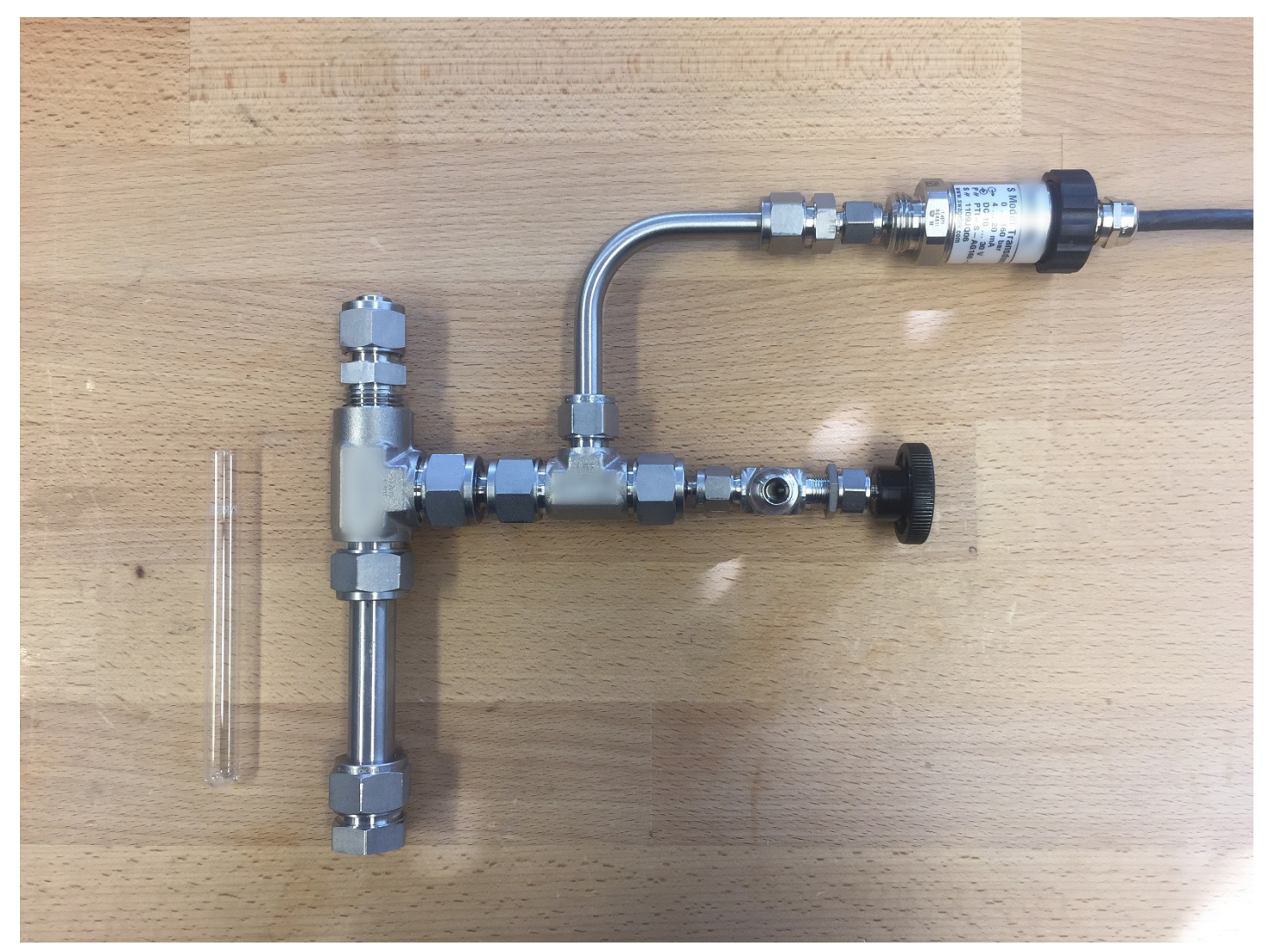

Figure S1.27: View of a $35 \mathrm{~mL}$ autoclave for in-situ IR and on-line pressure measurements closed with a tube fitting and a plug (right) together with a glass inset (left). 


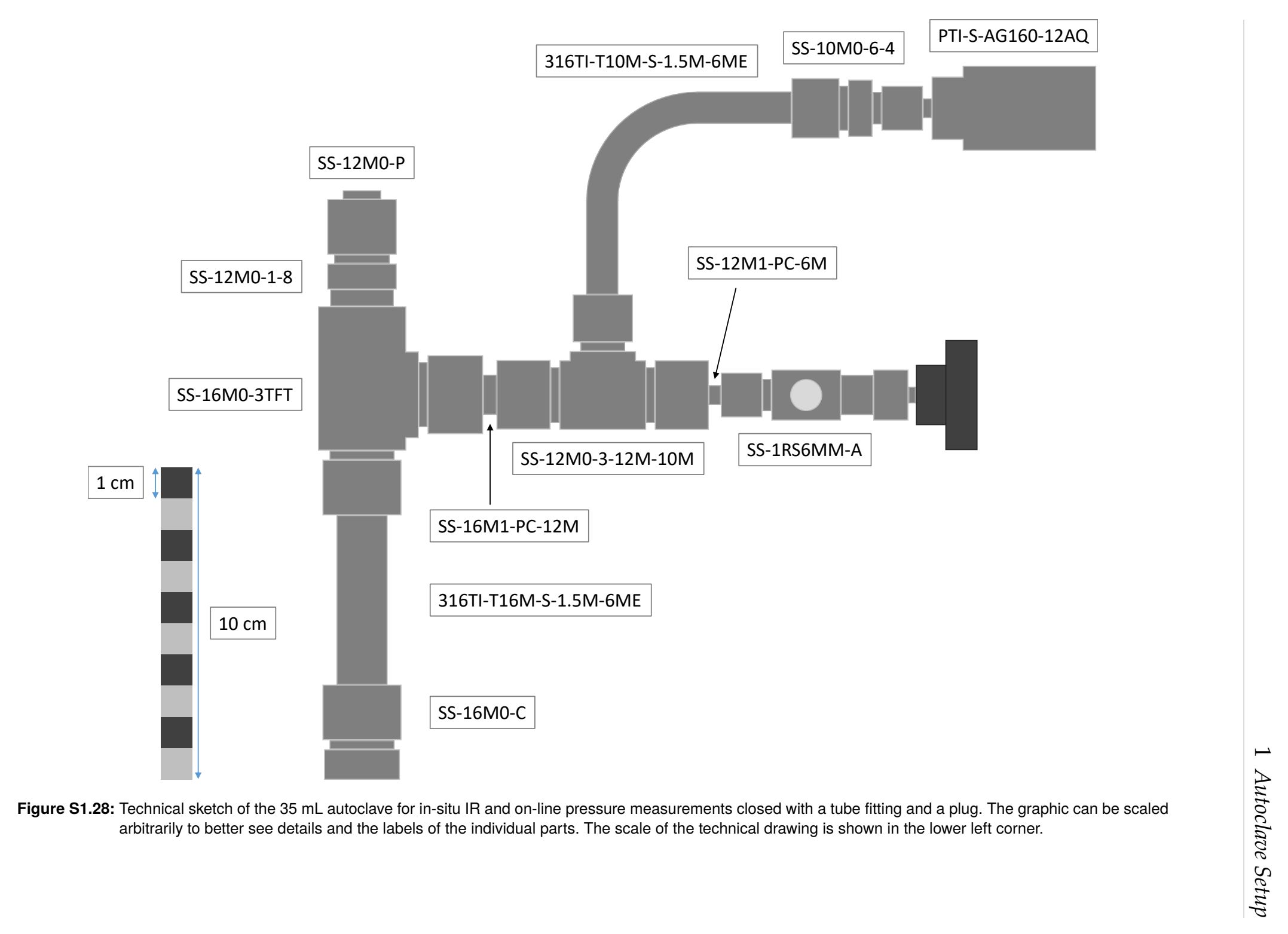




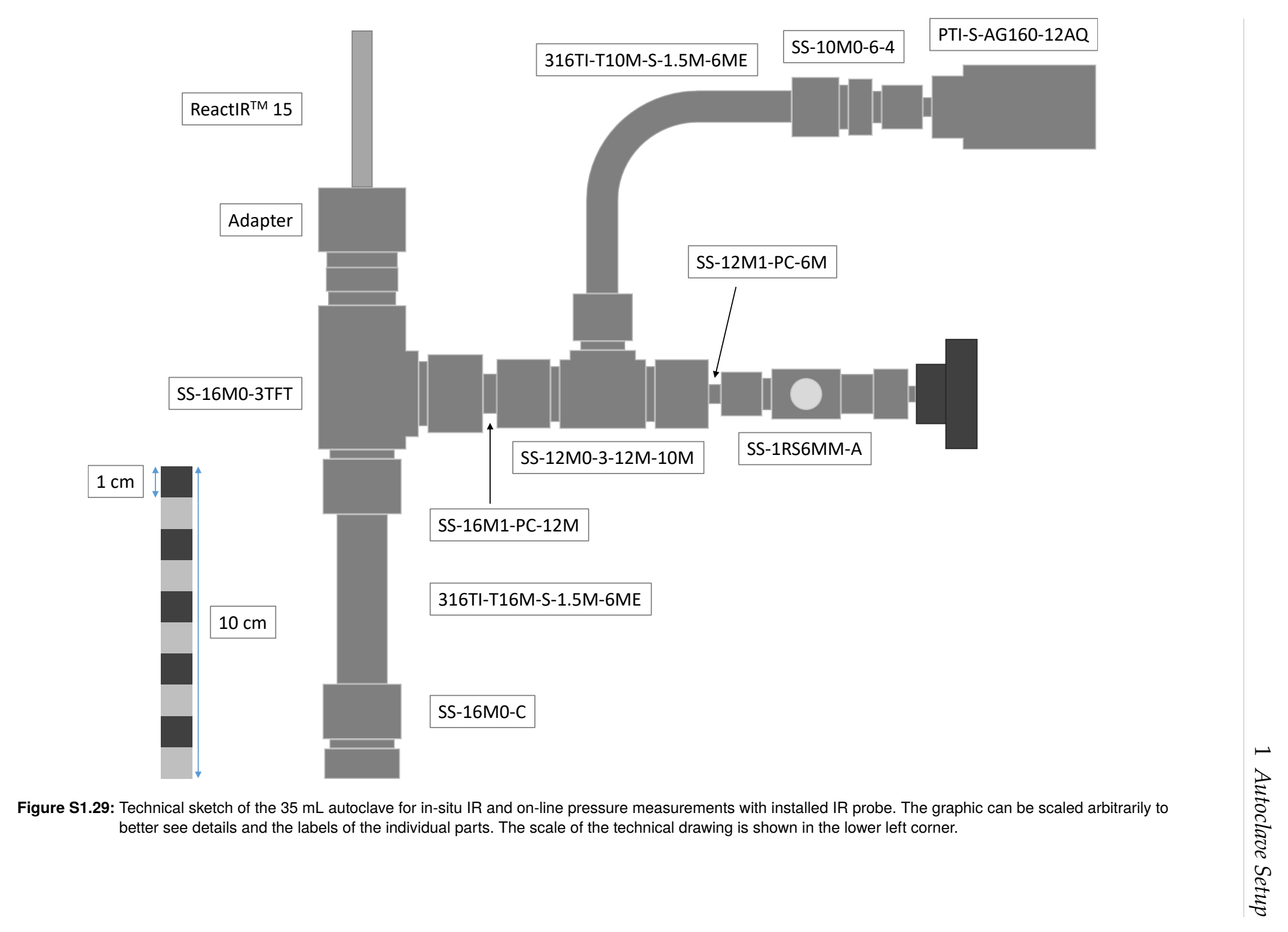




\subsection{Components of the Inert Gas Pressure Line}

Safety Advice: The independent construction of the inert gas pressure line setup requires great care. In case of doubt, this work must be carried out by a specialist. The authors accept no liability for damage, for the instructions or for the safety of the resulting setup. The assembly and use of this setup is at your own risk. The safety regulations of the individual parts used apply, which have to be carefully researched and read prior to assembly.

The inert gas pressure line was designed and built by our group. We used solely parts of stainless steel material, which were purchased from Swagelok (Swagelok company, USA). The parts used for the inert gas pressure line are listed in this section. Thereby, the reader is able to copy the setup presented or to use the given information to develop a setup according to his or her own needs.

Table S1.1: Components and their description of the inert gas pressure line setup.

\begin{tabular}{|c|c|}
\hline Component & Description \\
\hline \multicolumn{2}{|c|}{ Connector to gas cylinder ${ }^{a, b}$ Swagelok Gas Connector, $1 / 4$ in. Male NPT } \\
\hline \multirow[t]{2}{*}{ SS-6M0-7-4 } & Stainless Steel Swagelok Tube Fitting, Female \\
\hline & Connector, $6 \mathrm{~mm}$ Tube OD x 1/4 in. Female NPT \\
\hline \multirow[t]{4}{*}{ SS-FM4TM6SM6-120CM ${ }^{c, d}$} & FM Series Metal Hose, 316L Stainless Steel Braided \\
\hline & Hose Assembly, 316L Stainless Steel Core, $6 \mathrm{~mm}$ \\
\hline & Stainless Steel Swagelok Tube Adapter, 6 mm Stainless \\
\hline & Steel Swagelok Tube Fitting, $120 \mathrm{~cm}$ Length \\
\hline \multirow[t]{2}{*}{ SS-6M1-PC } & Stainless Steel Swagelok Tube Fitting, Port Connector, \\
\hline & $6 \mathrm{~mm}$ Tube OD \\
\hline \multirow[t]{2}{*}{ SS-6M0-2R-6M } & Stainless Steel Swagelok Tube Fitting, Tube Adapter \\
\hline & Elbow, $6 \mathrm{~mm}$ Tube OD \\
\hline \multirow[t]{2}{*}{ SS-1RS6MM } & Stainless Steel Integral Bonnet Needle Valve, $0.37 C_{\mathrm{V}}, 6$ \\
\hline & mm Swagelok Tube Fitting, Regulating Stem \\
\hline \multirow[t]{2}{*}{ SS-6TF-MM-LE ${ }^{e}$} & Stainless Steel Tee-Type Particulate Filter, $6 \mathrm{~mm}$ \\
\hline & Swagelok Tube Fitting, No Element \\
\hline \multirow[t]{2}{*}{ SS-6M0-4 } & Stainless Steel Swagelok Tube Fitting, Union Cross, 6 \\
\hline & mm Tube OD \\
\hline
\end{tabular}


Table S1.1: Components and their description of the inert gas pressure line setup. (continued)

\begin{tabular}{|c|c|}
\hline Component & Description \\
\hline PGI-63B-BG100-LASX ${ }^{f}$ & $\begin{array}{l}\text { General-Purpose Stainless Steel Gauge, } 63 \mathrm{~mm} \mathrm{(2} \mathrm{1/2} \\
\text { in.) Dial, } 0 \text { to } 100 \text { bar Dial Range, Lower Mount, } 6 \mathrm{~mm} \\
\text { Stainless Steel Tube Adapter, Unfilled }\end{array}$ \\
\hline SS-6M0-1-4 & $\begin{array}{l}\text { Stainless Steel Swagelok Tube Fitting, Male Connector, } \\
6 \mathrm{~mm} \text { Tube OD x } 1 / 4 \text { in. Male NPT }\end{array}$ \\
\hline КРB1P0A412Р20000 & $\begin{array}{l}\text { Medium- to High-Pressure Piston-Sensing } \\
\text { Back-Pressure Regulators, } 316 \text { Stainless Steel Body } \\
\text { Material, PCTFE Seat, PCTFE Seal Material, } 0 \text { to } 206 \\
\text { bar Pressure Control Range, } 0.06 C_{\mathrm{v}}, 1 / 4 \text { in. Female } \\
\text { NPT Ports }\end{array}$ \\
\hline SS-T6M-S-1.0M-6ME ${ }^{g}$ & $\begin{array}{l}\text { 316/316L Stainless Steel Seamless Tubing, } 6 \mathrm{~mm} \text { OD x } \\
1.0 \mathrm{~mm} \text { Wall x } 6 \text { Meters (Priced and ordered per } \\
\text { meter; order in } 6 \text { meter increments) }\end{array}$ \\
\hline SS-6M0-6 & $\begin{array}{l}\text { Stainless Steel Swagelok Tube Fitting, Union, } 6 \text { mm } \\
\text { Tube OD }\end{array}$ \\
\hline SS-4-HC-A-6MTA & $\begin{array}{l}\text { Stainless Steel Hose Connector, } 6 \text { mm Tube Adapter, } \\
1 / 4 \text { in. Hose ID }\end{array}$ \\
\hline SS-43GXS6MM & $\begin{array}{l}\text { Stainless Steel 1-Piece 40G Series 3-Way Ball Valve, } \\
0.90 C_{\mathrm{v}}, 6 \mathrm{~mm} \text { Swagelok Tube Fitting }\end{array}$ \\
\hline MS-NPK-43-1 & $\begin{array}{l}\text { Directional Nameplate Kit for } 43 \mathrm{G} \text { and } 43 \text { Series Ball } \\
\text { Valve }\end{array}$ \\
\hline SS-6M0-61 & $\begin{array}{l}\text { Stainless Steel Swagelok Tube Fitting, Bulkhead } \\
\text { Union, } 6 \mathrm{~mm} \text { Tube OD }\end{array}$ \\
\hline SS-FM4SM6SM6-90CM ${ }^{d}$ & $\begin{array}{l}\text { FM Series Metal Hose, 316L Stainless Steel Braided } \\
\text { Hose Assembly, 316L Stainless Steel Core, } 6 \mathrm{~mm} \\
\text { Stainless Steel Swagelok Tube Fittings, } 90 \mathrm{~cm} \text { Length }\end{array}$ \\
\hline SS-6M0-3 & $\begin{array}{l}\text { Stainless Steel Swagelok Tube Fitting, Union Tee, } 6 \\
\text { mm Tube OD }\end{array}$ \\
\hline
\end{tabular}

Continued on next page... 
Table S1.1: Components and their description of the inert gas pressure line setup. (continued)

\begin{tabular}{ll}
\hline Component & Description \\
\hline SS-PB4-TM6 & Multi-Purpose Push-On Hose End Connection, 6 mm \\
& Stainless Steel Tube Adapter, 1/4 in. Hose Size \\
SS-RL3S6MM & Stainless Steel Low Pressure Proportional Relief Valve, \\
& 6 mm Swagelok Tube Fitting \\
& Replacement Spring Kit for RL3 Series Proportional \\
177-13K-RL3 & Relief Valve \\
& Stainless Steel Swagelok Tube Fitting, Union Elbow, 6 \\
SS-6M0-9 & mm Tube OD \\
& Stainless Steel Miniature Gauge, 40 mm (1 1/2 in.) \\
PGI-40M-PC60-LASX $f$ & Dial, -30 in. Hg to 60 psi Dial Range, Lower Mount, 6 \\
& mm Stainless Steel Tube Adapter, Unfilled \\
& Stainless Steel Miniature Gauge, 40 mm (1 1/2 in.) \\
PGI-40M-PC100-LASX $f$ & Dial, -30 in. Hg to 100 psi Dial Range, Lower Mount, 6 \\
& mm Stainless Steel Tube Adapter, Unfilled \\
\hline
\end{tabular}

${ }^{a}$ The gas connectors have to be chosen according to national standards and depending on the gas cylinders used (for instance refer to the Compressed Gas Association standards (USA, CGA V-1), the British Standards Institution (UK, BS 341-3:2002) or the German Institute for Standardization (Germany, DIN477)).

${ }^{b}$ For safety reasons, pressure reducer should be connected downstream of the gas cylinders, with which the cylinder pressure can be reduced to a desired outlet pressure. Pressure regulators of this type, which should be used by anyone other than an expert, can be found in the Swagelok Pressure Regulators K Series (for instance KPP1NWF421P20000). Additional pressure gauges can be installed on the pressure reducer to facilitate handling and a different connection may be required for the hose used here (see SS-6M0-1-4). A filter should be installed between the gas cylinder and the pressure reducer.

${ }^{c}$ The hose can also be directly connected to the gas connectors in case no pressure reducer is installed, for instance using SS-FM4PF4SM6-120CM.

${ }^{d}$ The length of the connecting hose has to be chosen according to the users experimental setup.

${ }^{e}$ A Swagelok SS-4F-K4 series particulate filter can be installed as required. In our setup, we used Swagelok filters with $15 \mu \mathrm{m}$ nominal pore size (SS-6TF-MM-15).

$f$ Other pressure gauges can be installed according to the needs of the user.

$g$ On request also sold in 2 meter increments. 


\section{Handicraft Preparations}

For such an inert gas pressure line, as shown in section 1.1, we recommend covering the fittings and pipes with an aluminum plate for safety reasons (in our case, an aluminum plate of size $80 \mathrm{~cm} \times 60 \mathrm{~cm} \times 0.5 \mathrm{~cm}$ was cut to size). The holes for the screw connections to the front must then be drilled according to the desired individual parts.

The construction also requires the cutting and bending of tubes. If possible, the pipes used should be cut and bent by a specialist. If the appropriate tools are available, these processes can also be carried out by the user him- or herself. The four steps of cutting, deburring, cleaning and inspecting should be carried out carefully to avoid leaks and to guarantee the safety of the resulting setup.

\section{Required Tools}

The following tools are required for screwing the connections together:

- open-end wrench $13 \mathrm{~mm}$

- open-end wrench $14 \mathrm{~mm}$ (twice)

- open-end wrench $16 \mathrm{~mm}$

- open-end wrench $17 \mathrm{~mm}$

- open-end wrench $18 \mathrm{~mm}$

- open-end wrench $20 \mathrm{~mm}$

- open-end wrench $21 \mathrm{~mm}$

- open-end wrench $25 \mathrm{~mm}$

\section{Vacuum and Inert Gas Supply}

Vacuum Supply: In our setup, we connected the inert gas pressure line to a vacuubrand RZ 6 rotary vane vacuum pump using a connector $(6 \mathrm{~mm}$ tube fitting to DN25 nominal size flange; KSWA256-316) and highly flexible stainless steel corrugated hoses (DN25 nominal size flanges; FX25K100-304). Both, a flange connection reducer for connecting the hose 
and the vacuum pump (DN25/DN16 nominal size flanges; KF25R16-304) and a vacuum probe for measuring the vacuum downstream of the pump (DN16 nominal size flange; vacuubrand VSP 3000 and vacuubrand DCP 3000) were connected to the vacuum pump via a tee connector (DN16 nominal size flanges; TE16K-304).

Inert Gas Supply: In our setup, we connected the inert gas pressure line directly to the provided gas line for inert gas of the chemical laboratory using a flexible copper tube. 


\subsection{Reduced Setup of the Inert Gas Pressure Line}

If reactions with only one gas are to be carried out (for instance hydrogenation or hydroformylation reactions using hydrogen or synthesis gas, respectively) or if a simpler setup is required for financial reasons, the setup can also be reduced and designed to be more cost-effective. The following proposal does not include the second gas line and renounces the integration of the vacuum and inert gas supply into the apparatus. The reduced setup also does not need covering of the fittings and any tubes. Vacuum and inert gas supply is handled via a Schlenk line that is connected to the hose connector at the three-way ball valve.

Extreme Danger: In case of improper use, the gas pressure of the autoclave-sited gas line can be released into the connected Schlenk line which may cause shattering of the glass ware. For this reason, special care must be taken when handling this inert gas pressure line. Never release the pressure of the autoclave-sited gas line via the Schlenk line! After filling of the autoclave, the remaining gas of the inert gas pressure line should always be released using the installed piston-sensing back-pressure regulator.

Safety Advice: The independent construction of the inert gas pressure line setup requires great care. In case of doubt, this work must be carried out by a specialist. The authors accept no liability for damage, for the instructions or for the safety of the resulting setup. The assembly and use of this setup is at your own risk. The safety regulations of the individual parts used apply, which have to be carefully researched and read prior to assembly.

The inert gas pressure line was designed and built by our group. We used solely parts of stainless steel material, which were purchased from Swagelok (Swagelok company, USA). The parts used for the reduced setup of the inert gas pressure line are listed in this section. Thereby, the reader is able to copy the setup presented or to use the given information to develop a setup according to his or her own needs.

Table S1.2: Components and their description of the reduced inert gas pressure line setup.

\begin{tabular}{lll}
\hline Quant. & Component & Description \\
\hline $1 \quad$ Connector to gas cylinder \\
& $a, b$ & Swagelok Gas Connector, $1 / 4$ in. Male NPT \\
\hline Continued on next page...
\end{tabular}


Table S1.2: Components and their description of the reduced inert gas pressure line setup. (continued)

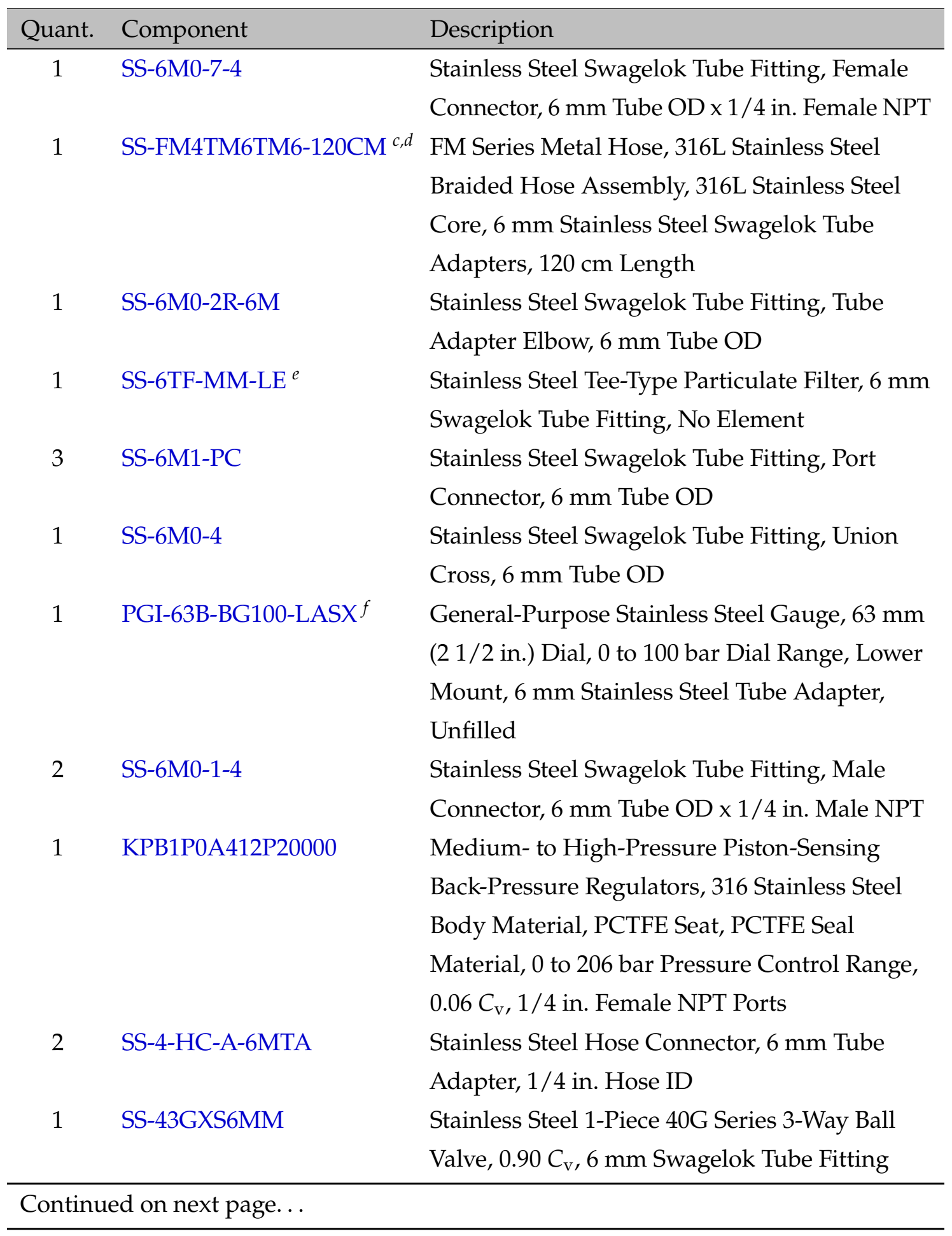


Table S1.2: Components and their description of the reduced inert gas pressure line setup. (continued)

\begin{tabular}{cll}
\hline Quant. & Component & Description \\
\hline 1 & SS-FM4TM6TM6-90CM $^{d}$ & FM Series Metal Hose, 316L Stainless Steel \\
& & Braided Hose Assembly, 316L Stainless Steel \\
& Core, $6 \mathrm{~mm}$ Stainless Steel Swagelok Tube \\
& Adapters, $90 \mathrm{~cm}$ Length \\
\hline
\end{tabular}

${ }^{a}$ The gas connectors have to be chosen according to national standards and depending on the gas cylinders used (for instance refer to the Compressed Gas Association standards (USA, CGA V-1), the British Standards Institution (UK, BS 341-3:2002) or the German Institute for Standardization (Germany, DIN477)).

${ }^{b}$ For safety reasons, pressure reducer should be connected downstream of the gas cylinders, with which the cylinder pressure can be reduced to a desired outlet pressure. Pressure regulators of this type, which should be used by anyone other than an expert, can be found in the Swagelok Pressure Regulators K Series (for instance KPP1NWF421P20000). Additional pressure gauges can be installed on the pressure reducer to facilitate handling and a different connection may be required for the hose used here (see SS-6M0-1-4). A filter should be installed between the gas cylinder and the pressure reducer.

${ }^{c}$ The hose can also be directly connected to the gas connectors in case no pressure reducer is installed, for instance using SS-FM4PF4TM6-120CM.

${ }^{d}$ The length of the connecting hose has to be chosen according to the users experimental setup.

${ }^{e}$ A Swagelok SS-4F-K4 series particulate filter can be installed as required. In our setup, we used Swagelok filters with $15 \mu \mathrm{m}$ nominal pore size (SS-6TF-MM-15).

${ }^{f}$ Other pressure gauges can be installed according to the needs of the user.

\section{Required Tools}

The following tools are required for screwing the connections together:

- open-end wrench $13 \mathrm{~mm}$

- open-end wrench $14 \mathrm{~mm}$ (twice)

- open-end wrench $16 \mathrm{~mm}$

- open-end wrench $17 \mathrm{~mm}$

- open-end wrench $20 \mathrm{~mm}$ 
- open-end wrench $25 \mathrm{~mm}$

\section{Vacuum and Inert Gas Supply}

In the reduced setup of the inert gas pressure line, the vacuum and inert gas supply is realized via a Schlenk line using the user's existing vacuum source and connected inert gas. 


\subsection{Components of Autoclaves}

Safety Advice: The independent construction of autoclaves requires great care. In case of doubt, this work must be carried out by a specialist. The authors accept no liability for damage, for the instructions or for the safety of the resulting autoclaves. The assembly and use of such autoclaves is at your own risk. The safety regulations of the individual parts used apply, which have to be carefully researched and read prior to assembly.

The autoclaves were designed and built by our group. We used solely parts of stainless steel material, partly with additional alloy, which were purchased from Swagelok (Swagelok company, USA). The parts used for the different autoclaves are listed in the following subsections. Thereby, the reader is able to copy one of the autoclaves or to use the given information to develop autoclaves according to his or her own needs.

\subsection{1 $10 \mathrm{~mL}$ Autoclave}

Table S1.3: Components and their description of the $10 \mathrm{~mL}$ autoclave.

\begin{tabular}{ll}
\hline Component & Description \\
\hline SS-10M0-C & 316 Stainless Steel Cap for $10 \mathrm{~mm}$ OD Tubing \\
316TI-T10M-S-1.5M-6ME ${ }^{a}$ & 316L Stainless Steel Titanium Alloyed Tubing, 10 mm \\
& OD x 1.5 mm Wall x 6 Meters (Priced and ordered per \\
& meter; order in 6 meter increments) \\
& Stainless Steel Swagelok Tube Fitting, Union Tee, 10 \\
SS-10M0-3 & mm Tube OD \\
& 316 Stainless Steel Plug for $10 \mathrm{~mm}$ Swagelok Tube \\
SS-10M0-P & Fitting \\
& Stainless Steel Swagelok Tube Fitting, Reducing Port \\
SS-10M1-PC-6M & Connector, 10 mm x 6 mm Tube OD \\
& Stainless Steel Integral Bonnet Angle-Pattern Needle \\
SS-1RS6MM-A & Valve, 6 mm Swagelok Tube Fitting, Regulating Stem \\
\hline
\end{tabular}

${ }^{a}$ On request also sold in 2 meter increments.

Notice: All safety advice mentioned in section 1.5 apply to this autoclave setup and must be taken into account. 
Safety Advice: A pressure relief valve should be installed during the reaction to ensure gas drainage if the pressure is too high. Depending on the pressures applied and the investigated reaction, several spring kits allow the setting of different threshold values for the pressure release. Since spring kits are offered for even higher pressures, it is pointed out at this point that such spring kits should not be used with the setup described in this work due to the pressure limitation of the latter.

Table S1.4: Components and their description of the proportional relief valve and the associated spring kits.

\begin{tabular}{ll}
\hline Component & Description \\
\hline SS-6R3A-MM & Stainless Steel High Pressure Proportional Relief \\
& Valve, 6 mm Swagelok Tube Fitting \\
177-R3A-K1-A & Blue Spring Kit for R3A Series Proportional Relief \\
& Valve, 50 to 350 psig (3.4 to 24.1 bar) \\
177-R3A-K1-B & Yellow Spring Kit for R3A Series Proportional Relief \\
& Valve, 350 to 750 psig (24.1 to 51.7 bar) \\
177-R3A-K1-C & Purple Spring Kit for R3A Series Proportional Relief \\
& Valve, 750 to 1500 psig (51.7 to 103 bar) \\
177-R3A-K1-D & Orange Spring Kit for R3A Series Proportional Relief \\
& Valve, 1500 to 2250 psig (103 to 155 bar) \\
\hline
\end{tabular}

\section{Spare Parts}

After some time (up to over a hundred reactions per autoclave, depending on use), the connector between the body and the proportional relief valve must be replaced as the 10 $\mathrm{mm}$ nut is no longer completely tight at high pressures (over approximately 80 bar total pressure). This problem does not arise as fast if no relief valve is used to close the autoclave, but only the steel plug. Replacing the connector is cost-effective and should therefore not be a reason to forgo the additional safety provided by a relief valve. The connector consists of the following individual parts: 
Table S1.5: Components and their description of the connecting piece between autoclave body and proportional relief valve.

\begin{tabular}{ll}
\hline Component & Description \\
\hline SS-6M0-NFSET & 316 Stainless Steel Nut and Ferrule Set (1 Nut/1 Front \\
& Ferrule/1 Back Ferrule) for $6 \mathrm{~mm}$ Tube Fitting, Please \\
& order in multiples of five \\
& Stainless Steel Swagelok Tube Fitting, Reducing Port \\
& Connector, 10 mm x 6 mm Tube OD \\
SS-10M1-PC-6M & 316 Stainless Steel Nut for $10 \mathrm{~mm}$ Swagelok Tube \\
SS-10M2-1 & Fitting \\
\hline
\end{tabular}

\section{Handicraft Preparations}

The construction also requires the cutting of tubes. If possible, the tube used should be cut by a specialist. If the appropriate tools are available, this process can also be carried out by the user him- or herself. The four steps of cutting, deburring, cleaning and inspecting should be carried out carefully to avoid leaks and to guarantee the safety of the resulting setup.

The tube length for our $10 \mathrm{~mL}$ autoclaves is $14 \mathrm{~cm}(10 \mathrm{~mm}$ OD).

\section{Required Tools}

The following tools are required for screwing the connections together:

- open-end wrench $14 \mathrm{~mm}$

- open-end wrench $17 \mathrm{~mm}$

- open-end wrench $18 \mathrm{~mm}$

- open-end wrench $19 \mathrm{~mm}$

- open-end wrench $21 \mathrm{~mm}$

\section{Additional Material}

If the same tube length is chosen, standard $7 \mathrm{in} .(17.78 \mathrm{~cm})$ NMR tubes can be used as glass inset. Small stirring bars should be used for mixing. 


\subsection{2 $15 \mathrm{~mL}$ Autoclave for on-line Pressure Measurements}

Table S1.6: Components and their description of the $15 \mathrm{~mL}$ autoclave for on-line pressure measurements.

\begin{tabular}{|c|c|}
\hline Component & Description \\
\hline SS-10M0-C & 316 Stainless Steel Cap for $10 \mathrm{~mm}$ OD Tubing \\
\hline 316TI-T10M-S-1.5M-6ME ${ }^{a}$ & $\begin{array}{l}\text { 316L Stainless Steel Titanium Alloyed Tubing, } 10 \mathrm{~mm} \\
\text { OD x } 1.5 \mathrm{~mm} \text { Wall x } 6 \text { Meters (Priced and ordered per } \\
\text { meter; order in } 6 \text { meter increments) }\end{array}$ \\
\hline SS-10M0-4 & $\begin{array}{l}\text { Stainless Steel Swagelok Tube Fitting, Union Cross, } 10 \\
\text { mm Tube OD }\end{array}$ \\
\hline SS-10M0-P & $\begin{array}{l}316 \text { Stainless Steel Plug for } 10 \mathrm{~mm} \text { Swagelok Tube } \\
\text { Fitting }\end{array}$ \\
\hline SS-10M0-6-4 & $\begin{array}{l}\text { Stainless Steel Swagelok Tube Fitting, Union, } 10 \mathrm{~mm} x \\
1 / 4 \text { in. Tube OD }\end{array}$ \\
\hline PTI-S-AG160-12AQ ${ }^{b}$ & $\begin{array}{l}\text { Industrial Pressure Transducer, Standard Industrial, } 0 \\
\text { to } 160 \text { bar, } 4 \text { to } 20 \mathrm{~mA} \text { Output Signal, Direct-wire } 4 \mathrm{ft} \\
\text { (1.5 m) flying lead (IP67/NEMA 4) Electrical } \\
\text { Connector, } 1 \text { / } 4 \text { in. Swagelok Tube Adapter }\end{array}$ \\
\hline SS-10M1-PC-6M & $\begin{array}{l}\text { Stainless Steel Swagelok Tube Fitting, Reducing Port } \\
\text { Connector, } 10 \mathrm{~mm} \times 6 \mathrm{~mm} \text { Tube OD }\end{array}$ \\
\hline SS-1RS6MM & $\begin{array}{l}\text { Stainless Steel Integral Bonnet Needle Valve, } 0.37 C_{V}, 6 \\
\text { mm Swagelok Tube Fitting, Regulating Stem }\end{array}$ \\
\hline
\end{tabular}

$a$ On request also sold in 2 meter increments.

${ }^{b}$ If available, PTI-S-AG160-12AS would be even better. Otherwise, the $1 / 4$ in. tube adapter can be used together with the $6 \mathrm{~mm}$ tube fitting without any problems.

Notice: All general remarks and safety advice mentioned in section 1.5 and subsection 1.5.1 also apply to this autoclave setup and must be taken into account.

The on-line pressure gauge consists of the pressure transducer PTI-S-AG160-12AQ of Swagelok (Swagelok Company, USA) with a Neutrik NC3 MX XLR cable connector and the adXi data acquisition box (analog-to-digital converter) of Trapp ChemTech (Trapp ChemTech 
GmbH \& Co. KG, Germany). For data acquisition, we used the data acquisition software adXplorer of Trapp ChemTech (Trapp ChemTech GmbH \& Co. KG, Germany).

\section{Handicraft Preparations}

The construction also requires the cutting and bending of tubes. If possible, the pipes used should be cut and bent by a specialist. If the appropriate tools are available, these processes can also be carried out by the user him- or herself. The four steps of cutting, deburring, cleaning and inspecting should be carried out carefully to avoid leaks and to guarantee the safety of the resulting setup.

The tube length for our $15 \mathrm{~mL}$ autoclave for on-line pressure measurements is $14 \mathrm{~cm}(10 \mathrm{~mm}$ OD).

The tube length between the union cross tube fitting and the pressure transducer is $10 \mathrm{~cm}$ (10 $\mathrm{mm}$ OD, bent $90^{\circ}$ halfway).

\section{Required Tools}

The following tools are required for screwing the connections together:

- open-end wrench $14 \mathrm{~mm}$

- open-end wrench $15 \mathrm{~mm}$ (or better: open-end wrench 9/16 in.)

- open-end wrench $17 \mathrm{~mm}$

- open-end wrench $18 \mathrm{~mm}$

- open-end wrench $19 \mathrm{~mm}$

- open-end wrench $21 \mathrm{~mm}$

\section{Additional Material}

If the same tube length is chosen, standard $7 \mathrm{in} .(17.78 \mathrm{~cm}) \mathrm{NMR}$ tubes can be used as glass inset. Small stirring bars should be used for mixing. 


\subsection{3 $35 \mathrm{~mL}$ Autoclave}

Table S1.7: Components and their description of the $35 \mathrm{~mL}$ autoclave.

\begin{tabular}{ll}
\hline Component & Description \\
\hline SS-18M0-C & 316 Stainless Steel Cap for 18 mm OD Tubing \\
316TI-T18M-S-2.0M-6ME ${ }^{a}$ & 316L Stainless Steel Titanium Alloyed Tubing, 18 mm \\
& OD x 2.0 mm Wall x 6 Meters (Priced and ordered per \\
& meter; order in 6 meter increments) \\
& Stainless Steel Swagelok Tube Fitting, Reducing Union \\
SS-18M0-3-18M-12M & Tee, 18 mm x 18 mm x 12 mm Tube OD \\
& 316 Stainless Steel Plug for 18 mm Swagelok Tube \\
SS-18M0-P & Fitting \\
& Stainless Steel Swagelok Tube Fitting, Reducing Port \\
SS-12M1-PC-6M & Connector, 12 mm x 6 mm Tube OD \\
SS-1RS6MM-A & Stainless Steel Integral Bonnet Angle-Pattern Needle \\
& Valve, 6 mm Swagelok Tube Fitting, Regulating Stem \\
\hline
\end{tabular}

${ }^{a}$ On request also sold in 2 meter increments.

Notice: All safety advice mentioned in section 1.5 apply to this autoclave setup and must be taken into account.

Safety Advice: Since the installation of a proportional relief valve is not possible for this autoclave setup, special care must be taken when handling this autoclave. Therefore, only reactions that are understood and known well and where excessive gas formation may be ruled out should be performed in this autoclave. Otherwise, it is advisable to first examine the reactions in a $10 \mathrm{~mL}$ autoclave using a relief valve.

\section{Handicraft Preparations}

The construction also requires the cutting of tubes. If possible, the tube used should be cut by a specialist. If the appropriate tools are available, this process can also be carried out by the user him- or herself. The four steps of cutting, deburring, cleaning and inspecting should be carried out carefully to avoid leaks and to guarantee the safety of the resulting setup.

The tube length for our $35 \mathrm{~mL}$ autoclave is $14 \mathrm{~cm}$ (18 $\mathrm{mm} \mathrm{OD)}$. 


\section{Required Tools}

The following tools are required for screwing the connections together:

- open-end wrench 14 mm

- open-end wrench $17 \mathrm{~mm}$

- open-end wrench $22 \mathrm{~mm}$

- open-end wrench $27 \mathrm{~mm}$

- open-end wrench $30 \mathrm{~mm}$

\section{Additional Material}

If the same tube length is chosen, glass tubes with a length of $18 \mathrm{~cm}$ and an outer diameter of $12 \mathrm{~mm}$ should be used as glass inset. Small stirring bars should be used for mixing. 


\subsection{4 $30 \mathrm{~mL}$ Autoclave for in-situ IR Measurements}

Table S1.8: Components and their description of the $30 \mathrm{~mL}$ autoclave for in-situ IR measurements.

\begin{tabular}{|c|c|}
\hline Component & Description \\
\hline SS-16M0-C & 316 Stainless Steel Cap for 16 mm OD Tubing \\
\hline 316TI-T16M-S-1.5M-6ME ${ }^{a}$ & $\begin{array}{l}\text { 316L Stainless Steel Titanium Alloyed Tubing, } 16 \mathrm{~mm} \\
\text { OD x } 1.5 \mathrm{~mm} \text { Wall } \times 6 \text { Meters (Priced and ordered per } \\
\text { meter; order in } 6 \text { meter increments) }\end{array}$ \\
\hline SS-16M0-3TFT & $\begin{array}{l}\text { Stainless Steel Swagelok Tube Fitting, Female Run Tee, } \\
16 \mathrm{~mm} \text { Tube OD x } 1 / 2 \mathrm{in.} \text { Female NPT x } 16 \mathrm{~mm} \text { Tube } \\
\text { OD }\end{array}$ \\
\hline SS-12M0-1-8 & $\begin{array}{l}\text { Stainless Steel Swagelok Tube Fitting, Male Connector, } \\
12 \mathrm{~mm} \text { Tube OD x } 1 / 2 \mathrm{in} \text {. Male NPT }\end{array}$ \\
\hline SS-12M0-P & $\begin{array}{l}316 \text { Stainless Steel Plug for } 12 \mathrm{~mm} \text { Swagelok Tube } \\
\text { Fitting }\end{array}$ \\
\hline SS-16M1-PC-12M & $\begin{array}{l}\text { Stainless Steel Swagelok Tube Fitting, Reducing Port } \\
\text { Connector, } 16 \mathrm{~mm} \times 12 \mathrm{~mm} \text { Tube OD }\end{array}$ \\
\hline SS-12M0-3-12M-6M & $\begin{array}{l}\text { Stainless Steel Swagelok Tube Fitting, Reducing Union } \\
\text { Tee, } 12 \mathrm{~mm} \times 12 \mathrm{~mm} \times 6 \mathrm{~mm} \text { Tube OD }\end{array}$ \\
\hline PGI-50M-BG100-LASX ${ }^{b}$ & $\begin{array}{l}\text { Miniature Industrial Pressure Gauge, } 50 \mathrm{~mm}, 0 \text { to } 100 \\
\text { bar, psi secondary, Lower Mount, } 6 \mathrm{~mm} \text { Swagelok } \\
\text { Tube Adapter }\end{array}$ \\
\hline SS-12M1-PC-6M & $\begin{array}{l}\text { Stainless Steel Swagelok Tube Fitting, Reducing Port } \\
\text { Connector, } 12 \mathrm{~mm} \text { × } 6 \mathrm{~mm} \text { Tube OD }\end{array}$ \\
\hline SS-1RS6MM-A & $\begin{array}{l}\text { Stainless Steel Integral Bonnet Angle-Pattern Needle } \\
\text { Valve, } 6 \mathrm{~mm} \text { Swagelok Tube Fitting, Regulating Stem }\end{array}$ \\
\hline Mettler-Toledo ReactIR 15 & $\begin{array}{l}\text { Real-time, in-situ infrared-based reaction monitoring } \\
\text { system }\end{array}$ \\
\hline Mettler-Toledo High & Adapter to install the probe to the autoclave: $6.35 \mathrm{~mm}$ \\
\hline Pressure Adapters $^{c}$ & Probe, $1 / 2$ in. Male NPT \\
\hline
\end{tabular}


Table S1.8: Components and their description of the $30 \mathrm{~mL}$ autoclave for in-situ IR measurements. (continued)

\section{Component Description}

a On request also sold in 2 meter increments.

$b$ This gauge is primarily used to monitor the total pressure in the autoclave so that the maximum usable pressure of the ReactIR probe is not exceeded, but can also be used for manual pressure measurement.

$c$ The high pressure adapters have to be directly ordered at Mettler-Toledo.

Notice: All general remarks and safety advice mentioned in section 1.5 and subsection 1.5.3 also apply to this autoclave setup and must be taken into account.

For our setup, we used the ReactIR 15 of Mettler-Toledo (Mettler-Toledo GmbH, Germany) with the DiComp probe sensor based on diamond (DST Series $6.3 \mathrm{~mm}$ AgX Fiber Conduit, $1.5 \mathrm{~m}$ fiber length, $216 \mathrm{~mm}$ probe length, $\mathrm{pH}$ range 1 to 14 , temperature range -80 to $180^{\circ} \mathrm{C}$, maximum pressure of 69 bar).

Safety Advice: If the same real-time in-situ analysis tool is chosen, a total pressure of 69 bar must not be exceeded! Before performing any analysis, the resistance of the IR probe to the chemicals and solvents involved in the reaction has to be considered and if necessary another probe has to be chosen.

\section{Handicraft Preparations}

The construction also requires the cutting of tubes. If possible, the tube used should be cut by a specialist. If the appropriate tools are available, this process can also be carried out by the user him- or herself. The four steps of cutting, deburring, cleaning and inspecting should be carried out carefully to avoid leaks and to guarantee the safety of the resulting setup.

The tube length for our $30 \mathrm{~mL}$ autoclave for in-situ IR measurements is $10 \mathrm{~cm}$ (16 mm OD).

\section{Required Tools}

The following tools are required for screwing the connections together:

- open-end wrench $14 \mathrm{~mm}$

- open-end wrench $17 \mathrm{~mm}$ 
- open-end wrench $21 \mathrm{~mm}$

- open-end wrench $22 \mathrm{~mm}$ (twice or use the adjustable end wrench 0-30 mm)

- open-end wrench $23 \mathrm{~mm}$

- open-end wrench $24 \mathrm{~mm}$

- open-end wrench $25 \mathrm{~mm}$

- open-end wrench $27 \mathrm{~mm}$

- adjustable end wrench 0-30 mm (or: open-end wrench $11 / 8$ in.)

\section{Additional Material}

If the same tube length is chosen, glass tubes with a length of $12 \mathrm{~cm}$ and an outer diameter of $12 \mathrm{~mm}$ should be used as glass inset. Test tubes of the appropriate size can also be used. Small stirring bars should be used for mixing. 


\subsection{5 $35 \mathrm{~mL}$ Autoclave for in-situ IR and on-line Pressure Measurements}

Table S1.9: Components and their description of the $35 \mathrm{~mL}$ autoclave for in-situ IR and on-line pressure measurements.

\begin{tabular}{|c|c|}
\hline Component & Description \\
\hline SS-16M0-C & 316 Stainless Steel Cap for $16 \mathrm{~mm}$ OD Tubing \\
\hline 316TI-T16M-S-1.5M-6ME ${ }^{a}$ & $\begin{array}{l}\text { 316L Stainless Steel Titanium Alloyed Tubing, } 16 \mathrm{~mm} \\
\text { OD x } 1.5 \mathrm{~mm} \text { Wall x } 6 \text { Meters (Priced and ordered per } \\
\text { meter; order in } 6 \text { meter increments) }\end{array}$ \\
\hline SS-16M0-3TFT & $\begin{array}{l}\text { Stainless Steel Swagelok Tube Fitting, Female Run Tee, } \\
16 \mathrm{~mm} \text { Tube OD x } 1 / 2 \text { in. Female NPT x } 16 \text { mm Tube } \\
\text { OD }\end{array}$ \\
\hline SS-12M0-1-8 & $\begin{array}{l}\text { Stainless Steel Swagelok Tube Fitting, Male Connector, } \\
12 \mathrm{~mm} \text { Tube OD x } 1 / 2 \text { in. Male NPT }\end{array}$ \\
\hline SS-12M0-P & $\begin{array}{l}316 \text { Stainless Steel Plug for } 12 \mathrm{~mm} \text { Swagelok Tube } \\
\text { Fitting }\end{array}$ \\
\hline SS-16M1-PC-12M & $\begin{array}{l}\text { Stainless Steel Swagelok Tube Fitting, Reducing Port } \\
\text { Connector, } 16 \mathrm{~mm} \text { x } 12 \mathrm{~mm} \text { Tube OD }\end{array}$ \\
\hline SS-12M0-3-12M-10M & $\begin{array}{l}\text { Stainless Steel Swagelok Tube Fitting, Reducing Union } \\
\text { Tee, } 12 \mathrm{~mm} \times 12 \mathrm{~mm} \times 10 \mathrm{~mm} \text { Tube OD }\end{array}$ \\
\hline 316TI-T10M-S-1.5M-6ME ${ }^{a}$ & $\begin{array}{l}\text { 316L Stainless Steel Titanium Alloyed Tubing, } 10 \mathrm{~mm} \\
\text { OD x } 1.5 \mathrm{~mm} \text { Wall x } 6 \text { Meters (Priced and ordered per } \\
\text { meter; order in } 6 \text { meter increments) }\end{array}$ \\
\hline SS-10M0-6-4 & $\begin{array}{l}\text { Stainless Steel Swagelok Tube Fitting, Union, } 10 \mathrm{~mm} x \\
1 / 4 \text { in. Tube OD }\end{array}$ \\
\hline PTI-S-AG160-12AQ ${ }^{b}$ & $\begin{array}{l}\text { Industrial Pressure Transducer, Standard Industrial, } 0 \\
\text { to } 160 \text { bar, } 4 \text { to } 20 \mathrm{~mA} \text { Output Signal, Direct-wire } 4 \mathrm{ft} \\
\text { (1.5 m) flying lead (IP67/NEMA 4) Electrical } \\
\text { Connector, } 1 / 4 \text { in. Swagelok Tube Adapter }\end{array}$ \\
\hline SS-12M1-PC-6M & $\begin{array}{l}\text { Stainless Steel Swagelok Tube Fitting, Reducing Port } \\
\text { Connector, } 12 \mathrm{~mm} \text { × } 6 \mathrm{~mm} \text { Tube OD }\end{array}$ \\
\hline
\end{tabular}


Table S1.9: Components and their description of the $35 \mathrm{~mL}$ autoclave for in-situ IR and on-line pressure measurements. (continued)

\begin{tabular}{ll}
\hline Component & Description \\
\hline SS-1RS6MM-A & $\begin{array}{l}\text { Stainless Steel Integral Bonnet Angle-Pattern Needle } \\
\text { Valve, } 6 \mathrm{~mm} \text { Swagelok Tube Fitting, Regulating Stem }\end{array}$ \\
\hline Mettler-Toledo ReactIR 15 & $\begin{array}{l}\text { Real-time, in-situ infrared-based reaction monitoring } \\
\text { system }\end{array}$ \\
& Adapter to install the probe to the autoclave: $6.35 \mathrm{~mm}$ \\
Mettler-Toledo High & Probe, $1 / 2$ in. Male NPT \\
Pressure Adapters ${ }^{c}$ & ${ }^{a}$ On request also sold in 2 meter increments. \\
${ }^{b}$ If available, PTI-S-AG160-12AS would be even better. Otherwise, the $1 / 4$ in. tube adapter \\
can be used together with the 6 mm tube fitting without any problems. \\
${ }^{c}$ The high pressure adapters have to be directly ordered at Mettler-Toledo.
\end{tabular}

Notice: All general remarks and safety advice mentioned in section 1.5 and subsection 1.5.3 also apply to this autoclave setup and must be taken into account.

For our setup, we used the ReactIR 15 of Mettler-Toledo (Mettler-Toledo GmbH, Germany) with the DiComp probe sensor based on diamond (DST Series $6.3 \mathrm{~mm} \mathrm{AgX} \mathrm{Fiber} \mathrm{Conduit,}$ $1.5 \mathrm{~m}$ fiber length, $216 \mathrm{~mm}$ probe length, $\mathrm{pH}$ range 1 to 14 , temperature range -80 to $180^{\circ} \mathrm{C}$, maximum pressure of 69 bar).

Safety Advice: If the same real-time in-situ analysis tool is chosen, a total pressure of 69 bar must not be exceeded! Before performing any analysis, the resistance of the IR probe to the chemicals and solvents involved in the reaction has to be considered and if necessary another probe has to be chosen.

The on-line pressure gauge consists of the pressure transducer PTI-S-AG160-12AQ of Swagelok (Swagelok Company, USA) with a Neutrik NC3 MX XLR cable connector and the adXi data acquisition box (analog-to-digital converter) of Trapp ChemTech (Trapp ChemTech $\mathrm{GmbH} \& \mathrm{Co}$. KG, Germany). For data acquisition, we used the data acquisition software adXplorer of Trapp ChemTech (Trapp ChemTech GmbH \& Co. KG, Germany). 


\section{Handicraft Preparations}

The construction also requires the cutting and bending of tubes. If possible, the pipes used should be cut and bent by a specialist. If the appropriate tools are available, these processes can also be carried out by the user him- or herself. The four steps of cutting, deburring, cleaning and inspecting should be carried out carefully to avoid leaks and to guarantee the safety of the resulting setup.

The tube length for our $35 \mathrm{~mL}$ autoclave for in-situ IR and on-line pressure measurements is $10 \mathrm{~cm}(16 \mathrm{~mm}$ OD).

The tube length between the union tee tube fitting and the pressure transducer is $10 \mathrm{~cm}$ (10 $\mathrm{mm}$ OD, bent $90^{\circ}$ halfway).

\section{Required Tools}

The following tools are required for screwing the connections together:

- open-end wrench $14 \mathrm{~mm}$

- open-end wrench $17 \mathrm{~mm}$

- open-end wrench $21 \mathrm{~mm}$

- open-end wrench $22 \mathrm{~mm}$ (twice or use the adjustable end wrench 0-30 mm)

- open-end wrench $23 \mathrm{~mm}$

- open-end wrench $24 \mathrm{~mm}$

- open-end wrench $25 \mathrm{~mm}$

- open-end wrench $27 \mathrm{~mm}$

- adjustable end wrench 0-30 mm (or: open-end wrench 11/8 in.)

\section{Additional Material}

If the same tube length is chosen, glass tubes with a length of $12 \mathrm{~cm}$ and an outer diameter of $12 \mathrm{~mm}$ should be used as glass inset. Test tubes of the appropriate size can also be used. Small stirring bars should be used for mixing. 


\subsection{Further Equipment Used}

Reactions at Room Temperature: For performing (multiple) catalytic reactions at room temperature, we use a IKA RO 5 magnetic stirrer (IKA-Werke GmbH \& Co. KG, Germany).

Reactions at High Temperatures: For performing catalytic reactions at high temperatures, we use IKA RCT basic magnetic stirrers (IKA-Werke GmbH \& Co. KG, Germany) together with VWR VT-5 electronic contact thermometers (VWR International GmbH, Germany). As heating fluid, we use a commercially available silicone oil.

Reactions at Low Temperatures: For performing catalytic reactions at low temperatures, we use IKA RCT basic magnetic stirrers (IKA-Werke GmbH \& Co. KG, Germany) together with VWR VT-5 electronic contact thermometers (VWR International GmbH, Germany). The cooling before and during the pressurization of the autoclave is realized by using an appropriate cooling bath depending on the desired temperature in a KGW Isotherm $12 \mathrm{C}$ Dewar flask (KGW-Isotherm Karlsruher Glastechnisches Werk - Schieder GmbH, Germany). Over the course of the reaction, a Huber Ministat 230 with Pilot ONE cryostat (Peter Huber Kältemaschinenbau AG, Germany) is used for cooling. The coolant is pumped through a stainless steel KGW Isotherm TSS-G $1000 \mathrm{~W}$ tempering beaker (KGW-Isotherm Karlsruher Glastechnisches Werk - Schieder GmbH, Germany). As coolant, we use the Huber SilOil M60.115/200.05 thermofluid (Peter Huber Kältemaschinenbau AG, Germany). 


\section{Applications of Autoclaves}

\subsection{General Procedure for Pressurized Reactions}

The catalytic setup presented in this work has been used by our group for several projects before. The precise workflow can be found in the respective publications, ${ }^{[1-11]}$ whereas this chapter should give an overview of the general procedure for pressurized reactions that can be performed using the setup.

The catalyses are performed in stainless steel high-pressure autoclaves using a glass tube as inset and a small stirring bar for mixing. The catalysis mixture has to be prepared in a Schlenk tube, which is connected to the inert gas pressure line via a connecting hose (see

[1] Storch, G.; Trapp, O. Temperature-Controlled Bidirectional Enantioselectivity in a Dynamic Catalyst for Asymmetric Hydrogenation. Angew. Chem., Int. Ed. 2015, 54, 3580-3586.

[2] Storch, G.; Deberle, L.; Menke, J.-M.; Rominger, F.; Trapp, O. A stereodynamic phosphoramidite ligand derived from 3,3'-functionalized ortho-biphenol and its rhodium(I) complex. Chirality 2016, 28, 744-748.

[3] Storch, G.; Trapp, O. By-design enantioselective self-amplification based on non-covalent product-catalyst interactions. Nat. Chem. 2017, 9, 179-187.

[4] Siebert, M.; Storch, G.; Rominger, F.; Trapp, O. Temperature-Controlled Bidirectional Enantioselectivity in Asymmetric Hydrogenation Reactions Utilizing Stereodynamic Iridium Complexes. Synthesis 2017, 49, 3485-3494.

[5] Storch, G.; Trapp, O. Supramolecular chirality transfer in a stereodynamic catalysts. Chirality 2018, 30, 1150-1160.

[6] Siebert, M.; Seibicke, M.; Siegle, A. F.; Kräh, S.; Trapp, O. Selective Ruthenium-Catalyzed Transformation of Carbon Dioxide: An Alternative Approach toward Formaldehyde. J. Am. Chem. Soc. 2019, 141, 334-341.

[7] Scholtes, J. F.; Trapp, O. Inducing Enantioselectivity in a Dynamic Catalyst by Supramolecular Interlocking. Angew. Chem., Int. Ed. 2019, 58, 6306-6310.

[8] Seibicke, M.; Siebert, M.; Siegle, A. F.; Gutenthaler, S. M.; Trapp, O. Application of Hetero-Triphos Ligands in the Selective Ruthenium-Catalyzed Transformation of Carbon Dioxide to the Formaldehyde Oxidation State. Organometallics 2019, 38, 1809-1814.

[9] Scholtes, J. F.; Trapp, O. Enantioselectivity Induced by Stereoselective Interlocking: A Novel Core Motif for Tropos Ligands. Chem. Eur. J. 2019, 25, 11707-11714.

[10] Scholtes, J. F.; Trapp, O. Design and synthesis of a stereodynamic catalyst with reversal of selectivity by enantioselective self-inhibition. Chirality 2019, 31, 1028-1042.

[11] Siebert, M.; Krennrich, G.; Seibicke, M.; Siegle, A. F.; Trapp, O. Identifying high-performance catalytic conditions for carbon dioxide reduction to dimethoxymethane by multivariate modelling. Chem. Sci. 2019, 10, 10466-10474. 
Figure S1.1). The autoclave is evacuated and flushed with inert gas three times before the desired amount of catalysis mixture is transferred into the glass inset. ${ }^{1}$ The gas lines used are purged with the respective gases at least seven times. The autoclave is pressurized with the desired gas. In case two gases are used, the autoclave is pressurized with the gas that is supposed to have the lower partial pressure. Then, the autoclave is further pressurized with the second gas. The closed autoclave is disconnected from the inert gas pressure line and the catalysis mixture is stirred at the desired temperature (everything inbetween $-40^{\circ} \mathrm{C}$ to $100^{\circ} \mathrm{C}$ ) for the desired time. The gas is discharged carefully in a fume hood and the catalysis mixture is analyzed according to the needs of the analytes.

Reactions at Room Temperature: The exact procedure described above can be used.

Reactions at High Temperatures: The exact procedure described above can be used.

Reactions at Low Temperatures: In order to guarantee a precise sequence of the reaction and to avoid undesired (side) reactions, a cold bath which has the temperature of the later cooling medium or is even colder should already be used during filling. After the transfer of the catalysis mixture into the glass inset of the autoclave, the latter should be cooled for at least $5 \mathrm{~min}$ prior to pressurization. For the larger autoclaves, temperature control for $10 \mathrm{~min}$ is advisable if the temperature difference to the room temperature is large (more than $20^{\circ} \mathrm{C}$ ).

Reactions using Carbon Dioxide: If $\mathrm{CO}_{2}$ is used in a reaction in addition to another gas, the autoclave should be pressurized with $\mathrm{CO}_{2}$ first. Then, the $\mathrm{CO}_{2}$ can be deposited by cooling the autoclave to $-78^{\circ} \mathrm{C}$ using a cold bath for $5 \mathrm{~min}$. For the larger autoclaves, temperature control for $10 \mathrm{~min}$ is advisable if higher pressures of $\mathrm{CO}_{2}$ (above 20 bar) are used. Finally, the autoclave can be further pressurized with the second gas. This enables the precise adjustment not only of the $\mathrm{CO}_{2}$ but also of the second gas partial pressure without knowing the exact mixing volumes of the gases.

In case that the catalysis mixture should be heated after $\mathrm{CO}_{2}$ was deposited and the autoclave was pressurized with a second gas, the autoclave should be allowed to warm to room temperature for $10 \mathrm{~min}$. For the larger autoclaves, the warm-up time should be extended to $20 \mathrm{~min}$.

Since the connection for the inert gas pressure line is located on the body of the autoclave, the catalysis mixture can be transferred into the glass inset in counter-flow, so that no glovebox is required for the filling of the autoclaves, provided that the solids used can be weighed in air. 
NMR Spectroscopic Analysis before and after Catalysis under Inert Conditions: The NMR tube autoclave with an NMR tube as glass inset is evacuated and flushed with inert gas three times before the desired amount of catalysis mixture is transferred into the glass inset. The NMR tube is sealed airtight in counter-flow and NMR spectroscopic measurements can be performed. After NMR analysis, the NMR tube is carefully placed in the autoclave in counter-flow and opened again (it is important that the NMR tube is inserted slowly so that no oxygen or moisture are brought into the autoclave). A small stirring bar can be inserted into the NMR tube. The autoclave is closed and pressurized with gas(es). After the desired reaction time, the autoclave is reconnected to the inert gas pressure line, the connected tube is evacuated and flushed with inert gas three times, the autoclave is carefully vented via the connector nut and then an inert gas flow is established in the autoclave via the inert gas pressure line. The stirring bar can be taken out of the NMR tube in counter-flow, the NMR tube can be sealed airtight and NMR spectroscopic measurements can be performed. 


\subsubsection{Workflow for a Reaction at Room Temperature}

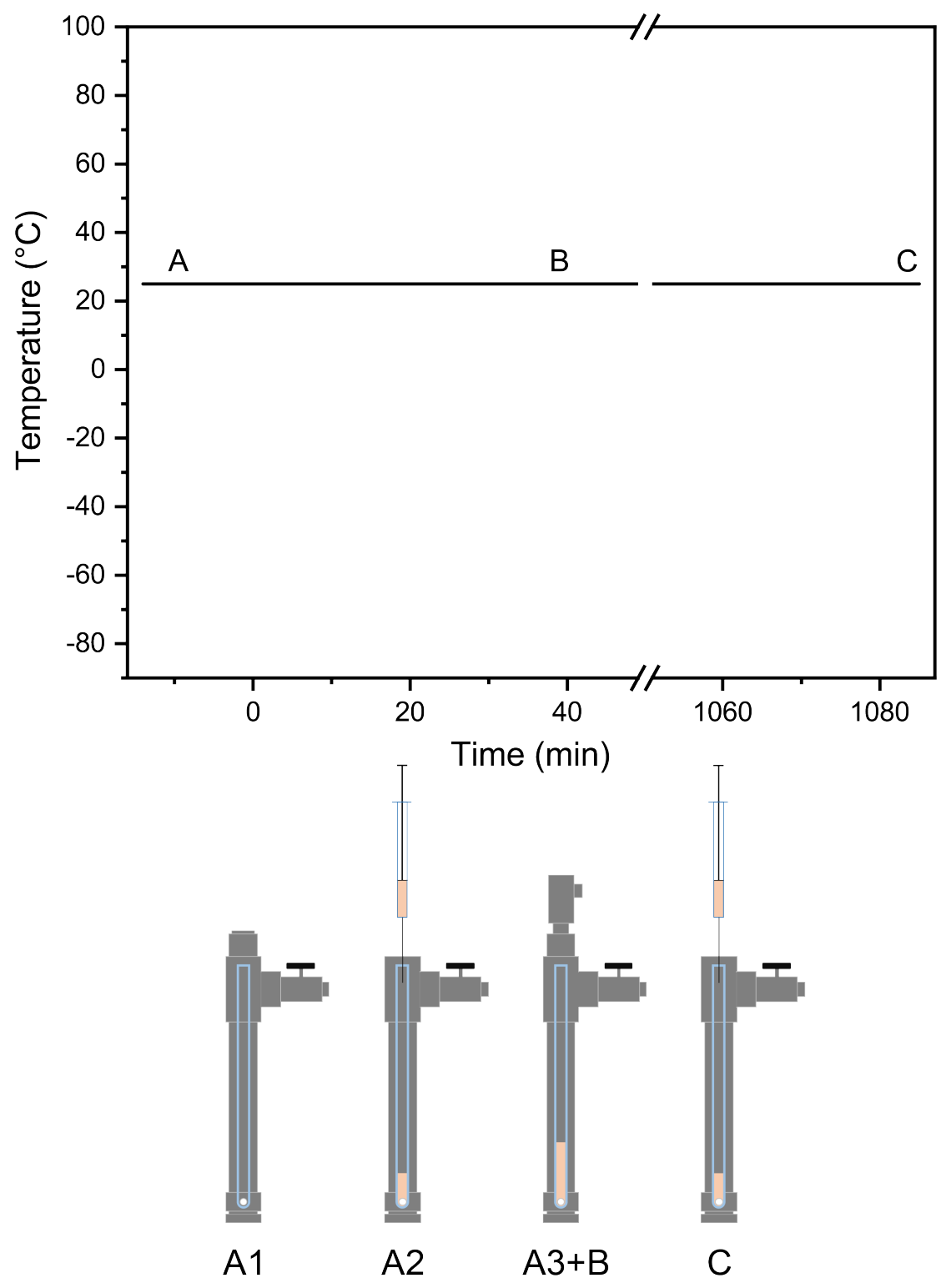

Figure S2.1: Workflow for a reaction at room temperature: exemplary timeline of an experimental procedure regarding every step and the respective temperature at which it was performed together with a schematic drawing of the work steps carried out. 
A1: A glass inset is placed in the autoclave and the autoclave is closed. Evacuation of the autoclave and flushing with inert gas at $25^{\circ} \mathrm{C}$.

A2: Opening of the autoclave and transfer of the catalysis mixture into the glass inset in an inert gas counter-flow at $25^{\circ} \mathrm{C}$.

A3: Installing of the proportional relief valve in an inert gas counter-flow at $25^{\circ} \mathrm{C}$. Afterwards, the autoclave is pressurized with the gas(es).

B: The autoclave is kept at $25^{\circ} \mathrm{C}$ over the course of the reaction ( $18 \mathrm{~h}$ in the example).

C: The autoclave is vented carefully and a sample is taken for analyzation or quantification at $25^{\circ} \mathrm{C}$. 


\subsubsection{Workflow for a Reaction at High Temperature}
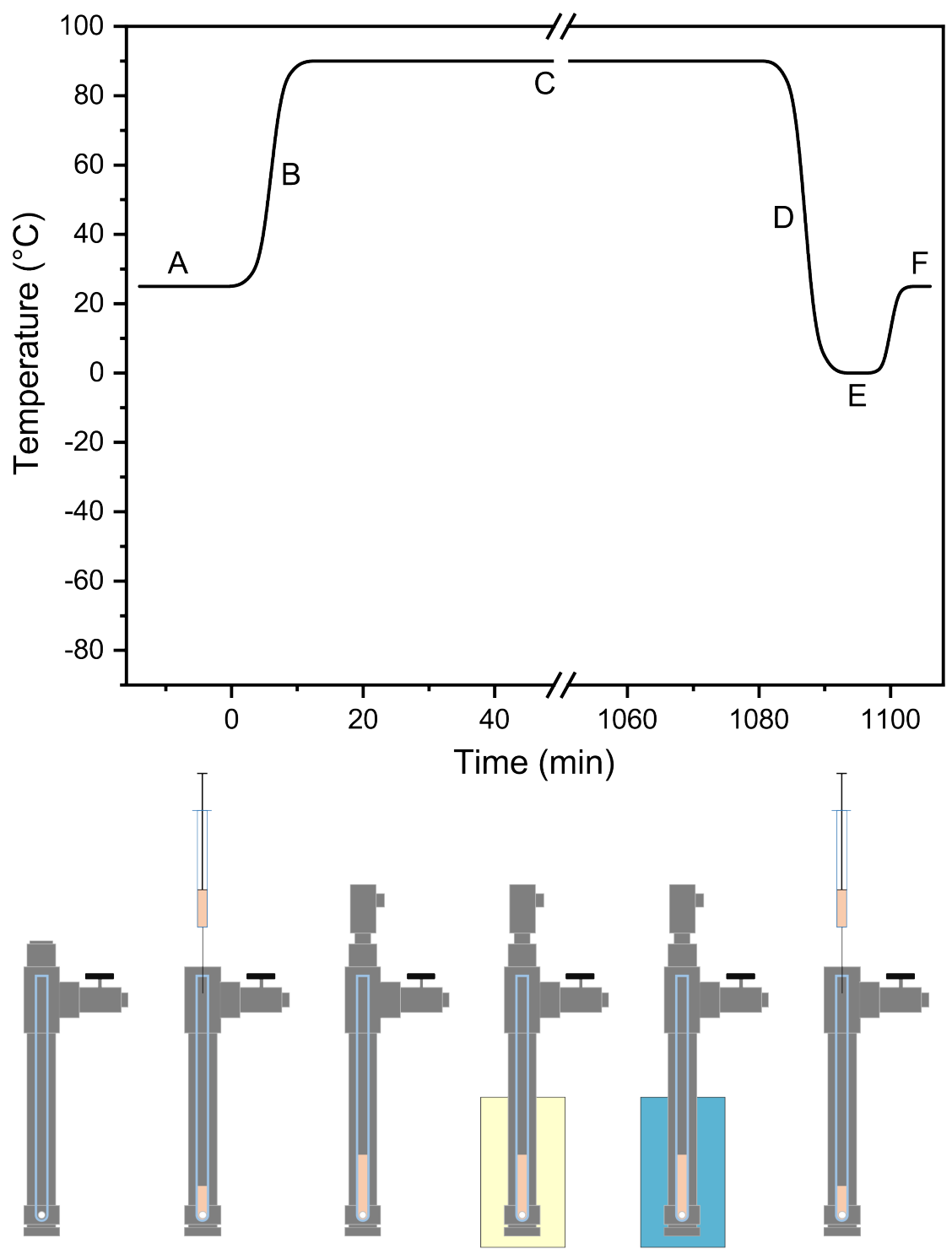

A1

A2

A3

$\mathrm{B}+\mathrm{C}$

$\mathrm{D}+\mathrm{E}$

$\mathrm{F}$

Figure S2.2: Workflow for a reaction at high temperature: exemplary timeline of an experimental procedure regarding every step and the respective temperature at which it was performed together with a schematic drawing of the work steps carried out. 
A1: A glass inset is placed in the autoclave and the autoclave is closed. Evacuation of the autoclave and flushing with inert gas at $25^{\circ} \mathrm{C}$.

A2: Opening of the autoclave and transfer of the catalysis mixture into the glass inset in an inert gas counter-flow at $25^{\circ} \mathrm{C}$.

A3: Installing of the proportional relief valve in an inert gas counter-flow at $25^{\circ} \mathrm{C}$. Afterwards, the autoclave is pressurized with the gas(es).

B: Heating of the autoclave to the respective temperature $\left(90^{\circ} \mathrm{C}\right.$ in the example) using a preheated oil bath. The temperature of the oil bath is stable within $\pm 0.1{ }^{\circ} \mathrm{C}$ after the autoclave is tempered at the desired temperature.

C: The autoclave is kept at constant temperature over the course of the reaction ( $18 \mathrm{~h}$ in the example).

D: Cooling of the autoclave to $0^{\circ} \mathrm{C}$ using an ice bath (in order to fasten the cooling process).

E: The autoclave is kept at $0^{\circ} \mathrm{C}$ for $15 \mathrm{~min}$.

F: The autoclave is vented carefully and a sample is taken for analyzation or quantification at $25^{\circ} \mathrm{C}$. 


\subsubsection{Workflow for a Reaction at Low Temperature}

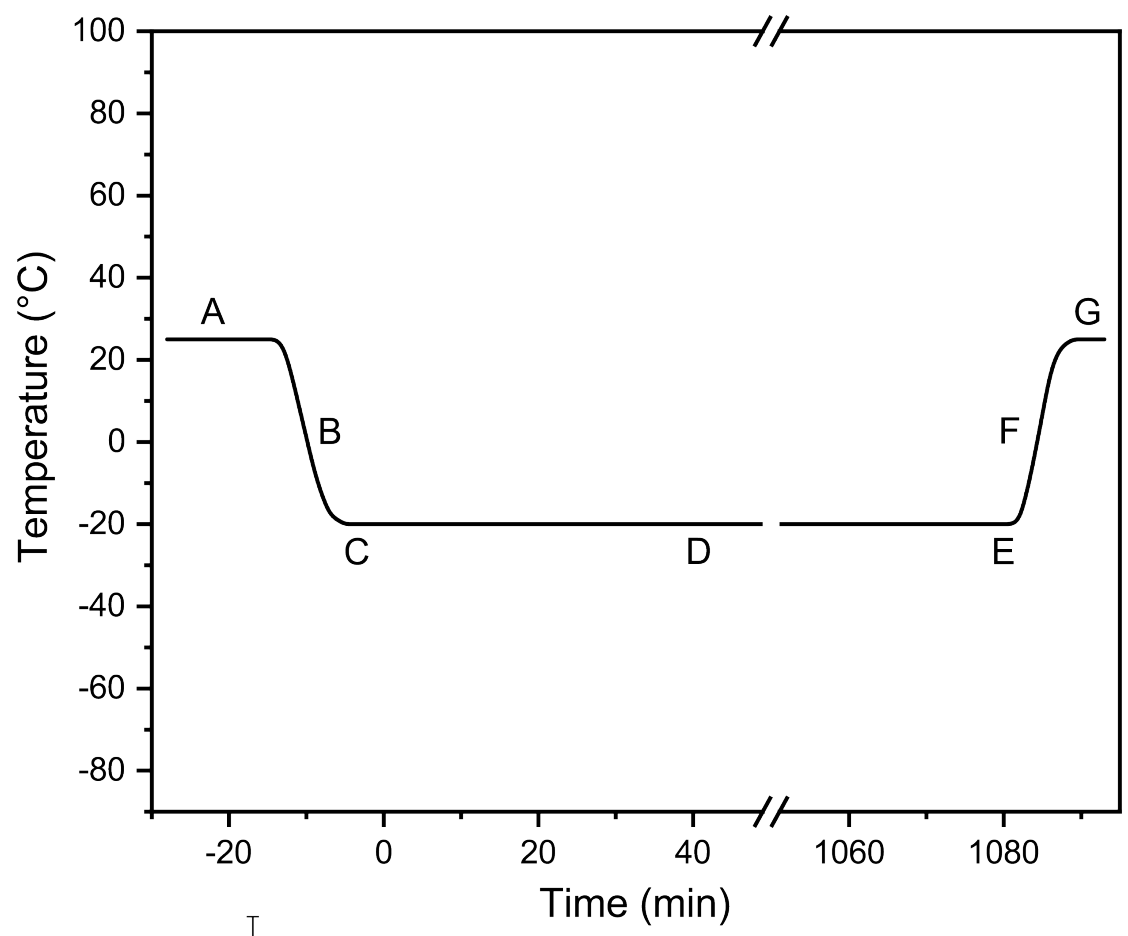

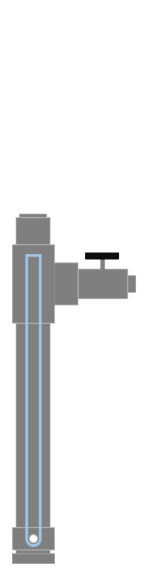

A1

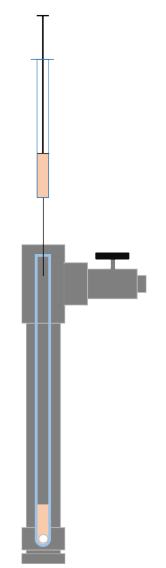

A2

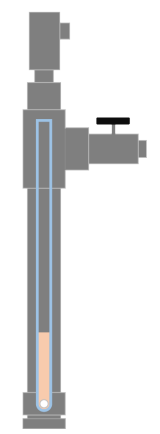

A3

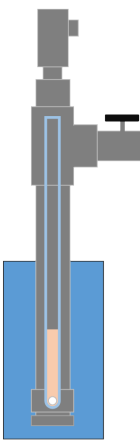

$B+C$

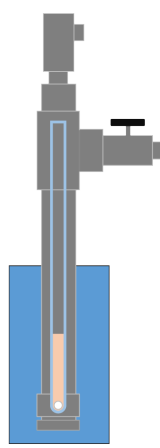

$D+E$

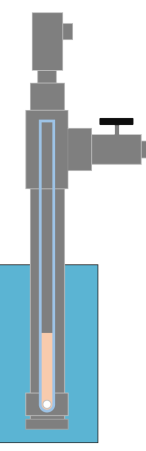

$\mathrm{F}$

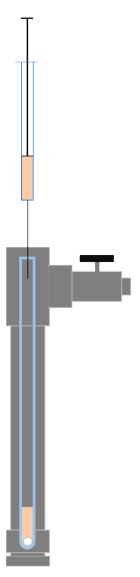

G

Figure S2.3: Workflow for a reaction at low temperature: exemplary timeline of an experimental procedure regarding every step and the respective temperature at which it was performed together with a schematic drawing of the work steps carried out. 
A1: A glass inset is placed in the autoclave and the autoclave is closed. Evacuation of the autoclave and flushing with inert gas at $25^{\circ} \mathrm{C}$.

A2: Opening of the autoclave and transfer of the catalysis mixture into the glass inset in an inert gas counter-flow at $25^{\circ} \mathrm{C}$.

A3: Installing of the proportional relief valve in an inert gas counter-flow at $25^{\circ} \mathrm{C}$.

B: Cooling of the autoclave to the respective temperature $\left(-20^{\circ} \mathrm{C}\right.$ in the example) using a cold bath.

C: The autoclave is kept at the respective temperature $\left(-20^{\circ} \mathrm{C}\right.$ in the example) for 5 to $10 \mathrm{~min}$. Afterwards, the autoclave is pressurized with the gas(es).

D: The autoclave is kept at the respective temperature $\left(-20^{\circ} \mathrm{C}\right.$ in the example) over the course of the reaction ( $18 \mathrm{~h}$ in the example) using a cryostat.

E: The autoclave is vented to stop the reaction.

F: Warming of the autoclave to $25^{\circ} \mathrm{C}$ using a water bath.

G: A sample is taken for analyzation or quantification at $25^{\circ} \mathrm{C}$. 


\subsubsection{Workflow when using Carbon Dioxide in a Reaction at Higher Temperatures}

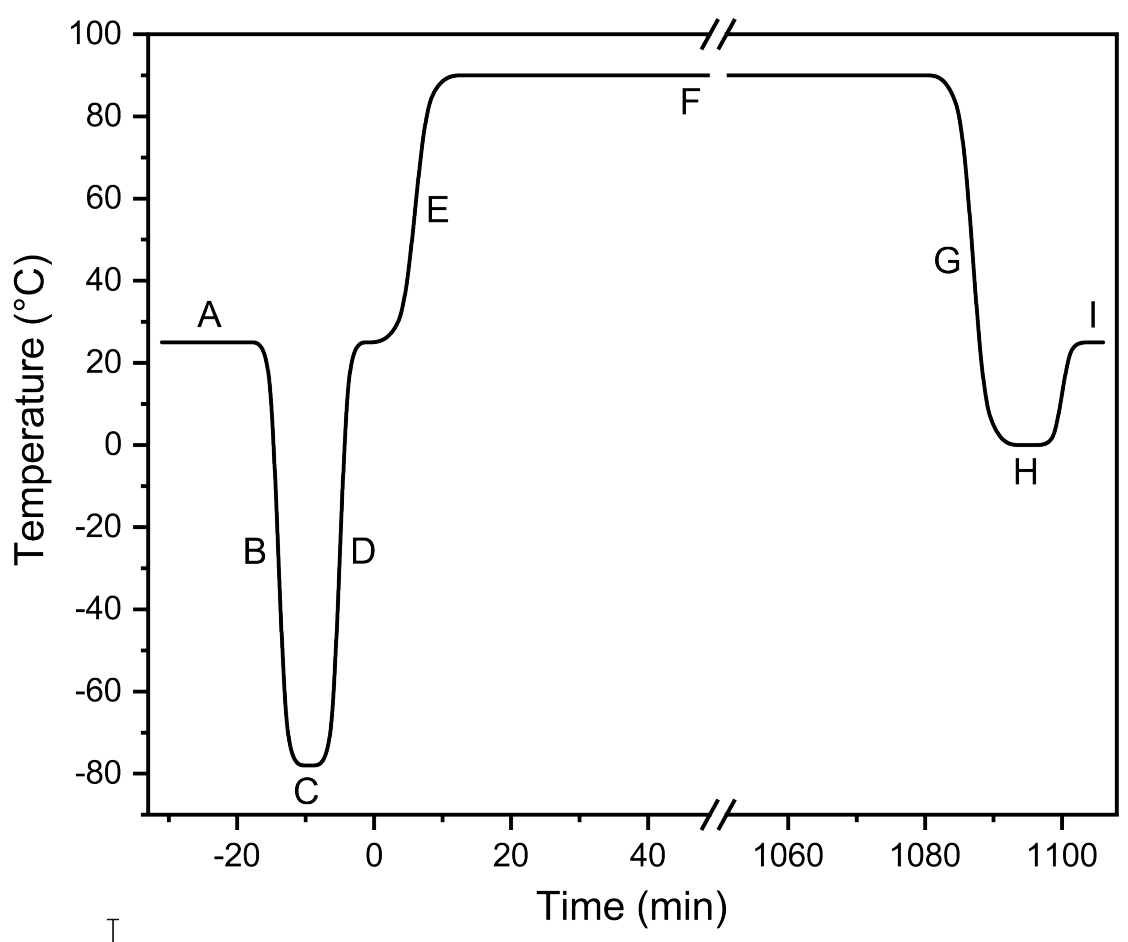

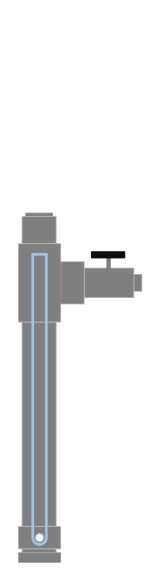

A1

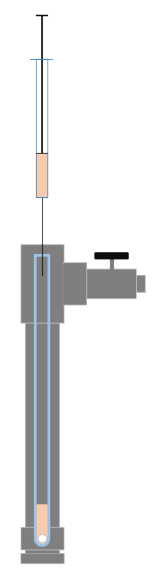

A2

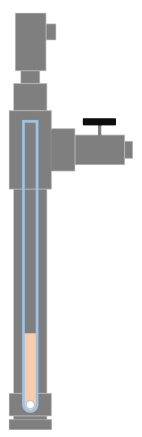

A3

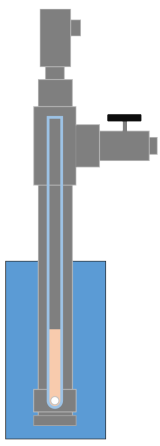

$\mathrm{B}+\mathrm{C}$

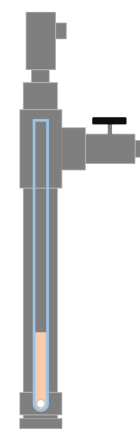

D

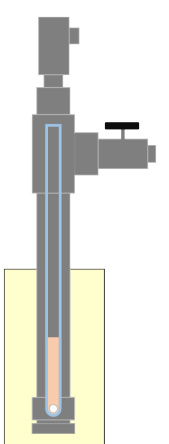

$E+F$

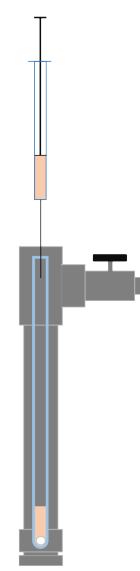

I

Figure S2.4: Workflow when using $\mathrm{CO}_{2}$ in a reaction at higher temperature: exemplary timeline of an experimental procedure regarding every step and the respective temperature at which it was performed together with a schematic drawing of the work steps carried out. 
A1: A glass inset is placed in the autoclave and the autoclave is closed. Evacuation of the autoclave and flushing with inert gas at $25^{\circ} \mathrm{C}$.

A2: Opening of the autoclave and transfer of the catalysis mixture into the glass inset in an inert gas counter-flow at $25^{\circ} \mathrm{C}$.

A3: Installing of the proportional relief valve in an inert gas counter-flow at $25^{\circ} \mathrm{C}$. Afterwards, the autoclave is pressurized with $\mathrm{CO}_{2}$.

B: Cooling of the autoclave to $-78^{\circ} \mathrm{C}$ using an acetone / dry-ice bath.

C: The autoclave is kept at $-78^{\circ} \mathrm{C}$ for 5 to $10 \mathrm{~min}$ in order to deposit $\mathrm{CO}_{2}$. Afterwards, the autoclave is pressurized with the second gas.

D: Warming of the autoclave to $25^{\circ} \mathrm{C}$ for 10 to $20 \mathrm{~min}$.

E: Heating of the autoclave to the respective temperature $\left(90^{\circ} \mathrm{C}\right.$ in the example) using a preheated oil bath. The temperature of the oil bath is stable within $\pm 0.1^{\circ} \mathrm{C}$ after the autoclave is tempered at the desired temperature.

F: The autoclave is kept at constant temperature over the course of the reaction (18 h in the example).

G: Cooling of the autoclave to $0^{\circ} \mathrm{C}$ using an ice bath (in order to fasten the cooling process).

$\mathrm{H}: \quad$ The autoclave is kept at $0^{\circ} \mathrm{C}$ for $15 \mathrm{~min}$.

I: The autoclave is vented carefully and a sample is taken for analyzation or quantification at $25^{\circ} \mathrm{C}$. 


\subsection{Documentation of the Work Steps}

\section{Setting up the Experiment:}

1. Make sure that the inert gas pressure line is depressurized on both gas lines and that vacuum and the inert gas are working properly.

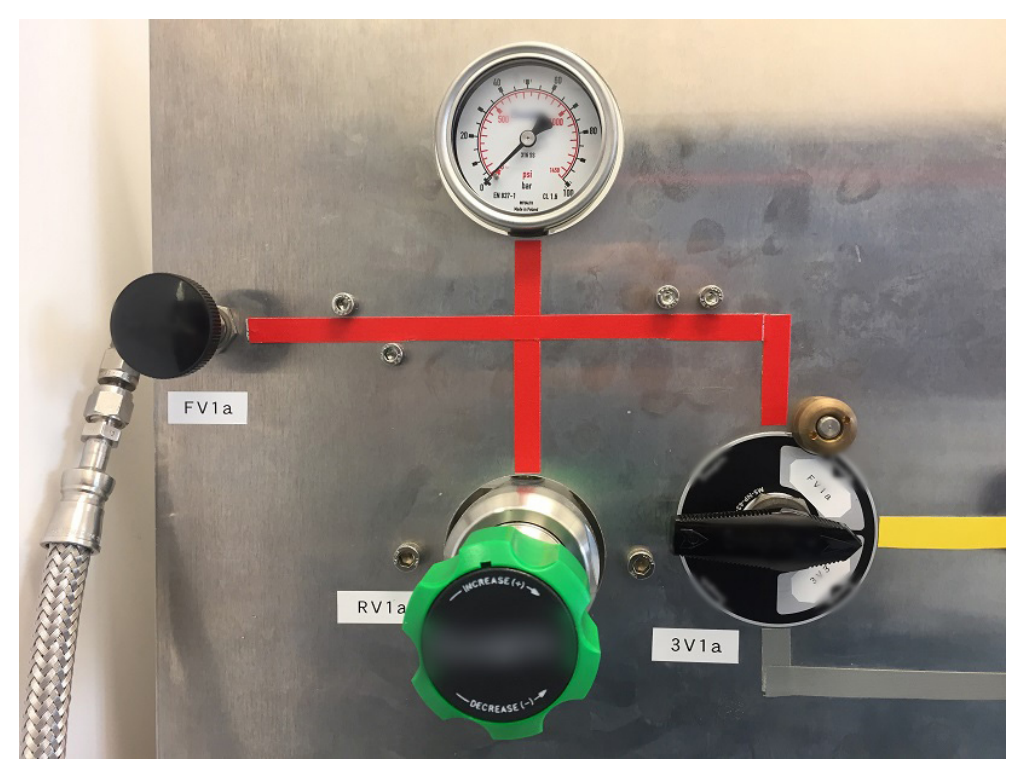

Figure S2.5: Manometer shows depressurized gas line. Depressurize using green pressure regulator if necessary.

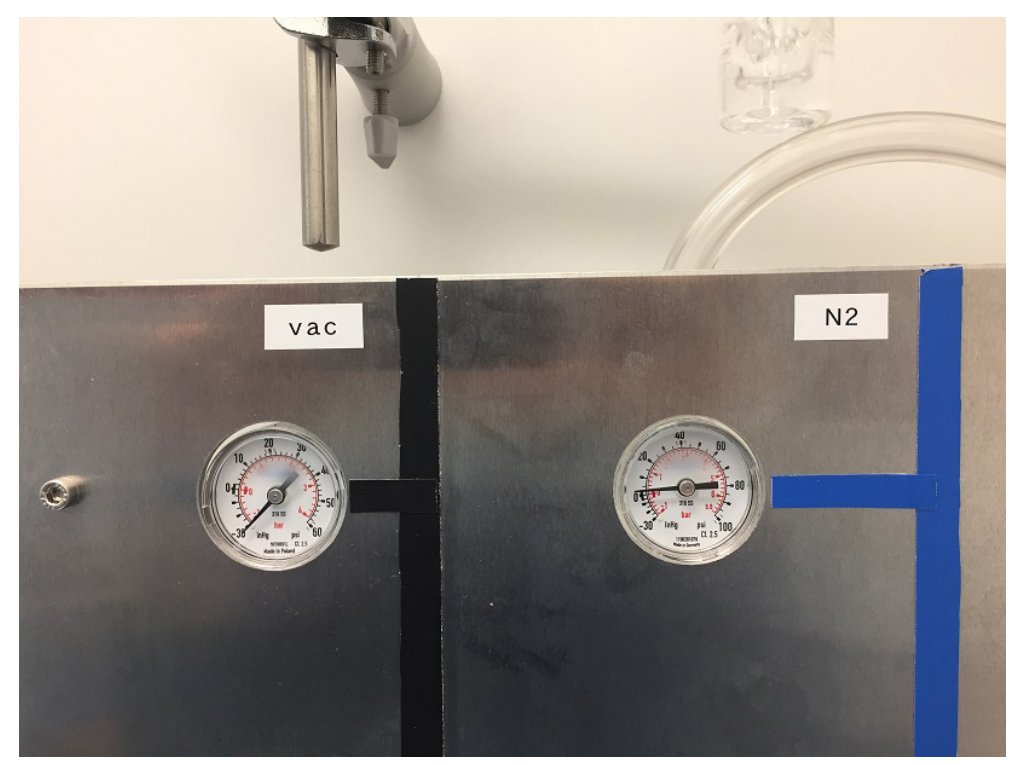

Figure S2.6: Manometers for vacuum (left) and inert gas (right). 
2. Connect your glassware with the prepared catalysis mixture to the inert gas pressure line using connector 3 (C3). Evacuate the hose and flush with inert gas (three times) using valve 3 V5. Always make sure that you do not contaminate the system. Afterwards, close valve 3V5.

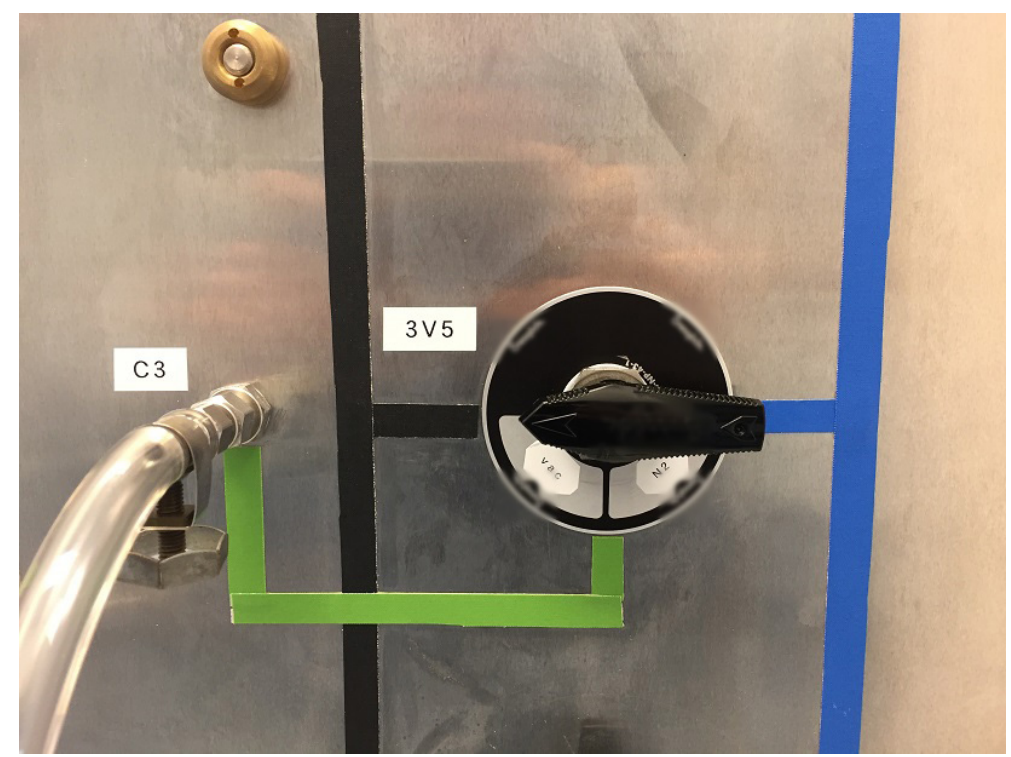

Figure S2.7: Vacuum on connector 3.

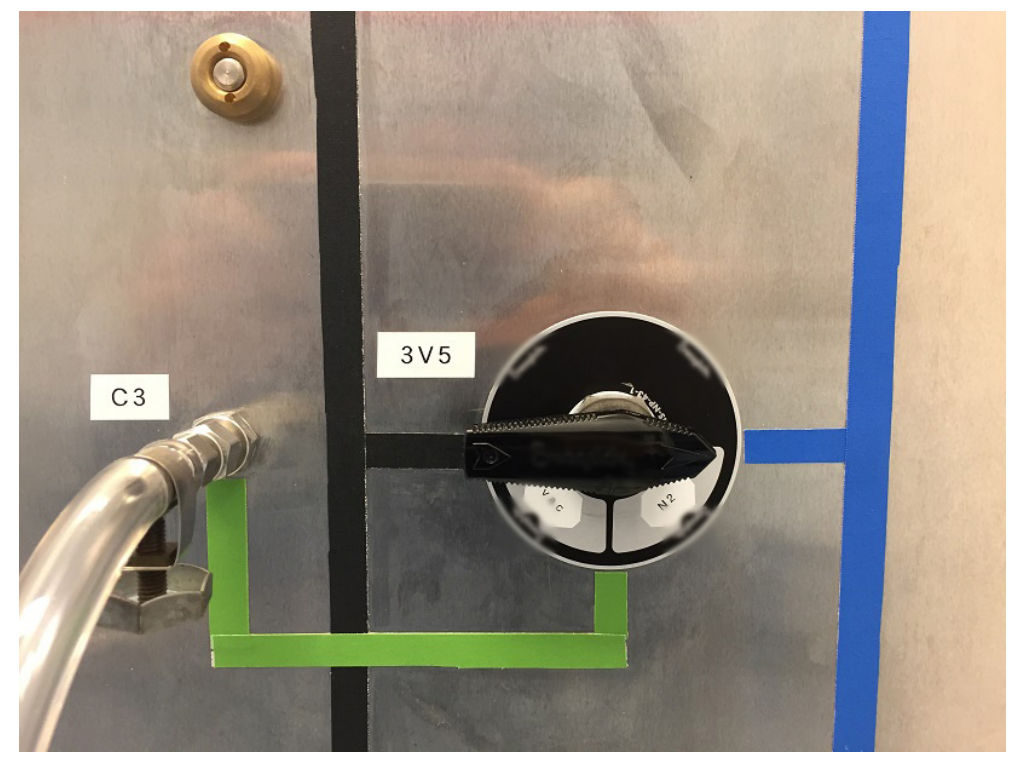

Figure S2.8: Inert gas flow on connector 3 . 
3. Prepare the autoclave: Slide the glass inset with a stirring bar into the autoclave, immobilize it with a PTFE or cut up seal ring and close the autoclave using the plug. Make sure that the needle valve FV2a or FV2b and the needle valve of the autoclave are open. Connect the autoclave to the system using connector $\mathbf{1}(\mathrm{C} 1)$ and evacuate and flush with inert gas (three times) using valves $3 \mathbf{V} 4,3 \mathrm{~V} 3,3 \mathrm{~V} 1 \mathrm{a} / \mathbf{b}$ and $3 \mathrm{~V} 2$.

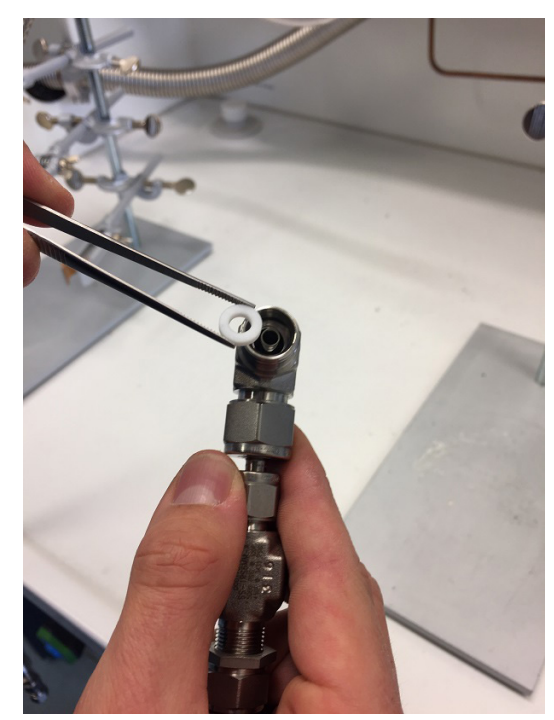

Figure S2.9: Immobilized NMR tube inside a $10 \mathrm{~mL}$ autoclave.

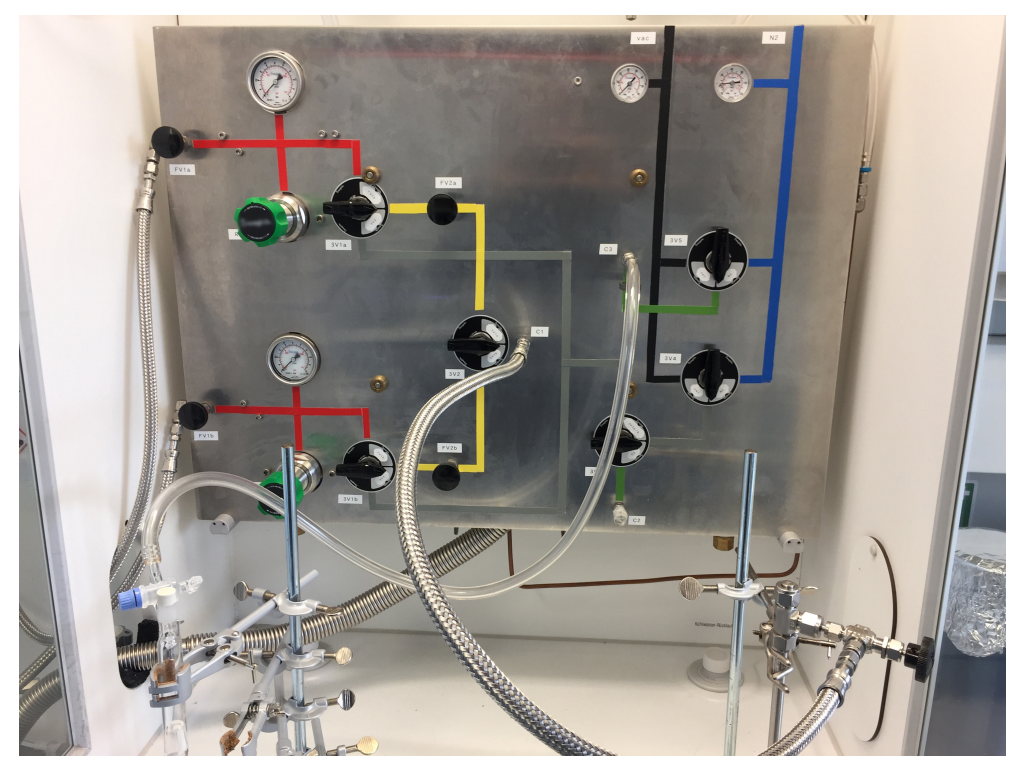

Figure S2.10: Autoclave is connected to the inert gas pressure line and closed with a plug. All three-way valves are closed. 


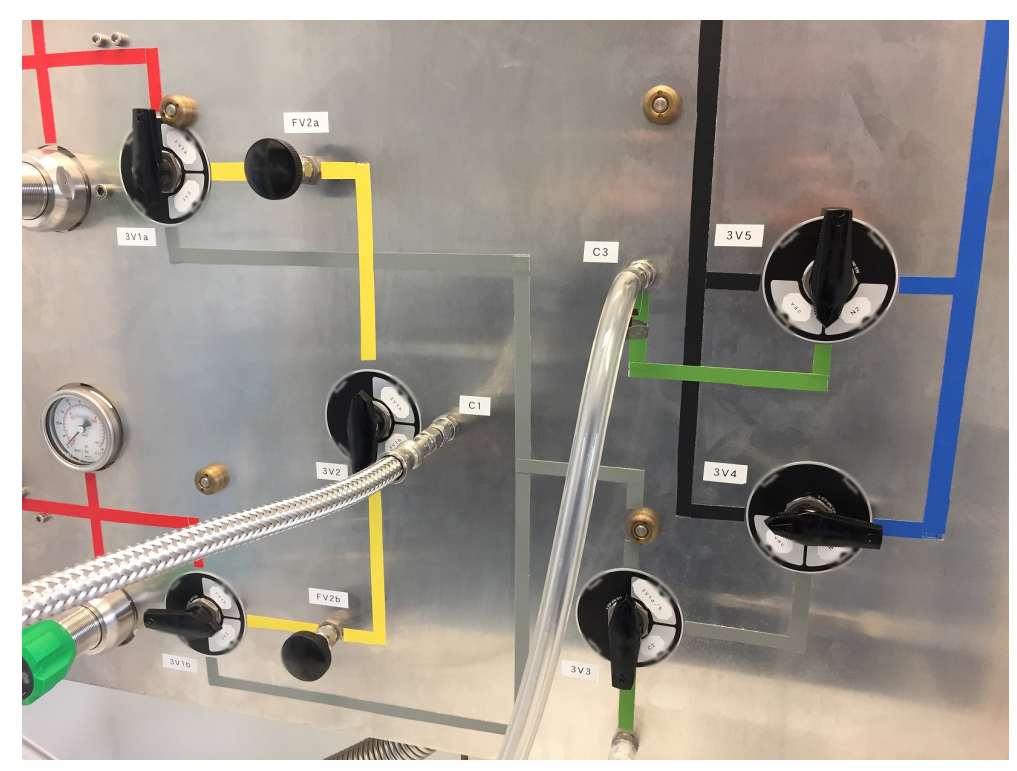

Figure S2.11: Vacuum on connector 1.

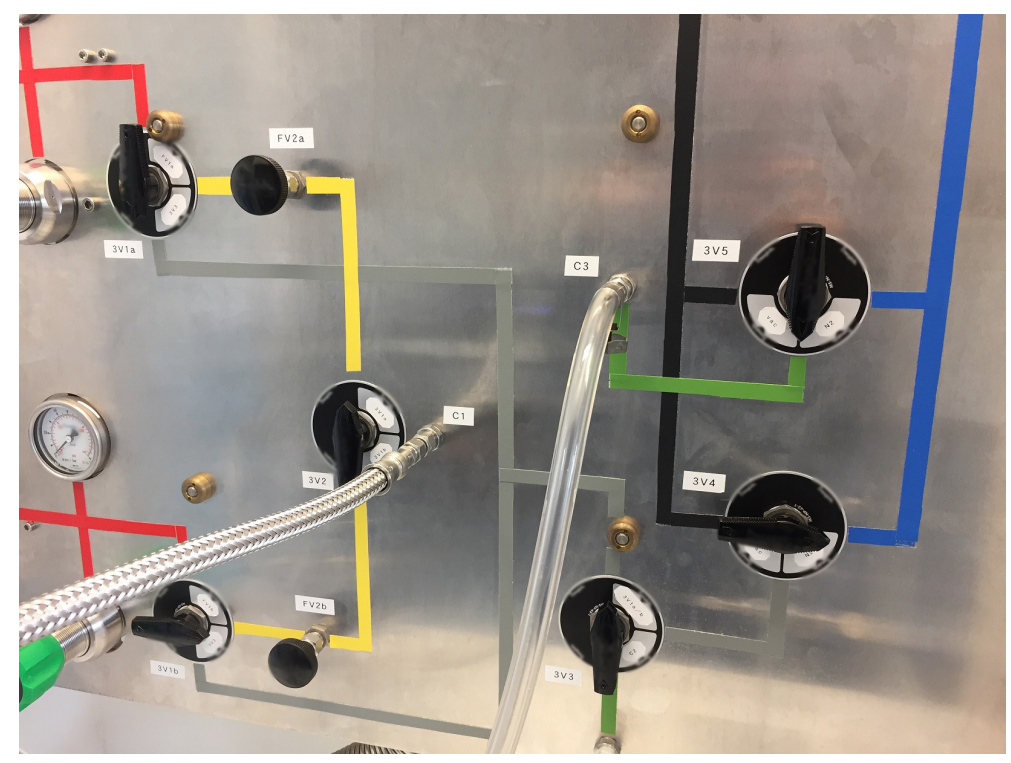

Figure S2.12: Inert gas flow on connector 1. 
4. Reopen valve $\mathbf{3 V} 5$ and under inert gas flow, remove the plug of the connected autoclave and transfer the catalysis mixture carefully into the glass inset (do not pull the syringe again). Afterwards, close valve 3V5.

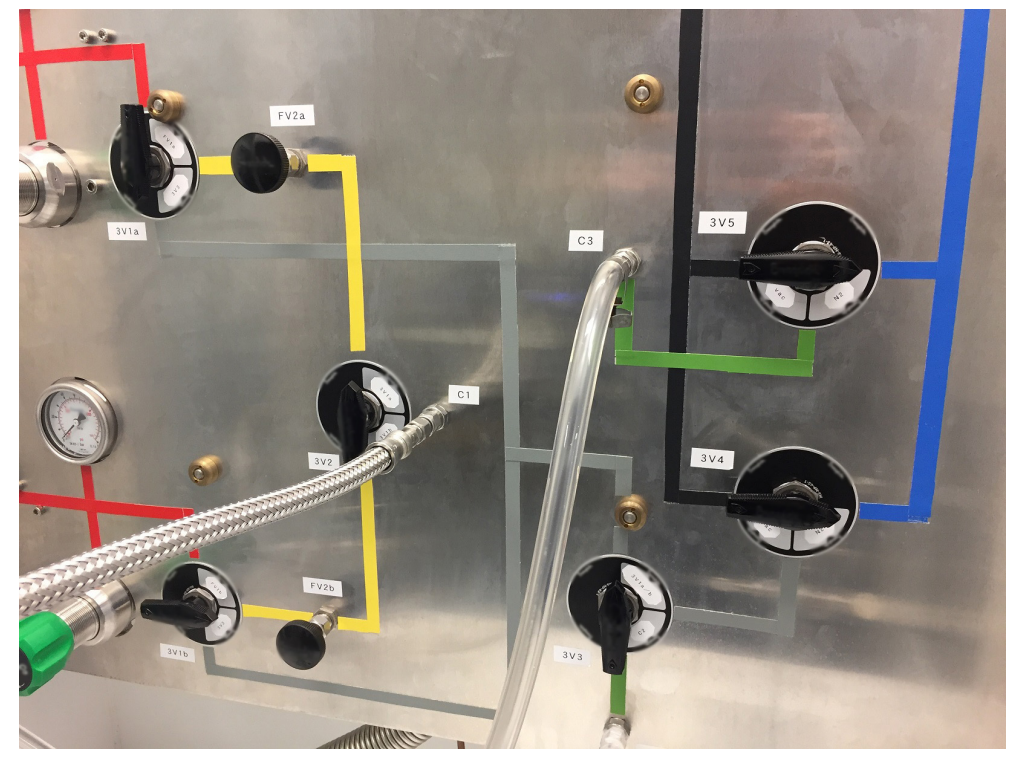

Figure S2.13: Both glass flask (connector 3) and autoclave (connector 1) are connected to inert gas to transfer the catalysis mixture.

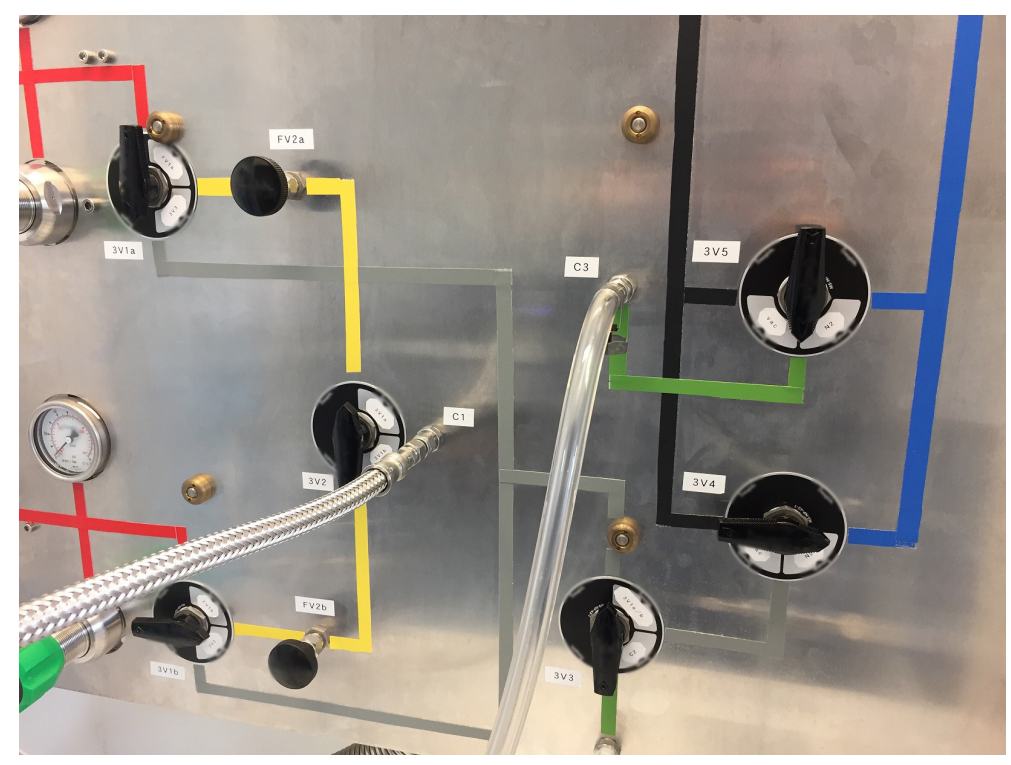

Figure S2.14: After transfer of the catalysis mixture, close the inert gas valve 3V5 to connector 3 . 
5. Loosely place the plug on the autoclave and purge the headspace for $2 \mathrm{~min}$. Then, seal the autoclave by tightening the plug. If a proportional relief valve is used, install and tighten the connector (10-to-6 $\mathrm{mm}$ ). Loosely place the relief valve on top of the connector and wait for 2 min to purge the headspace. Finally, tighten the nut to the relief valve.

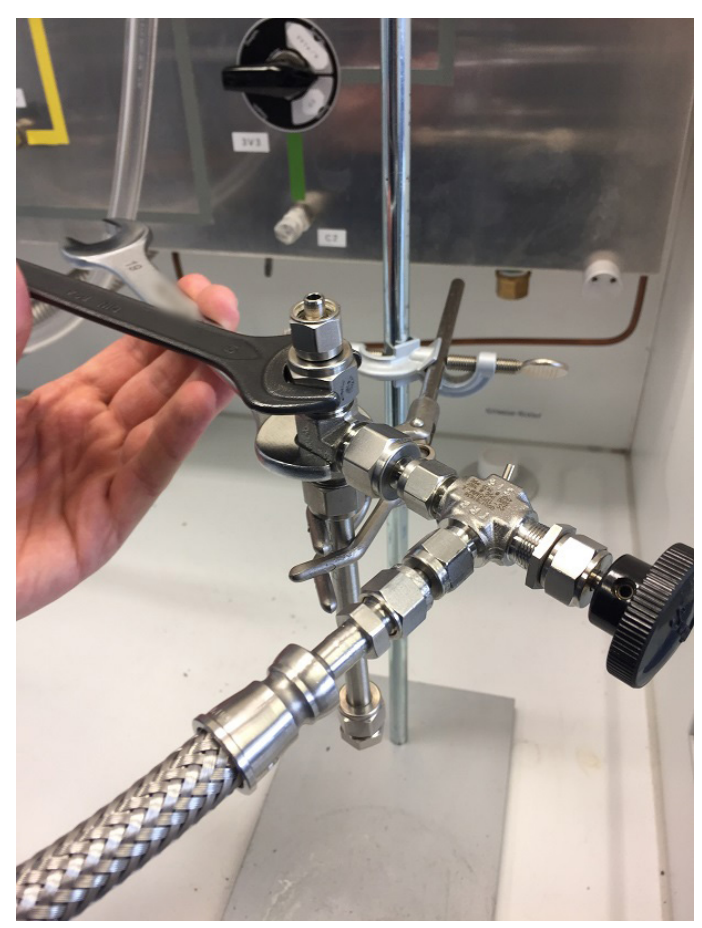

Figure S2.15: Install and tighten the connector under inert gas flow. Place the relief valve loosely on top and purge the headspace.

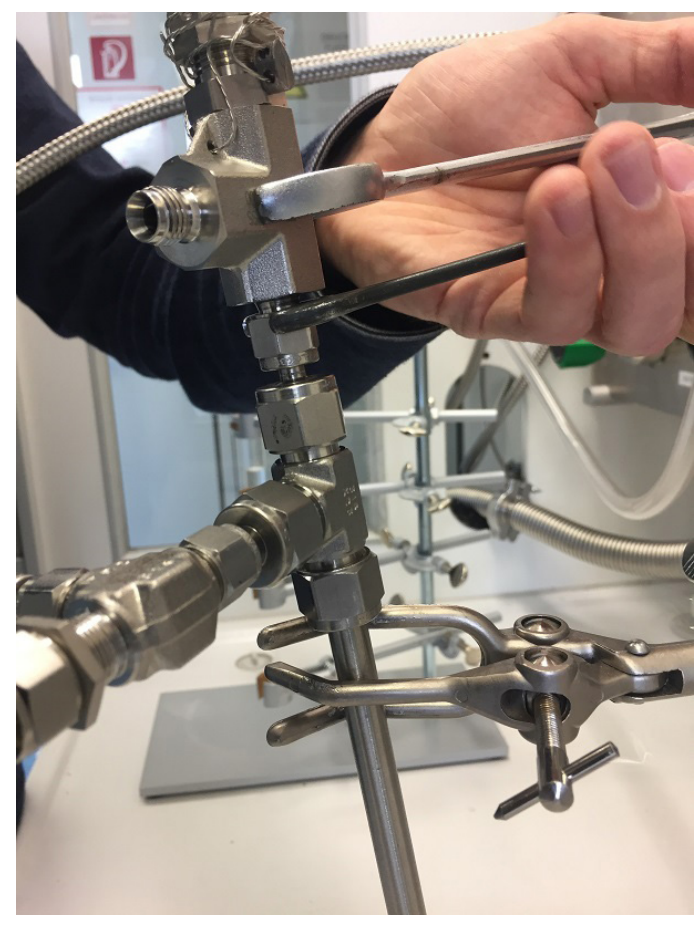

Figure S2.16: After purging, tighten the nut to the relief valve and close the needle valve of the autoclave. 
6. Close off the autoclave using its needle valve and evacuate the remaining system. At final pressure, close the gas bottle-sided three-way valve 3V1a or 3V1b. Re-pressurize the remaining system with inert gas. Finally, close three-way valves 3 V 3 and 3V4.

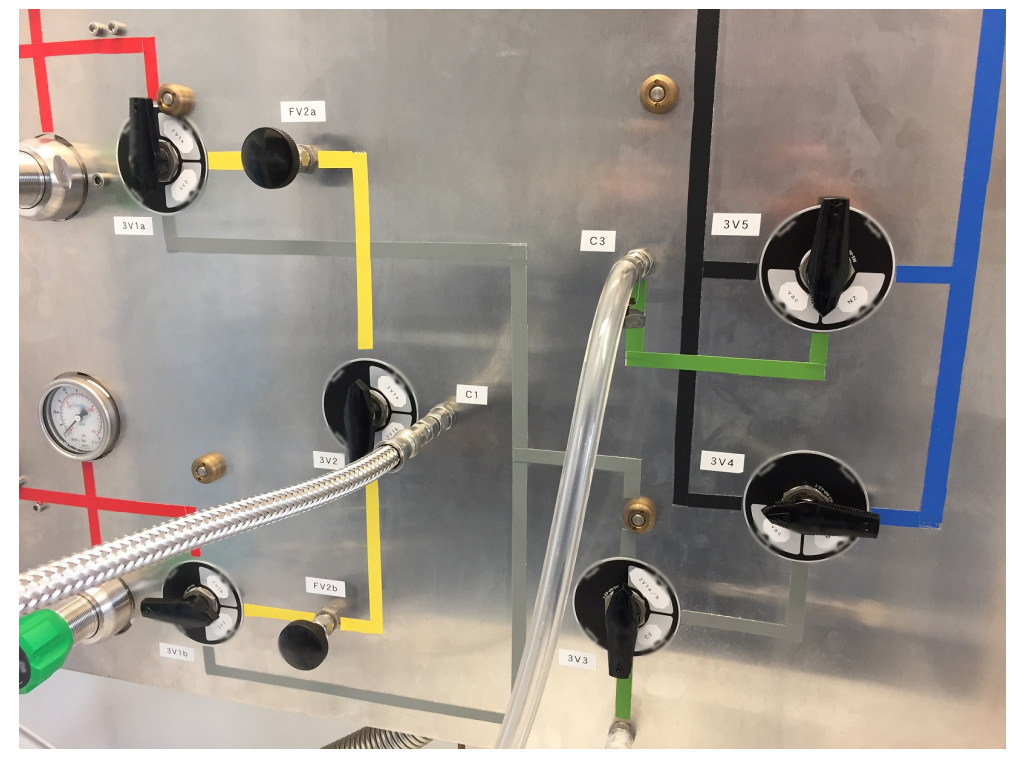

Figure S2.17: After closing the needle valve of the autoclave, evacuate the remaining system using valve $3 \mathrm{~V} 4$.

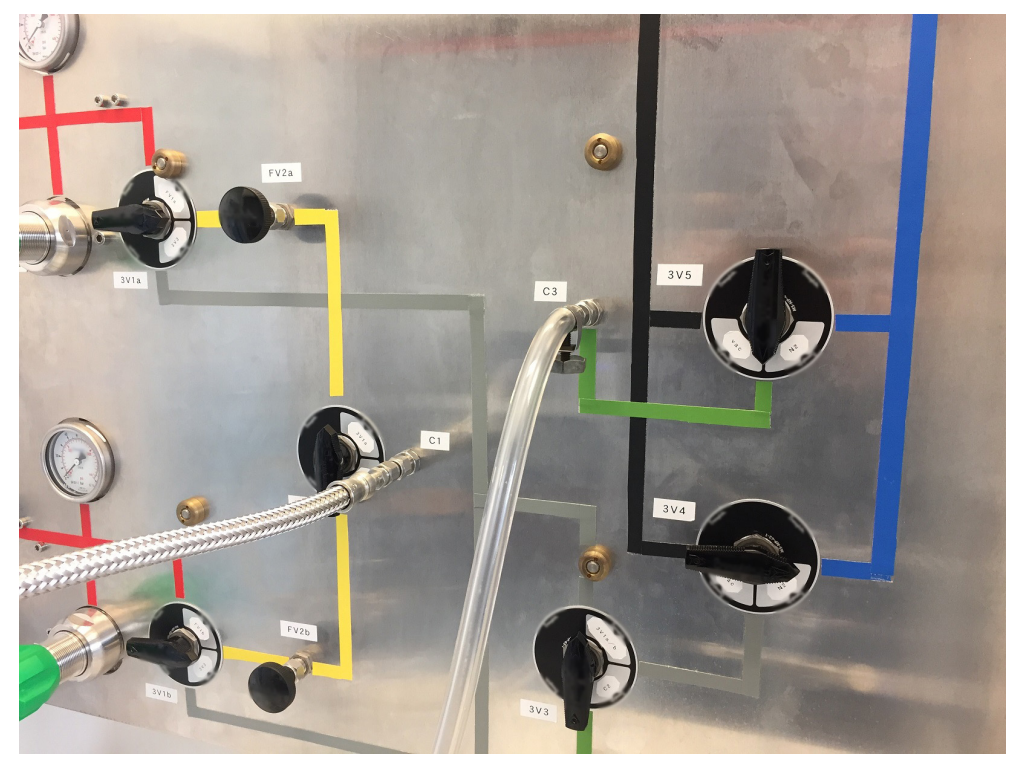

Figure S2.18: Seal off the right side by closing valve $3 \mathrm{~V} 1 \mathrm{a} / \mathrm{b}$ and re-pressurize it using valve $3 \mathrm{~V} 4$, before closing the valves $3 \mathrm{~V} 3$ and $3 \mathrm{~V} 4$. 
For low temperature experiments, place the sealed autoclave in a cold bath and equilibrate for 5-10 min before pressurizing the autoclave (step 9) - meanwhile, proceed with steps 7 and 8 .

7. Before opening the gas cylinder, make sure that the needle valve (FV1a or FV1b) of the gas line that you are using is open.

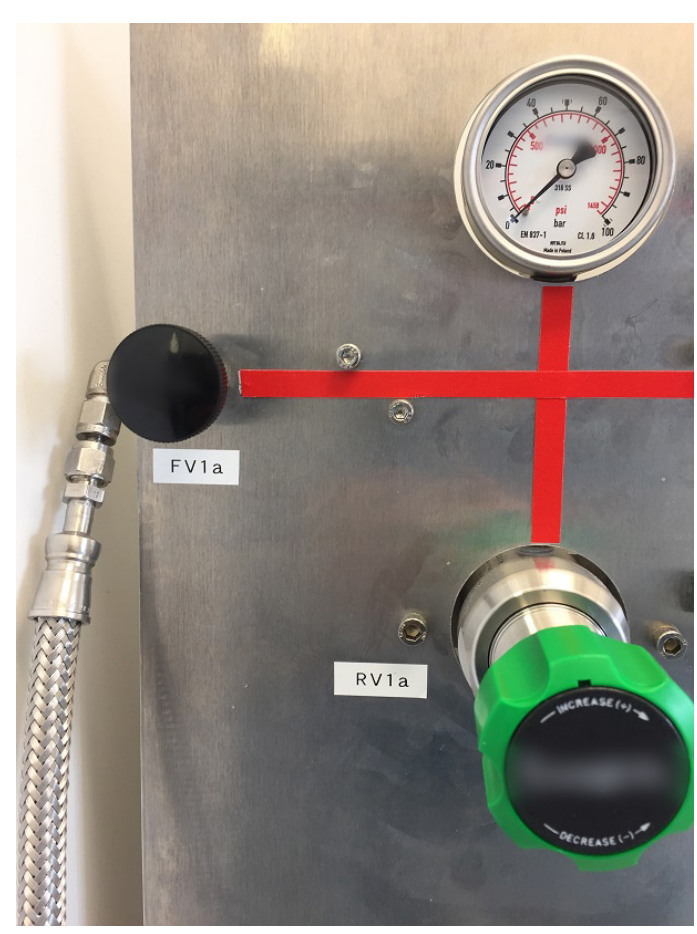

Figure S2.19: Check that needle valve $\mathrm{FV} 1 \mathrm{a} / \mathrm{b}$ is open before applying pressure! Risk of line damage and health hazard!

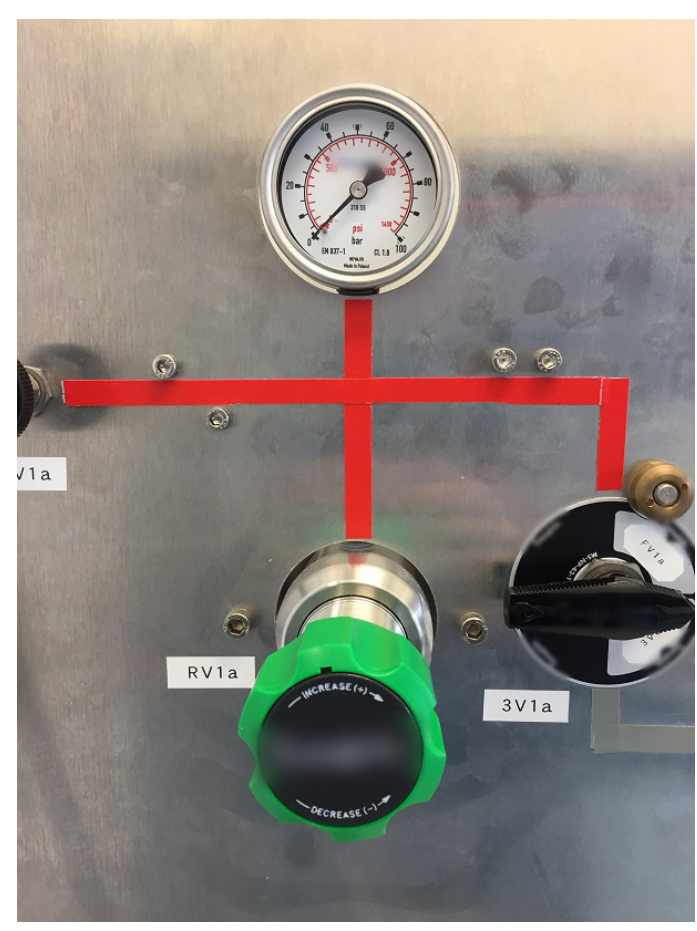

Figure S2.20: Carefully apply and release pressure using the green pressure regulator $\mathrm{RV} 1 \mathrm{a} / \mathrm{b}$ to purge the gas line.

8. Close the green pressure regulator (RV1a or RV1b) to a medium resistance, carefully open the bomb and apply 5-10 bar working gas. Release the gas using the pressure regulator to purge the system. Repeat 7 times.

9. Depending on your working pressure:

a) Reactions $\leq 20$ bar: Adjust the green pressure regulator (RV1a or RV1b) and pressurize the system slightly above working pressure.

Reactions > 20 bar: Adjust the green pressure regulator (RV1a or RV1b) and apply 20 bar. 
b) Open the gas bottle-sided three-way valve $3 \mathbf{V 1 a}$ or $\mathbf{3 V 1 b}$ (make sure that the needle valve FV2a or FV2b is still open). Three-way valve $\mathbf{3 V 2}$ (position line a or line b) should still be open.

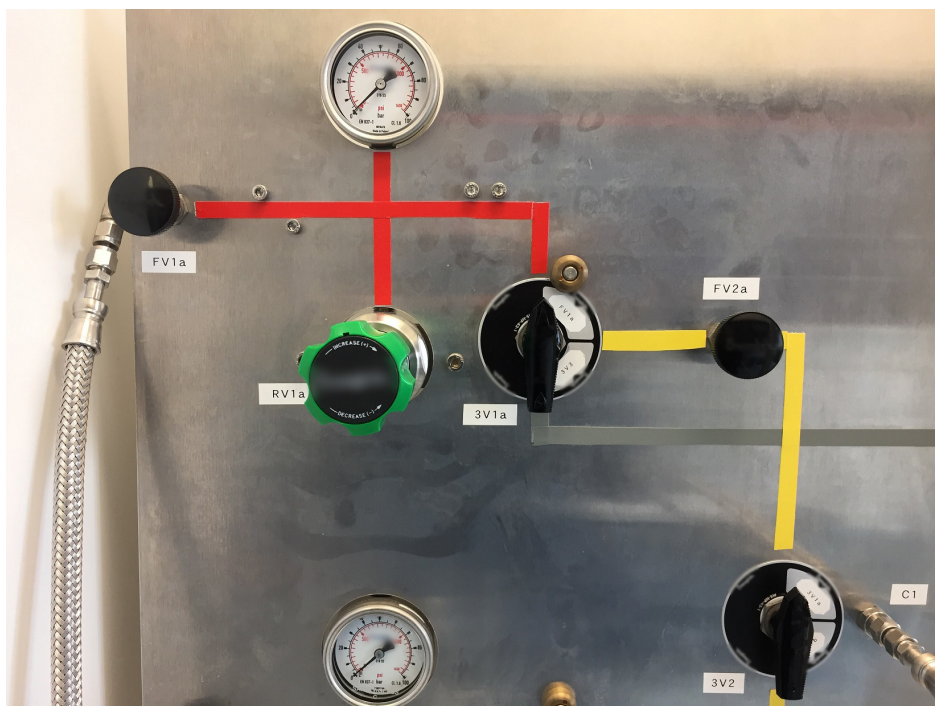

Figure S2.21: Expand working gas into the evacuated section of the line.

c) Shortly open the autoclave's needle valve and directly close it again after equilibration.

d) Re-pressurize the system slightly above the working pressure.

e) Re-open the autoclave's needle valve and directly close it again after equilibration. The autoclave should be under working pressure now. Otherwise, repeat procedure d) + e).

10. Depressurize the system using the green pressure regulator RV1a or RV1b. Close all three-way valves.

- In case two reaction gases are desired, repeat steps 6 to 10 using the other gas line.

- If $\mathrm{CO}_{2}$ should be deposited prior to pressurization with the second gas, place the sealed and pressurized autoclave in a cold bath $\left(-78^{\circ} \mathrm{C}\right)$ and equilibrate for 5-10 min. Afterwards, repeat steps 6 to 10 using the other gas line. 
11. Remove the autoclave from connector $\mathbf{1}(\mathbf{C 1})$ and place it on a magnetic stirrer for reactions at room temperature (600-800 rpm). For reactions at high temperatures, place the autoclave in a pre-heated silicon oil bath on a magnetic stirrer. For low temperature experiments, place the sealed and pressurized autoclave in a cryo-cooled bath on a magnetic stirrer. If $\mathrm{CO}_{2}$ was deposited and the autoclave should be heated, equilibrate the autoclave for 10 to $20 \mathrm{~min}$ at room temperature, before placing it in a pre-heated silicon oil bath on a magnetic stirrer. 


\section{Opening Pressurized Autoclaves:}

1. In a fume hood, carefully open the needle valve of the autoclave to release pressure. For high pressure reactions, pressure can also be released by carefully loosening the plug or the lower nut $(10 \mathrm{~mm})$ of the connector to the relief valve.

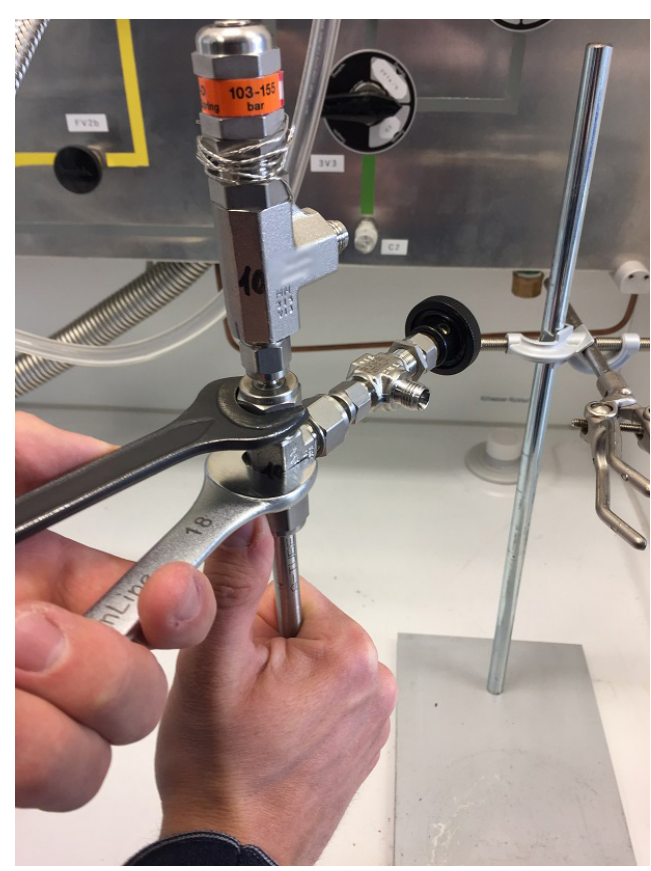

Figure S2.22: Releasing pressure by loosening the lower nut from a pressurized $10 \mathrm{~mL}$ autoclave.

2. Uninstall the plug or the relief valve and the connector. Use a tweezer to remove the sealing and take out the glass inset.

3. Check the autoclave, the plug or the relief valve and the connector for contamination. Clean with acetone if necessary. Clean (PTFE) or discard (rubber) the sealing if contaminated. 


\section{Asymmetric Hydrogenation}

\subsection{Preliminary Remarks}

Catalysis solutions were prepared in Schlenk tubes within an argon atmosphere under exclusion of air and moisture. All glassware was flame-dried prior to use and standard Schlenk techniques were applied.

\subsubsection{Solvents and Reagents}

Dry $\mathrm{MeOH}$ and $\mathrm{MeOH}-\mathrm{d}_{4}$ were bought, degassed by four Freeze-Pump-Thaw cycles and stored under exclusion of air and moisture. Argon gas (Ar 5.0) and hydrogen gas $\left(\mathrm{H}_{2}\right.$ 5.0) were purchased from Air Liquide (Air Liquide Deutschland $\mathrm{GmbH}$ ). Argon gas was dried by silica gel and molecular sieve $(4 \AA)$, whereas hydrogen gas was used without further purification. All other chemicals were purchased from manufacturing and trading companies (Sigma-Aldrich, Inc., USA and TCI Europe N.V., Belgium) and stored according to the respective instructions.

\subsubsection{NMR Spectroscopy}

NMR spectra were recorded on a $400 \mathrm{MHz}$ Bruker Avance III HD spectrometer and a 400 $\mathrm{MHz}$ Bruker Avance III HD spectrometer with a CryoProbe Prodigy (Bruker Corporation, USA). The solvent residual signals were used for internal calibration. ${ }^{[12]}$ Chemical shifts $\delta$ are reported in ppm.

For the quantification experiments, ${ }^{1} \mathrm{H}$ NMR spectra were obtained with a pulse width of $5.0 \mu \mathrm{s}\left(30^{\circ}\right.$ flip angle), an acquisition time of $5.1 \mathrm{~s}$ and a delay time of $10.0 \mathrm{~s}$. For qualitative

[12] Fulmer, G. R.; Miller, A. J. M.; Sherden, N. H.; Gottlieb, H. E.; Nudelman, A.; Stoltz, B. M.; Bercaw, J. E.; Goldberg, K. I. NMR Chemical Shifts of Trace Impurities: Common Laboratory Solvents, Organics, and Gases in Deuterated Solvents Relevant to the Organometallic Chemist. Organometallics 2010, 29, 2176-2179. 
analysis, ${ }^{1} \mathrm{H}$ NMR spectra were obtained with a pulse width of $3.6 \mu$ s ( $30^{\circ}$ flip angle), an acquisition time of $4.1 \mathrm{~s}$ and a delay time of $1.0 \mathrm{~s}$.

\subsubsection{Pressure Measurement}

The adXi data acquisition box (analog-to-digital converter) and the acquisition software adXplorer of Trapp ChemTech (Trapp ChemTech GmbH \& Co. KG, Germany) were used. A calibration for the conversion of the measured voltage in $\mathrm{mV}$ to hydrogen gas pressure in bar was performed using reference points at 1, 20, 50 and 100 bar. For reaction monitoring, the pressure was measured every second, but for visualization and fitting only every 360th data point was used. For visualization of the reaction monitoring and fitting of the reaction course, the software OriginPro 2018G (OriginLab Corporation, USA) was used.

\subsubsection{IR Spectroscopy}

The ReactIR 15 of Mettler-Toledo with the DiComp probe sensor based on diamond (DST Series $6.3 \mathrm{~mm} \mathrm{AgX} \mathrm{Fiber} \mathrm{Conduit,} 1.5 \mathrm{~m}$ fiber length, $216 \mathrm{~mm}$ probe length, $\mathrm{pH}$ range 1 to 14 , temperature range -80 to $180^{\circ} \mathrm{C}$, maximum pressure of $69 \mathrm{bar}$ ) and the Mettler-Toledo software iC IR 7.1 were used (Mettler-Toledo $\mathrm{GmbH}$, Germany). Before the catalysis solution was transferred into the autoclave, the background was measured within the autoclave. During reaction monitoring, an IR spectrum was measured every minute with 128 scans. For the sake of clarity, the IR spectrum was zeroed at the time of hydrogen gas pressurization by subtracting the reference spectrum at that time from all other spectra. As baseline correction, the Pearson's correction was applied. The temperature within the autoclave was monitored by the integrated temperature sensor in the IR probe. For visualization of the reaction monitoring and fitting of the reaction course, the software OriginPro 2018G (OriginLab Corporation, USA) was used.

\subsubsection{HPLC Analysis}

HPLC measurements were carried out on an Agilent Technologies (Agilent Technologies, Inc., USA) HPLC system equipped with a membrane solvent degasser (Agilent 1260 Infinity), an isocratic solvent pump (Agilent 1260 Infinity), an auto-sampling unit (Agilent 1200 Series), a thermostatted column compartment (Agilent 1260 Infinity) and a DAD detector (Agilent 1290 Infinity II). The performed separations were controlled with the help of the Agilent 
OpenLAB software (Agilent Technologies, Inc., USA). All solvents and additives used were obtained from VWR (VWR International, LLC., USA) in HPLC-grade quality (HiPerSolv CHROMANORM). Separations were followed on the basis of UV absorption spectra at $\lambda=210$ and $230 \mathrm{~nm}$. The separations were realized using the chiral chromatography columns Chiralpak IG-3 (4.6 mm x $150 \mathrm{~mm}, 3 \mu \mathrm{m})$ and Chiralpak IC (4.6 mm x $250 \mathrm{~mm}, 5 \mu \mathrm{m})$ of Daicel (Daicel Corporation, USA). 


\subsection{Demonstration of the Analytic Techniques in the Asymmetric Hydrogenation of 2-Phenylacrylic Acid}<smiles>C=C(C(=O)O)c1ccccc1</smiles>

The catalysis was performed according to the procedure elucidated in section 2.1.

A solution of 2-phenylacrylic acid (240 mg, $1.62 \mathrm{mmol}, 1.00$ eq.), diacetato[(S)-(-)-2,2'bis(diphenylphosphino)-1,1'-binaphthyl]ruthenium(II) (27.3 mg, 32.4 umol, $2 \mathrm{~mol} \%$ ) and trimethyl 1,3,5-benzenetricarboxylate ( $27.2 \mathrm{mg}, 108$ umol, 0.07 eq.) in anhydrous degassed $\mathrm{MeOH}-\mathrm{d}_{4}(6 \mathrm{~mL})$ was prepared.

A ${ }^{1} \mathrm{H}$ NMR spectrum was measured directly before the catalysis ( $0.5 \mathrm{~mL}$ catalysis solution). The catalysis was performed in a stainless steel high-pressure autoclave ( $35 \mathrm{~mL}$ total volume) with connected in-situ IR probe and a pressure transducer (see subsection 1.2.11). A glass tube as inset and a small stirring bar for mixing were used. The autoclave was evacuated and flushed with nitrogen three times before the catalysis solution $(5.0 \mathrm{~mL})$ was transferred into the glass inset in counter-flow. The hydrogen gas line was purged with $\mathrm{H}_{2}$ at least seven times. The in-situ IR and on-line pressure measurements were started, before the autoclave was pressurized with 50 bar $\mathrm{H}_{2}$ at room temperature. The reaction mixture was stirred at room temperature for $72 \mathrm{~h}$. The reaction was terminated by carefully venting the autoclave. A ${ }^{1} \mathrm{H}$ NMR spectrum was directly measured after the catalysis.

For the sake of clarity, the IR spectrum was zeroed at the time of hydrogen gas pressurization ( $t=4 \mathrm{~min}$ ) by subtracting the reference spectrum at that time from all other spectra. As baseline correction, the Pearson's correction was applied. The substrate 2-phenylacrylic acid was monitored at $1689 \mathrm{~cm}^{-1}$ (height to zero) and the product 2-phenylpropionic acid at $1727 \mathrm{~cm}^{-1}$ (height to zero). 


\section{IR Spectra of Reference Compounds}

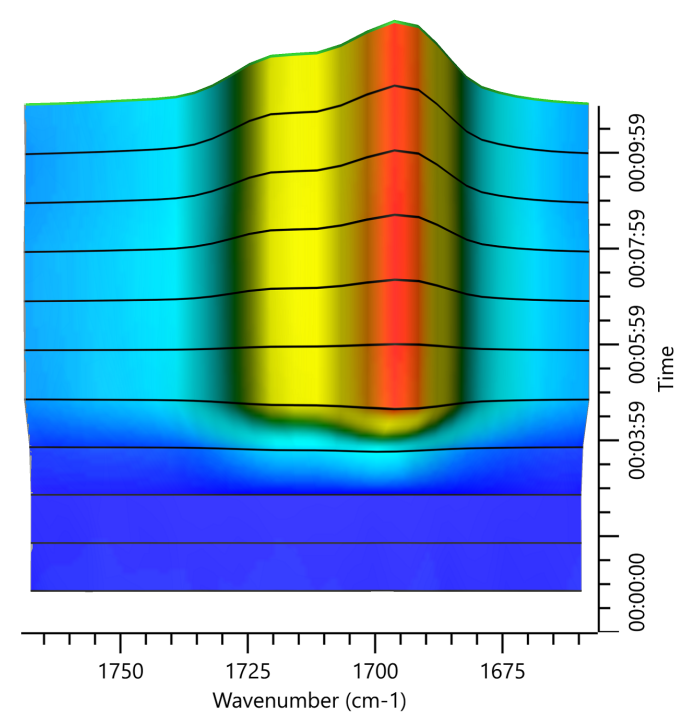

Figure S3.1: IR spectra of the substrate 2-phenylacrylic acid in $\mathrm{MeOH}$ (the $\mathrm{MeOH}$ background was subtracted).

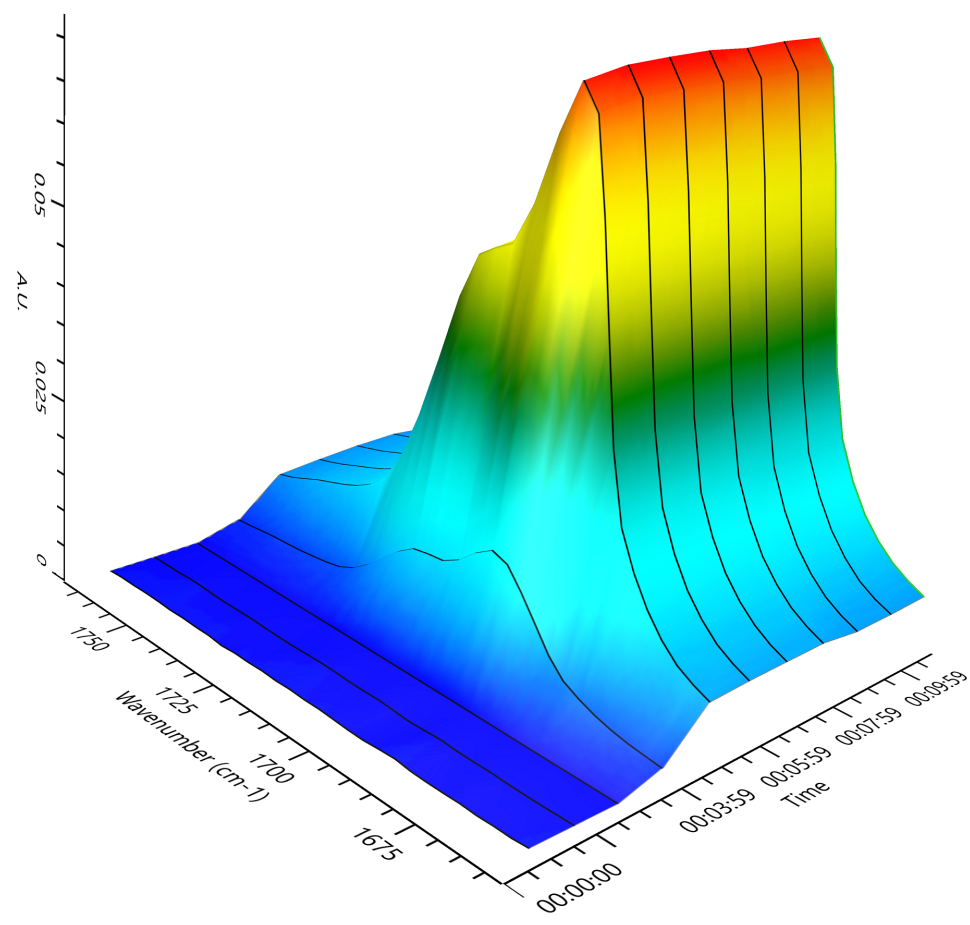

Figure S3.2: IR spectra of the substrate 2-phenylacrylic acid in $\mathrm{MeOH}$ (the $\mathrm{MeOH}$ background was subtracted). 


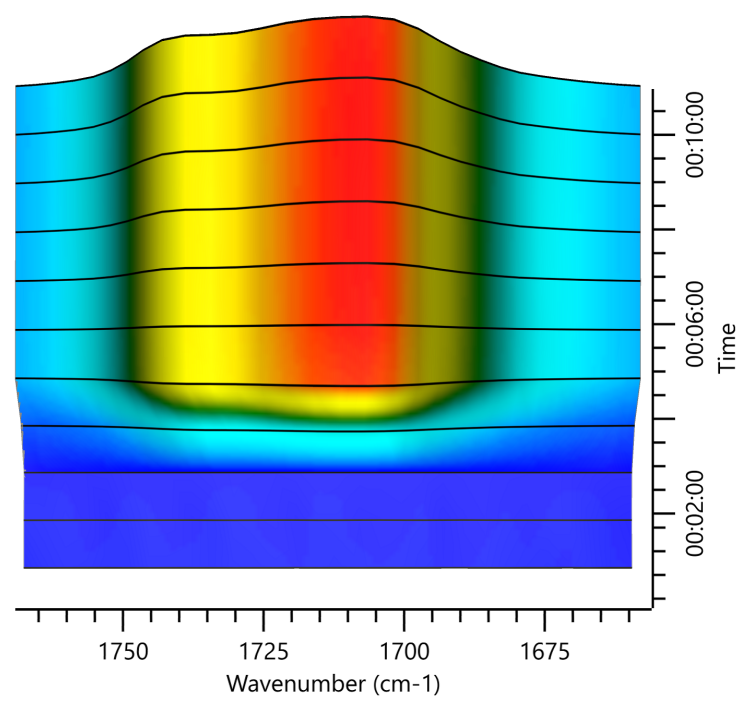

Figure S3.3: IR spectra of the product 2-phenylpropionic acid in $\mathrm{MeOH}$ (the $\mathrm{MeOH}$ background was subtracted).

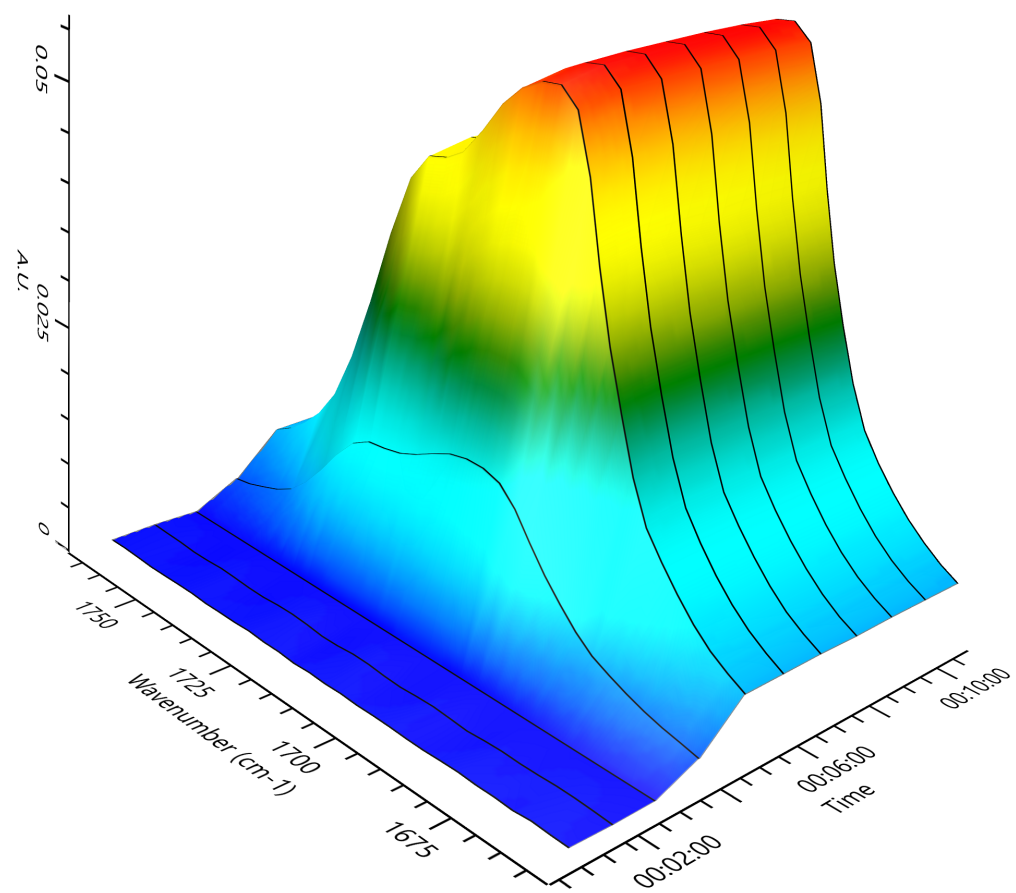

Figure S3.4: IR spectra of the product 2-phenylpropionic acid in $\mathrm{MeOH}$ (the $\mathrm{MeOH}$ background was subtracted). 


\section{Calibration for Conversion from Voltage to Pressure}

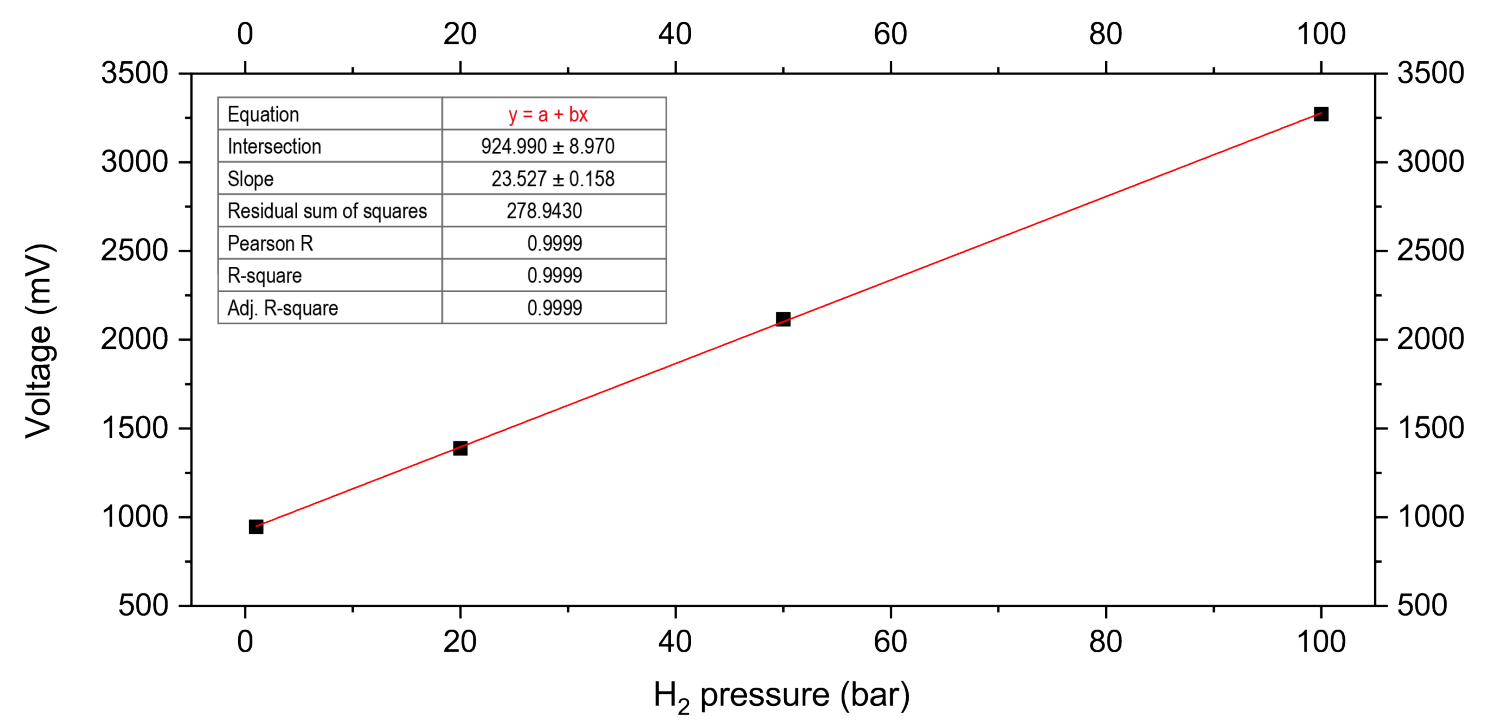

Figure S3.5: Calibration plot for the conversion from voltage in $\mathrm{mV}$ to pressure in bar.

Table S3.1: Calibration reference points for the conversion from voltage in $\mathrm{mV}$ to pressure in bar.

\begin{tabular}{ccc}
\hline Pressure (bar) & $\begin{array}{c}\text { Measured } \\
\text { Voltage }(\mathrm{mV})\end{array}$ & $\begin{array}{c}\text { Mean Value of } \\
\text { Voltage }(\mathrm{mV})\end{array}$ \\
\hline \multirow{2}{*}{100} & 3283 & 3272 \\
& 3269 & \\
& 3264 & 2116 \\
\hline \multirow{2}{*}{50} & 2125 & 1389 \\
\hline \multirow{2}{*}{20} & 2106 & \\
\multirow{2}{*}{1} & 1389 & 947 \\
& 947 & \\
\hline
\end{tabular}




\subsection{Asymmetric Hydrogenation of Prochiral $\alpha$-Substituted Acrylic Acids}

\subsubsection{Hydrogenation of 2-Phenylacrylic Acid}

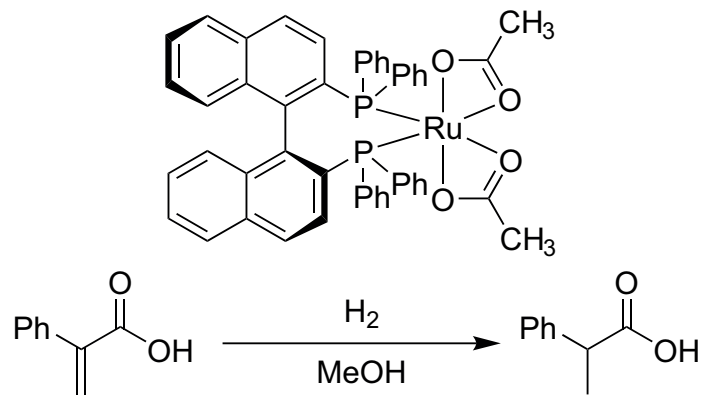

The catalyses were performed according to the procedure elucidated in section 2.1. All catalysis settings were performed twice and the mean value was taken for discussion.

A solution of 2-phenylacrylic acid (3.70 mg, $25.0 \mu \mathrm{mol}, 1.00$ eq.) and diacetato[(S)-(-)-2,2'bis(diphenylphosphino)-1,1'-binaphthyl]ruthenium(II) (526 jg, $625 \mathrm{nmol}, 2.5 \mathrm{~mol} \%$ ) in anhydrous degassed $\mathrm{MeOH}(0.5 \mathrm{~mL})$ was prepared using stock solutions of the substrate and the catalyst.

The catalyses were performed in stainless steel high-pressure autoclaves (10 $\mathrm{mL}$ total volume) using an NMR tube as inset and a small stirring bar for mixing. The autoclave was evacuated and flushed with nitrogen three times before the catalysis solution was transferred into the NMR tube inset. The hydrogen gas line was purged with $\mathrm{H}_{2}$ at least seven times. In case of reactions at 25 and $100^{\circ} \mathrm{C}$, the autoclave was directly pressurized with $\mathrm{H}_{2}$. In case of reactions at $0^{\circ} \mathrm{C}$, the autoclave was cooled to $0^{\circ} \mathrm{C}$ using a cold bath for $5 \mathrm{~min}$ before it was pressurized with $\mathrm{H}_{2}$. The reaction mixture was stirred at the respective temperature for $18 \mathrm{~h}$. In case of reactions at 0 and $25^{\circ} \mathrm{C}$, the reaction was terminated by carefully venting the autoclave. In case of reactions at $100^{\circ} \mathrm{C}$, the autoclave was cooled to $0^{\circ} \mathrm{C}$ using a cold bath for $10 \mathrm{~min}$ before it was carefully vented at $25^{\circ} \mathrm{C}$.

The reaction solution was eluted with EtOAc $(15 \mathrm{~mL})$ through a short pad of silica $(\mathrm{ca} .2 \mathrm{~cm})$ to remove metal residues. The volatile compounds were removed in vacuo. The conversion of the reaction was determined by NMR and the enantiomeric excess of the product by enantioselective HPLC analysis. 
The enantioselective HPLC analyses were carried out using:

Chiralpak IG-3 (4.6 mm x $150 \mathrm{~mm}, 3 \mu \mathrm{m})$, $n$-hexane:IPA:AcOH 95:5:0.1, $1 \mathrm{~mL} \mathrm{~min}^{-1}, 20^{\circ} \mathrm{C}$, $\lambda=210 \mathrm{~nm}$.

Table S3.2: Retention times for the substrate and the hydrogenation products of 2-phenylacrylic acid.

\begin{aligned} & \hline Compound Retention Time \\ & \hline substrate $4.52 \mathrm{~min} \\ &(R)$-enantiomer 4.71 to $4.77 \mathrm{~min} \\ &$ (S)-enantiomer 5.05 to $5.12 \mathrm{~min} \\ &$\hline\end{aligned}

In order to assign the configuration of the enantiomers, commercially purchased (S)-2phenylpropionic acid and racemized 2-phenylpropionic acid were analyzed by enantioselective HPLC. In order to ensure separation of the substrate and the resulting enantiomers, the substrate 2-phenylacrylic acid was analyzed under the same conditions. 


\section{HPLC Analysis of Reference Compounds}

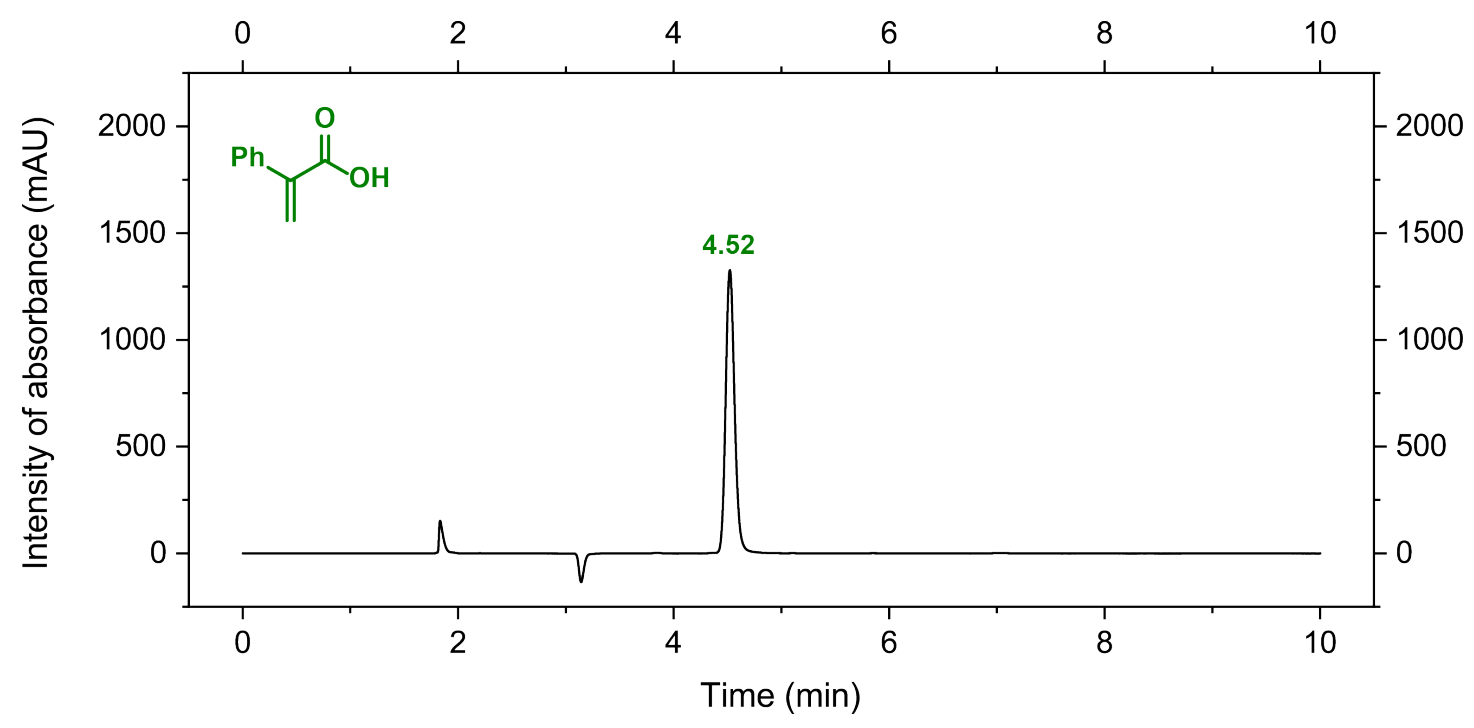

Figure S3.6: Chromatogram of the HPLC analysis of the substrate 2-phenylacrylic acid.

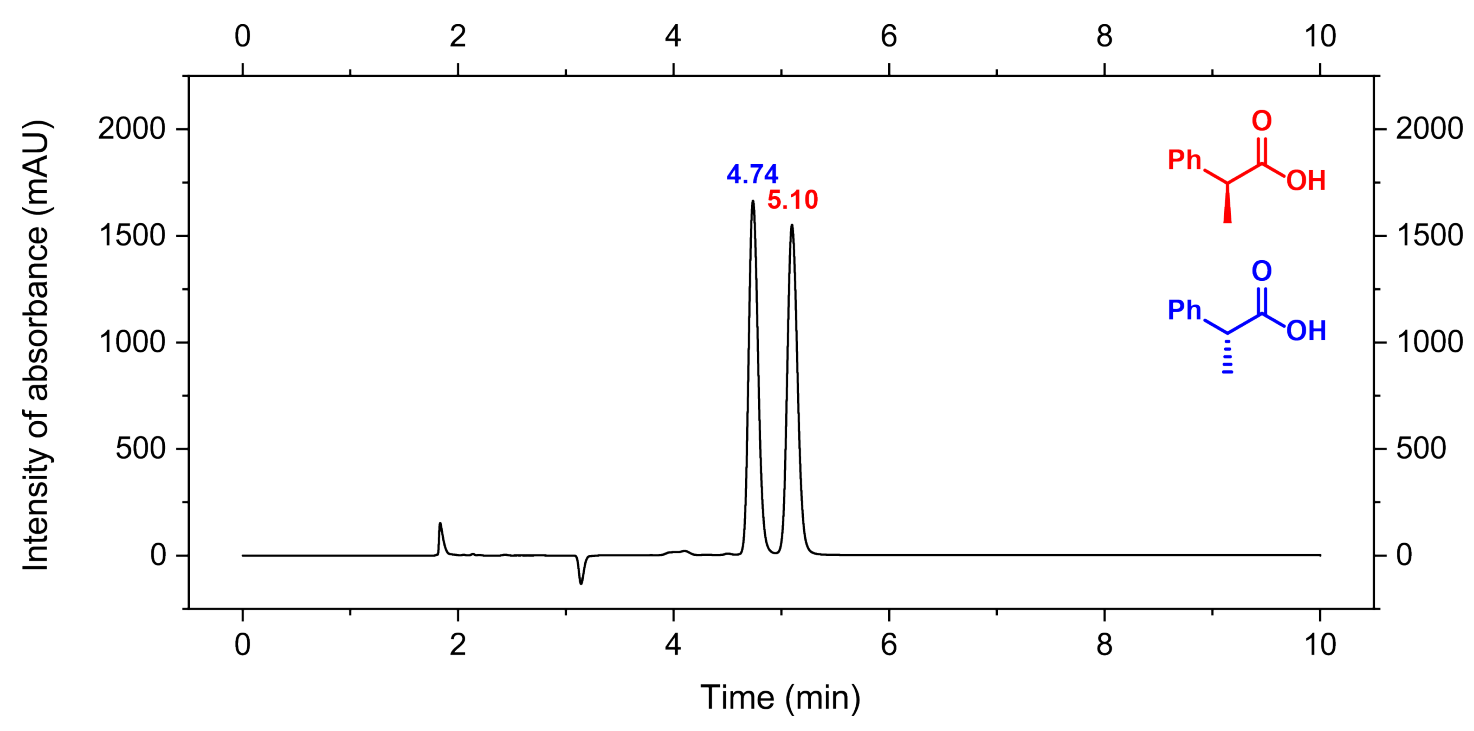

Figure S3.7: Chromatogram of the HPLC analysis of racemic 2-phenylpropionic acid. 


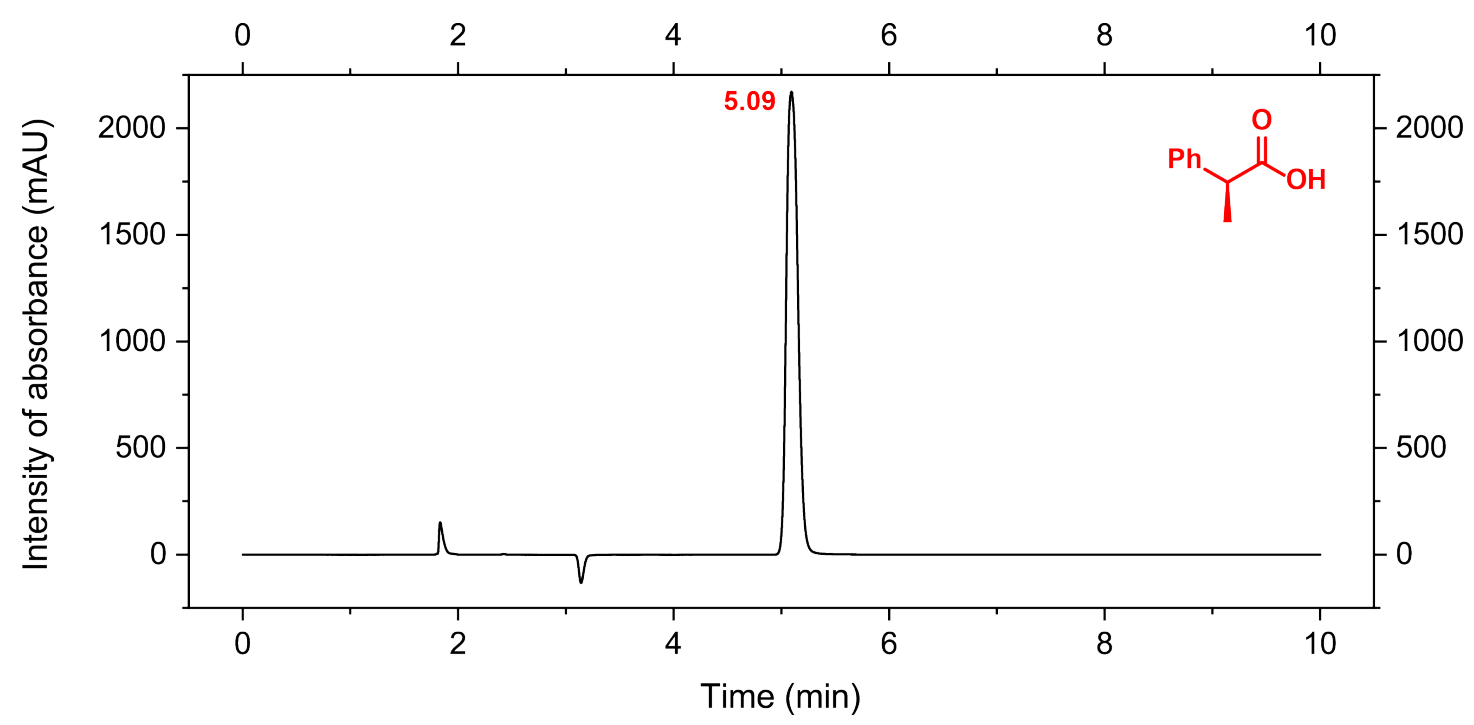

Figure S3.8: Chromatogram of the HPLC analysis of $(S)$-2-phenylpropionic acid.

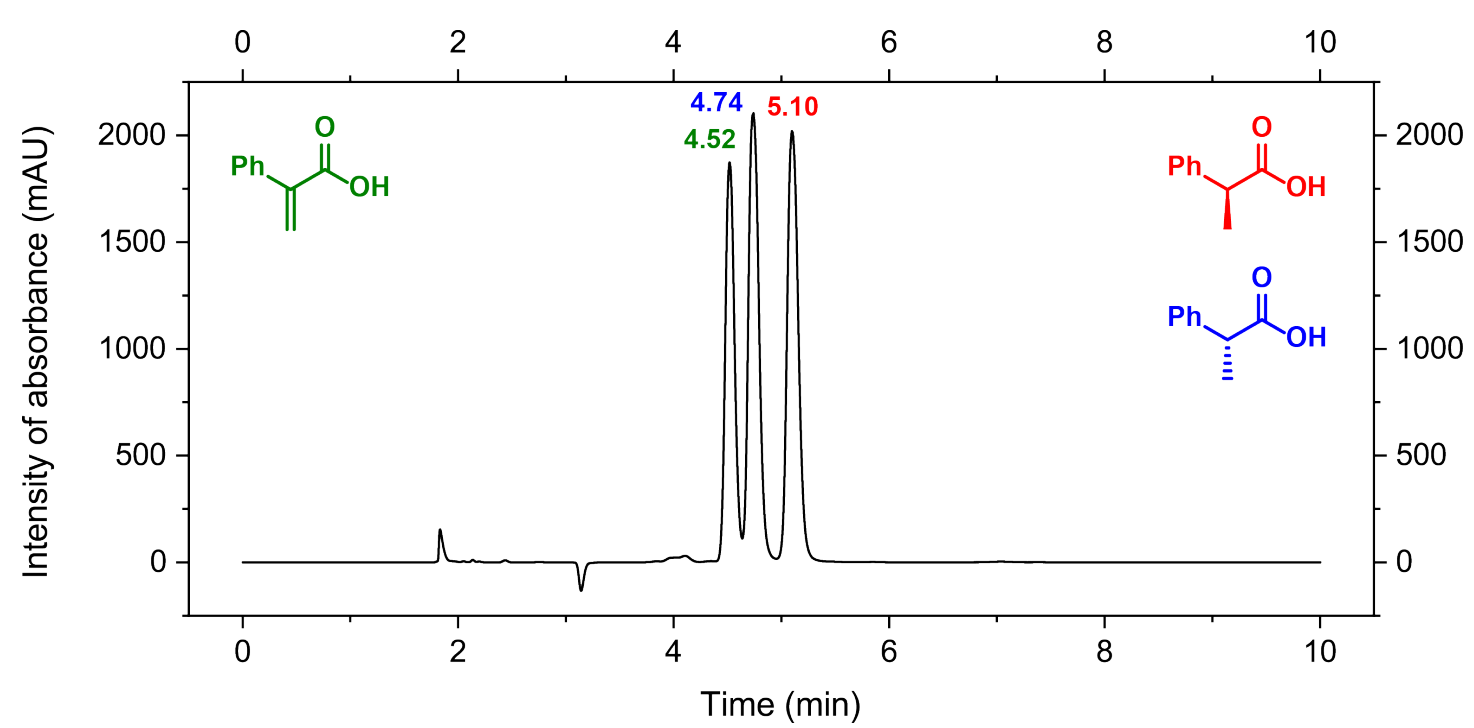

Figure S3.9: Chromatogram of the HPLC analysis of a mixture of the substrate 2-phenylacrylic acid and racemic 2phenylpropionic acid. 


\section{$25^{\circ} \mathrm{C}, 10$ bar}
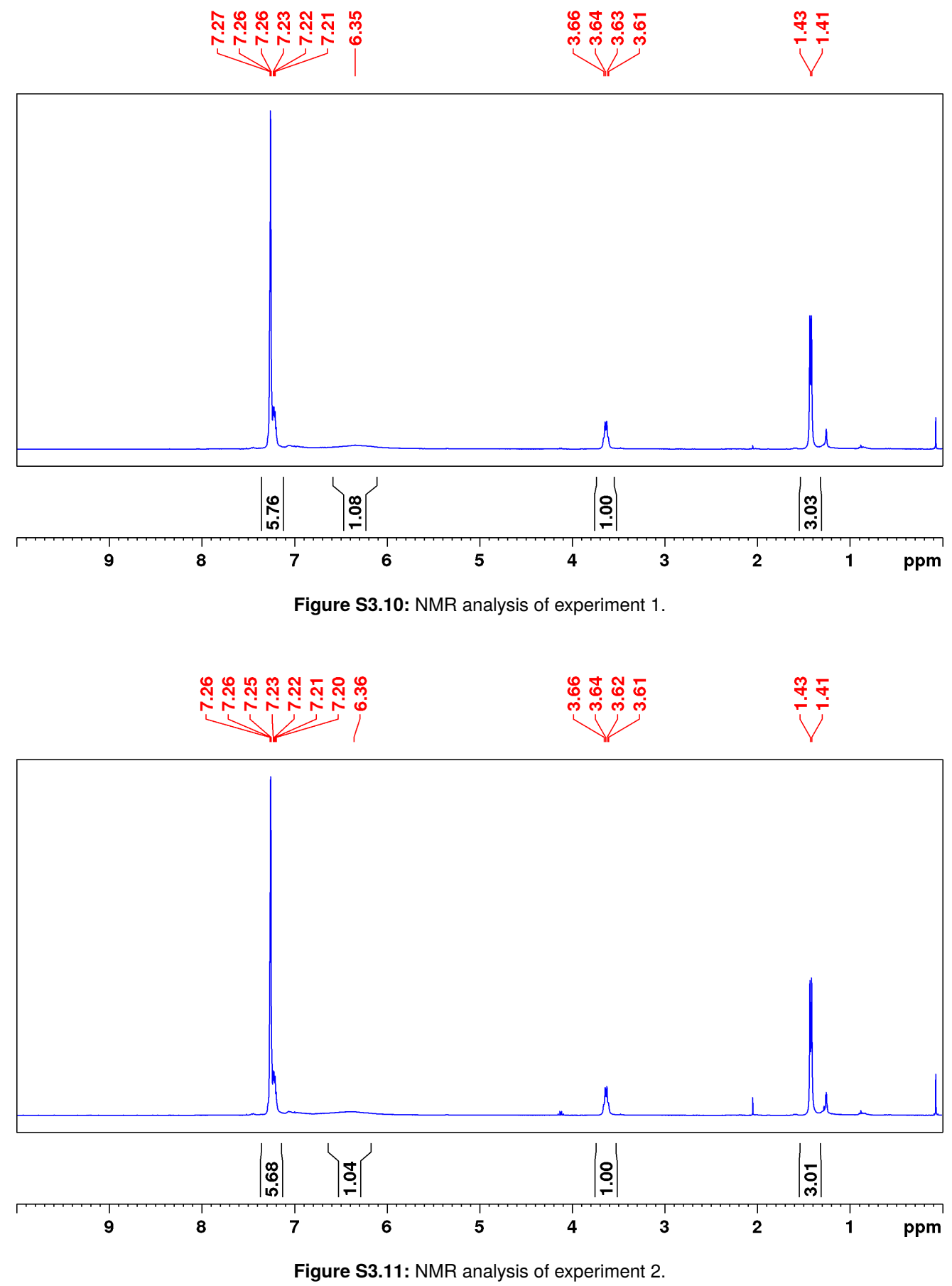


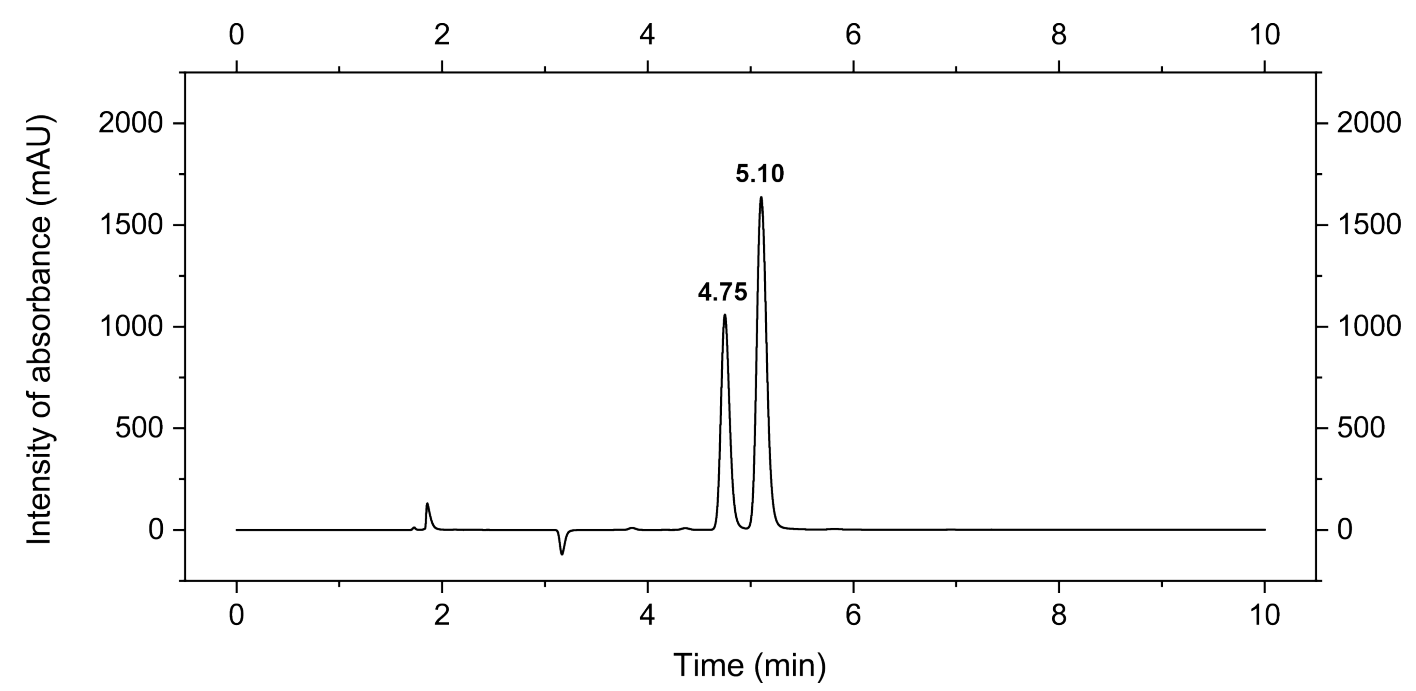

Figure S3.12: HPLC analysis of experiment 1.

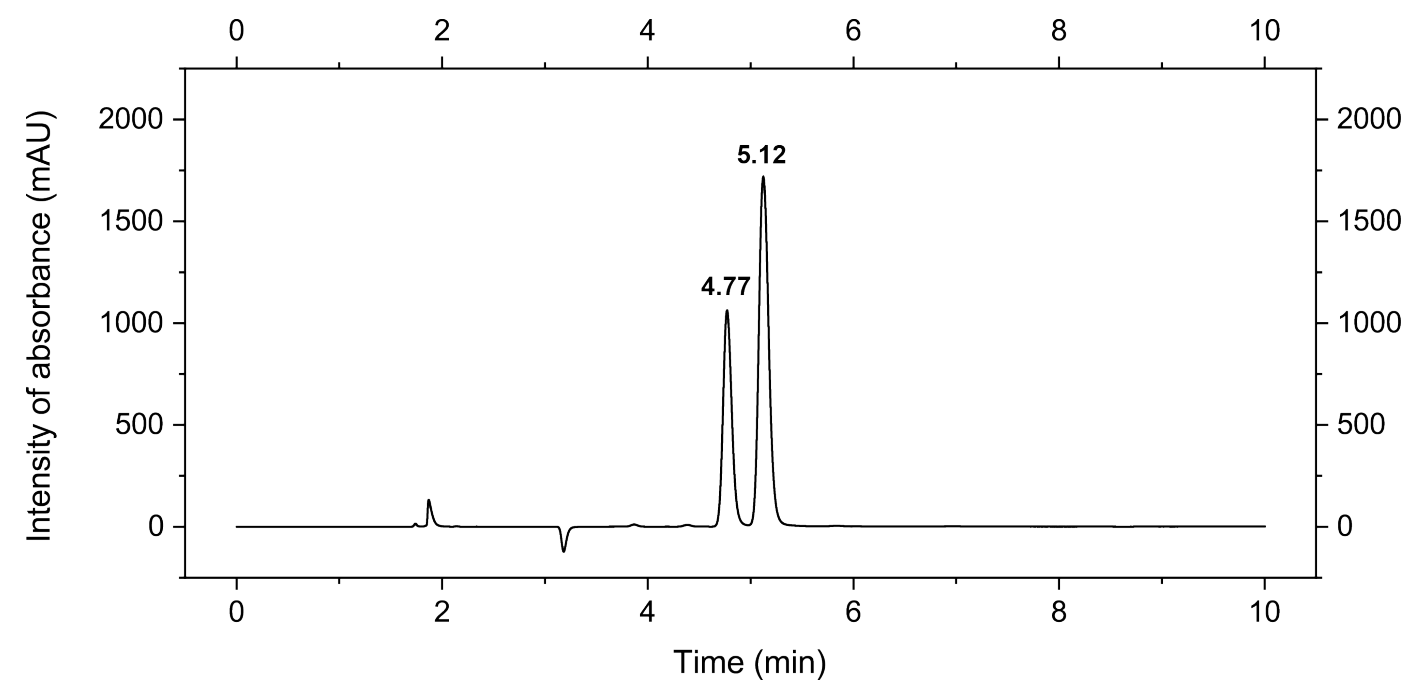

Figure S3.13: HPLC analysis of experiment 2.

Table S3.3: Results of the HPLC analyses.

\begin{tabular}{|c|c|c|c|c|c|c|c|}
\hline Exp. & En. & $t_{\text {ret }}(\min )$ & Height & Width & Area & Area\% & $e e$ \\
\hline \multirow[b]{2}{*}{1} & $R$ & 4.75 & 1061.2 & 0.0995 & 6332.3 & 36.4 & \multirow{2}{*}{$27 \% S$} \\
\hline & $S$ & 5.10 & 1640.1 & 0.1126 & 11081.5 & 63.6 & \\
\hline \multirow{3}{*}{2} & $R$ & 4.77 & 1065.5 & 0.0992 & 6342.1 & 35.2 & \multirow{2}{*}{$30 \% S$} \\
\hline & $S$ & 5.12 & 1723.4 & 0.1130 & 11687.9 & 64.8 & \\
\hline & & & & & \multicolumn{2}{|c|}{ Arithmethic mean } & $28 \% S$ \\
\hline
\end{tabular}




\section{$25^{\circ} \mathrm{C}, 20$ bar}
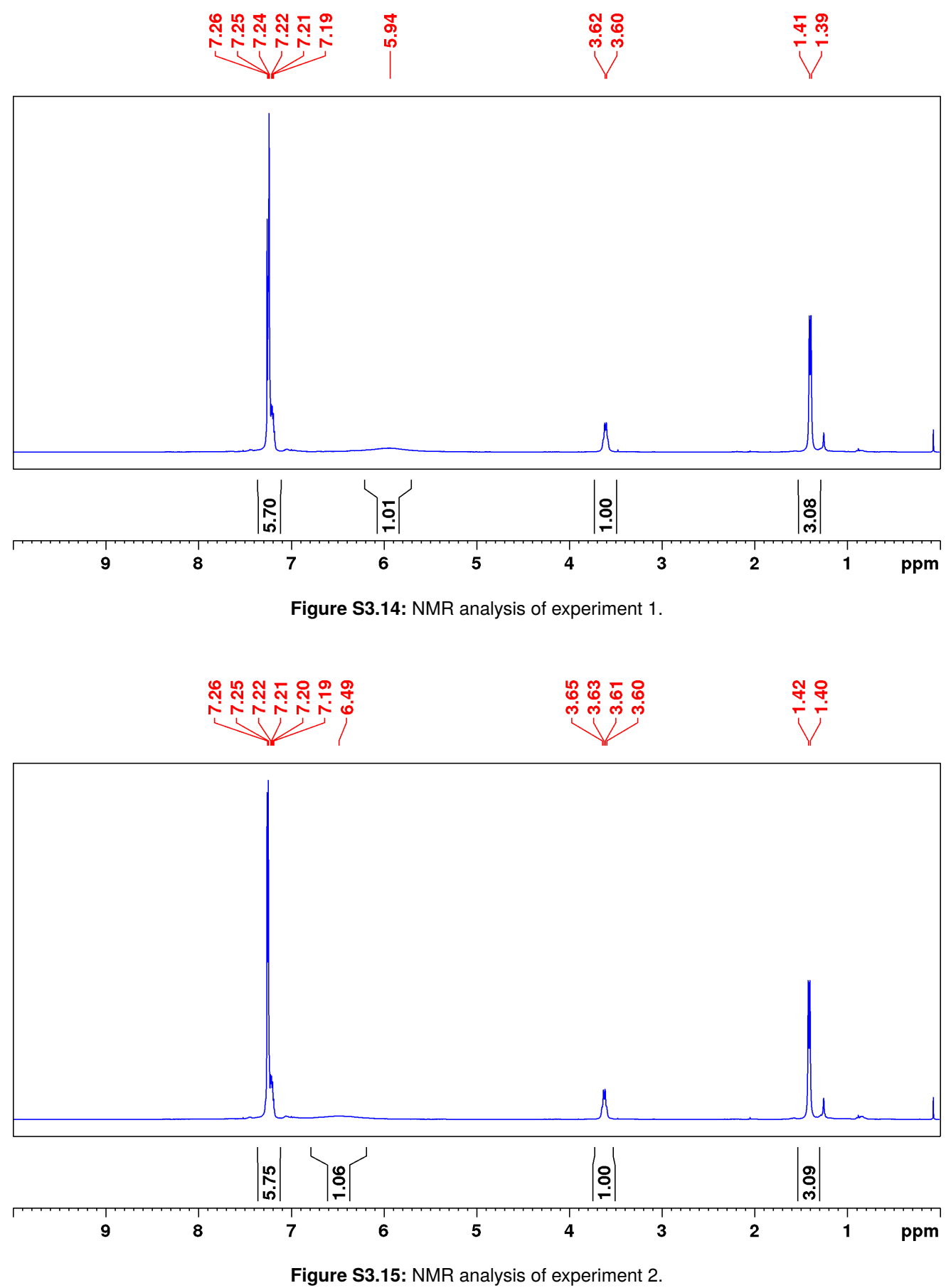


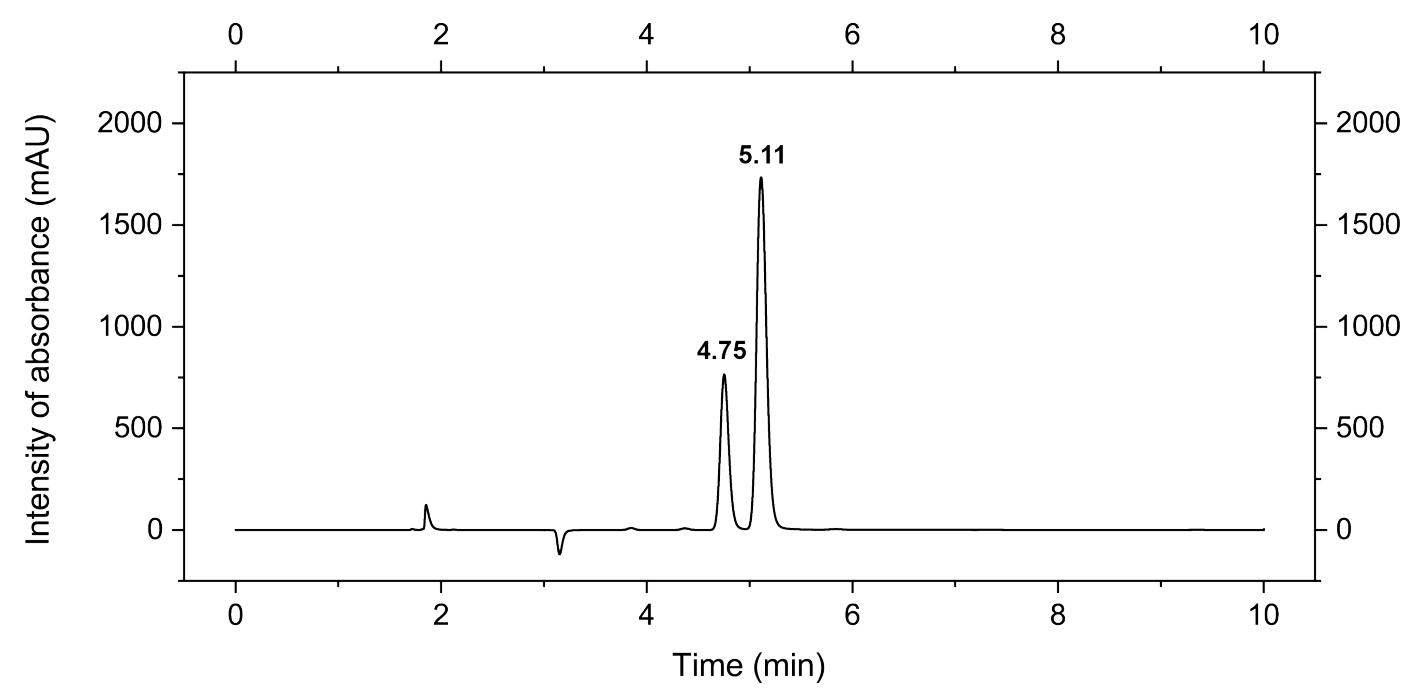

Figure S3.16: HPLC analysis of experiment 1.

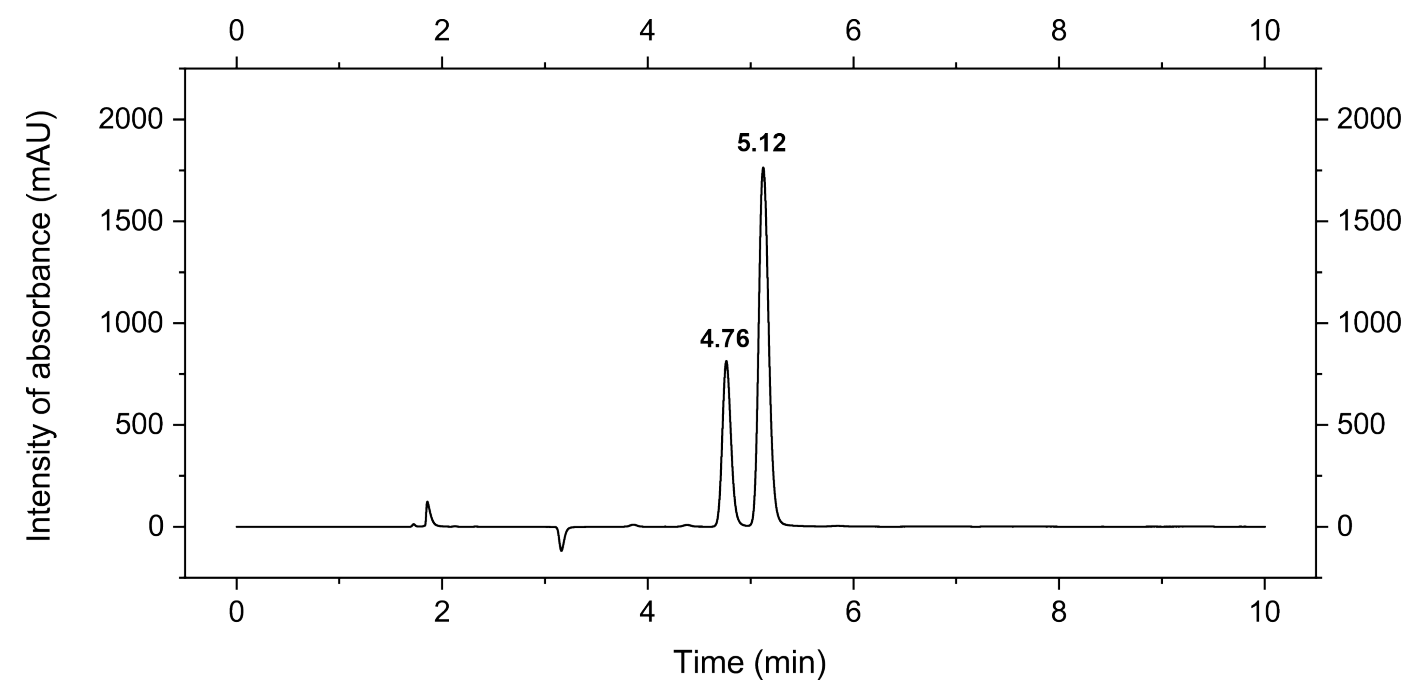

Figure S3.17: HPLC analysis of experiment 2.

Table S3.4: Results of the HPLC analyses.

\begin{tabular}{|c|c|c|c|c|c|c|c|}
\hline Exp. & En. & $t_{\text {ret }}(\min )$ & Height & Width & Area & Area \% & $e e$ \\
\hline \multirow{2}{*}{1} & $R$ & 4.75 & 768.3 & 0.0984 & 4534.3 & 27.7 & \multirow{2}{*}{$45 \% S$} \\
\hline & $S$ & 5.11 & 1737.8 & 0.1137 & 11855.8 & 72.3 & \\
\hline \multirow{2}{*}{2} & $R$ & 4.76 & 816.0 & 0.0987 & 4832.7 & 28.6 & \multirow{2}{*}{$43 \% S$} \\
\hline & $S$ & 5.12 & 1766.5 & 0.1138 & 12060.0 & 71.4 & \\
\hline & & & & & \multicolumn{2}{|c|}{ Arithmethic mean } & $44 \% S$ \\
\hline
\end{tabular}




\section{$25^{\circ} \mathrm{C}, 100$ bar}
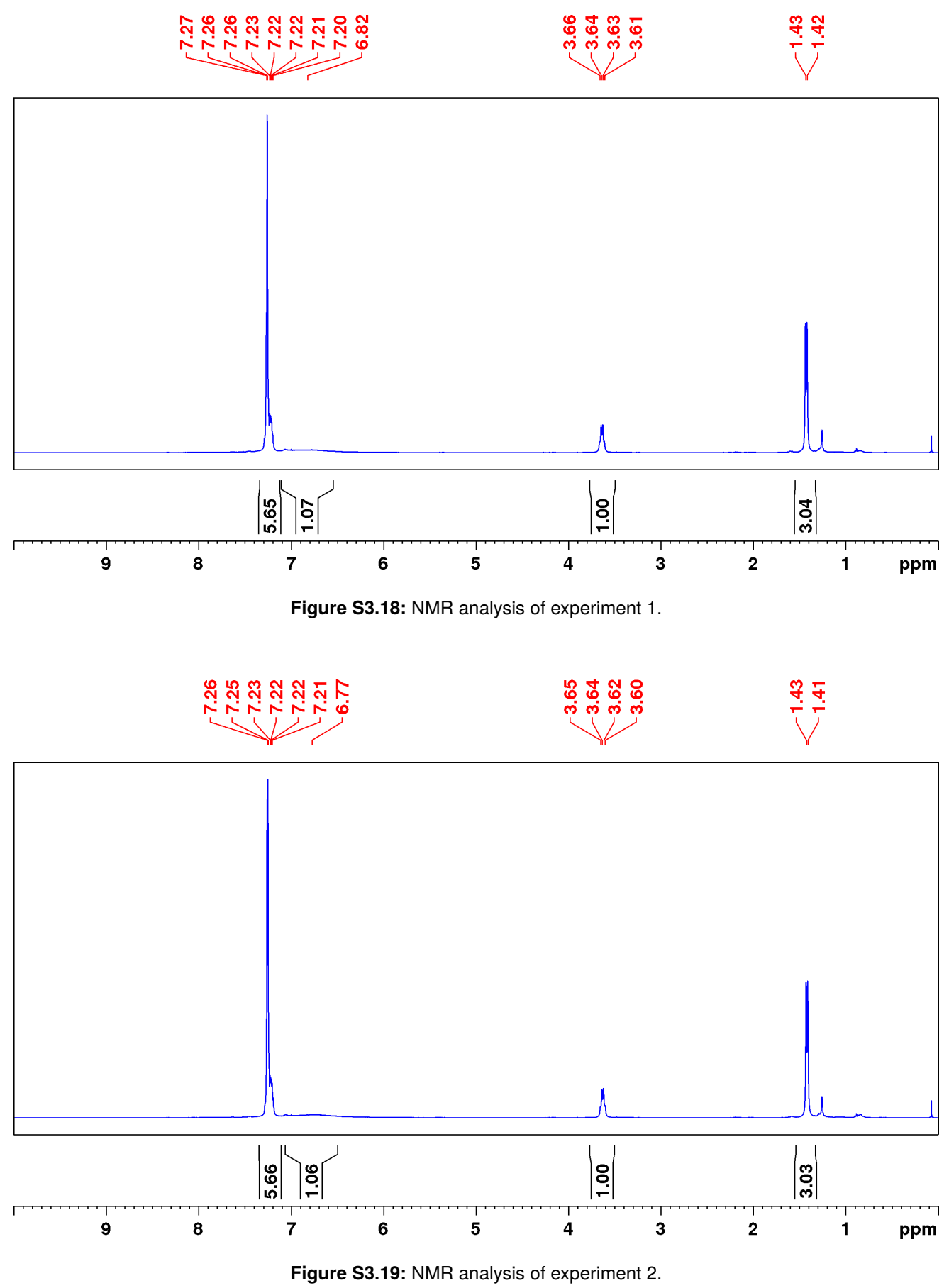


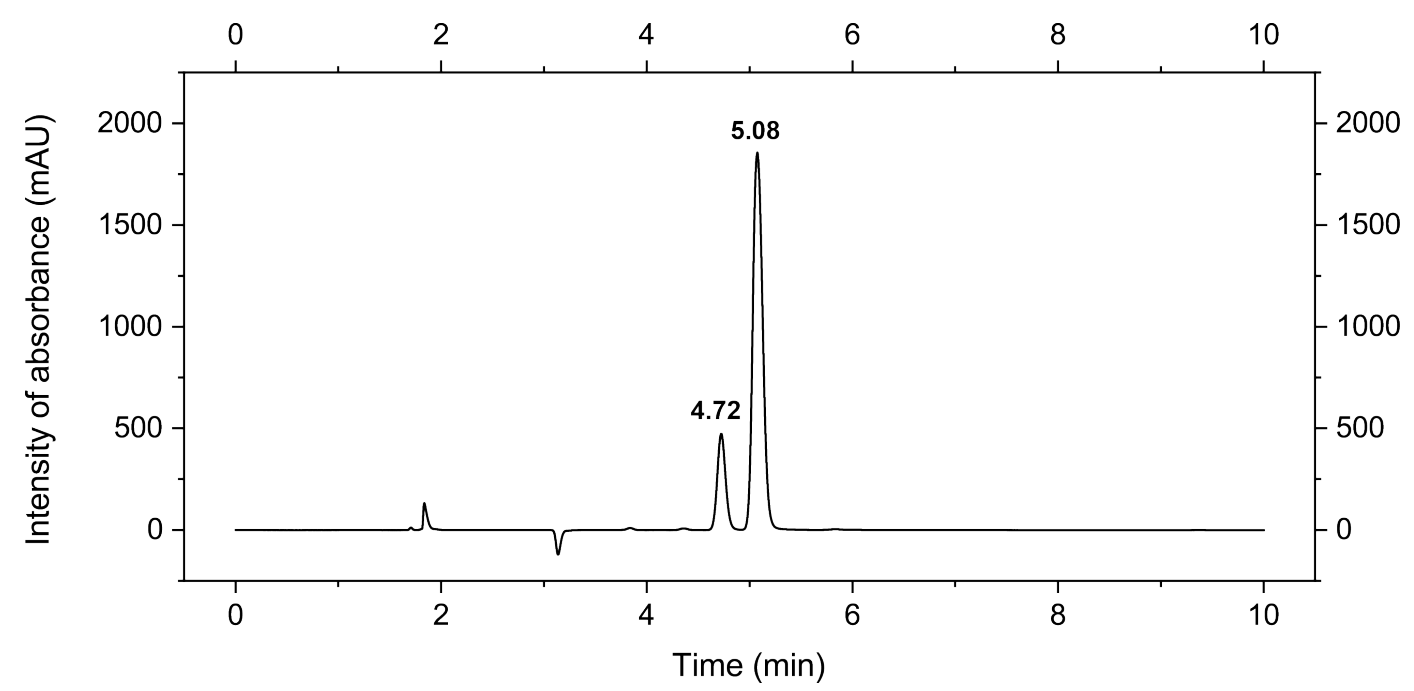

Figure S3.20: HPLC analysis of experiment 1.

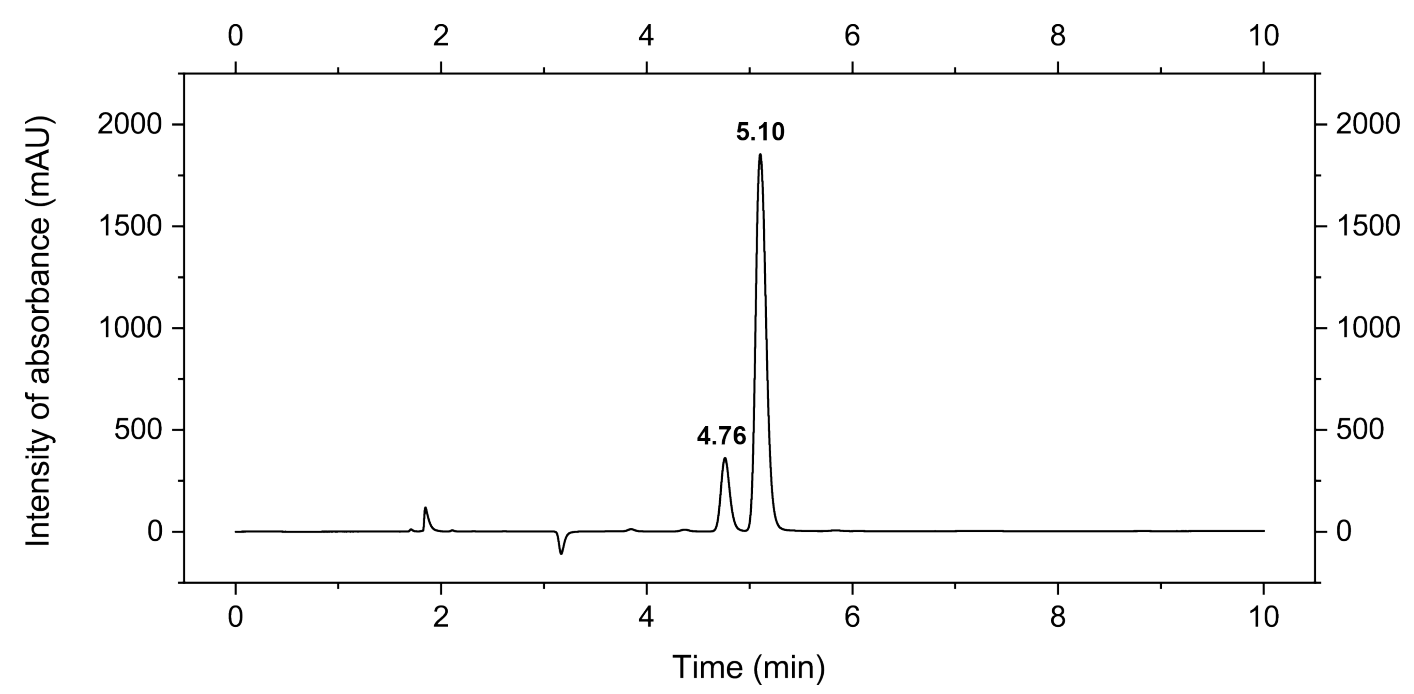

Figure S3.21: HPLC analysis of experiment 2.

Table S3.5: Results of the HPLC analyses.

\begin{tabular}{|c|c|c|c|c|c|c|c|}
\hline Exp. & En. & $t_{\text {ret }}(\min )$ & Height & Width & Area & Area $\%$ & $e e$ \\
\hline \multirow{2}{*}{1} & $R$ & 4.72 & 474.7 & 0.0945 & 2690.5 & 17.9 & \multirow{2}{*}{$64 \% S$} \\
\hline & $S$ & 5.08 & 1853.9 & 0.1112 & 12374 & 82.1 & \\
\hline \multirow{2}{*}{2} & $R$ & 4.76 & 362.3 & 0.1017 & 2211.6 & 14.4 & \multirow{2}{*}{$71 \% S$} \\
\hline & $S$ & 5.10 & 1851.0 & 0.1188 & 13193.5 & 85.6 & \\
\hline & & & & & \multicolumn{2}{|c|}{ Arithmethic mean } & $68 \% S$ \\
\hline
\end{tabular}




\section{$0^{\circ} \mathrm{C}, 100 \mathrm{bar}$}
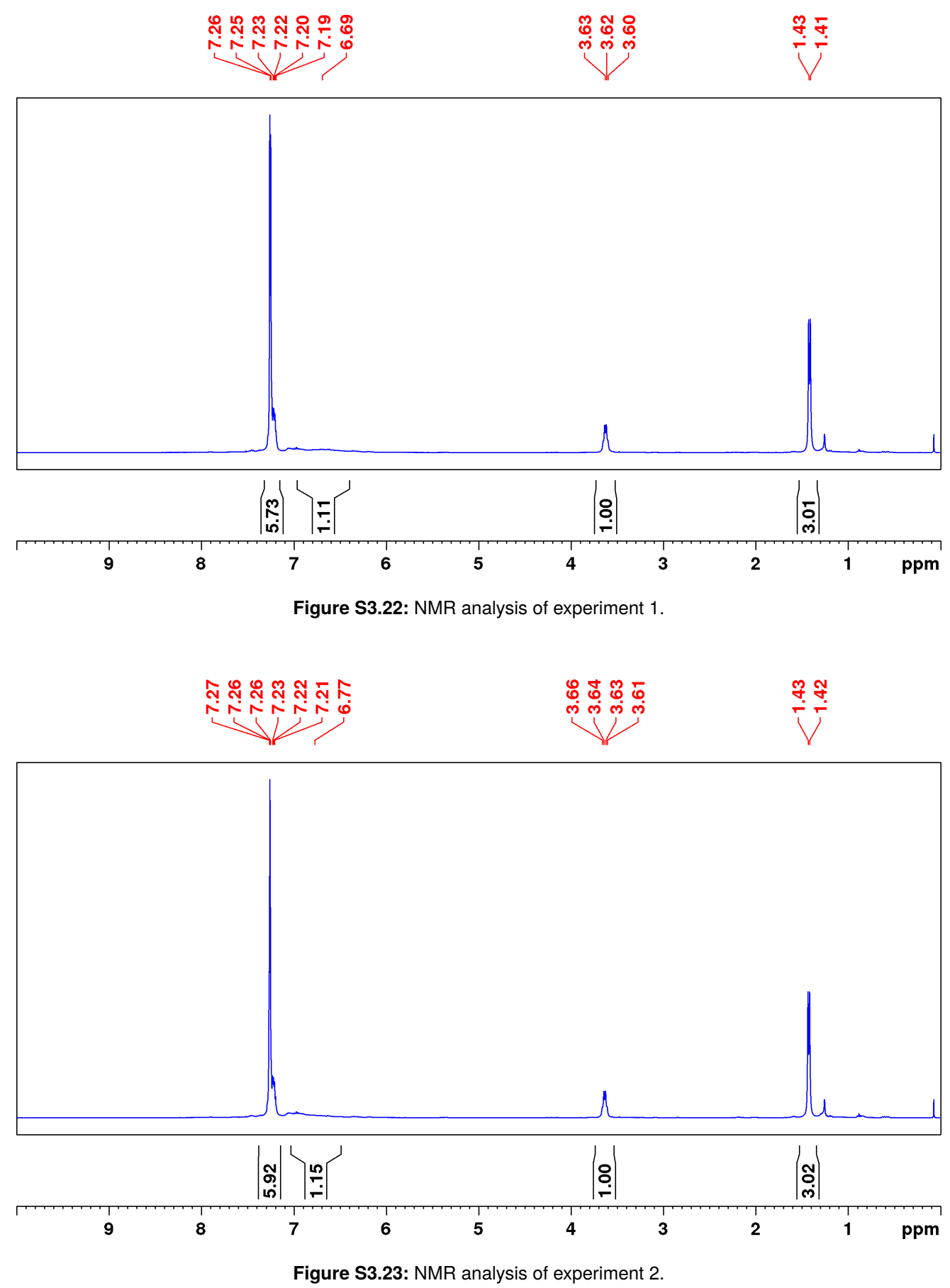


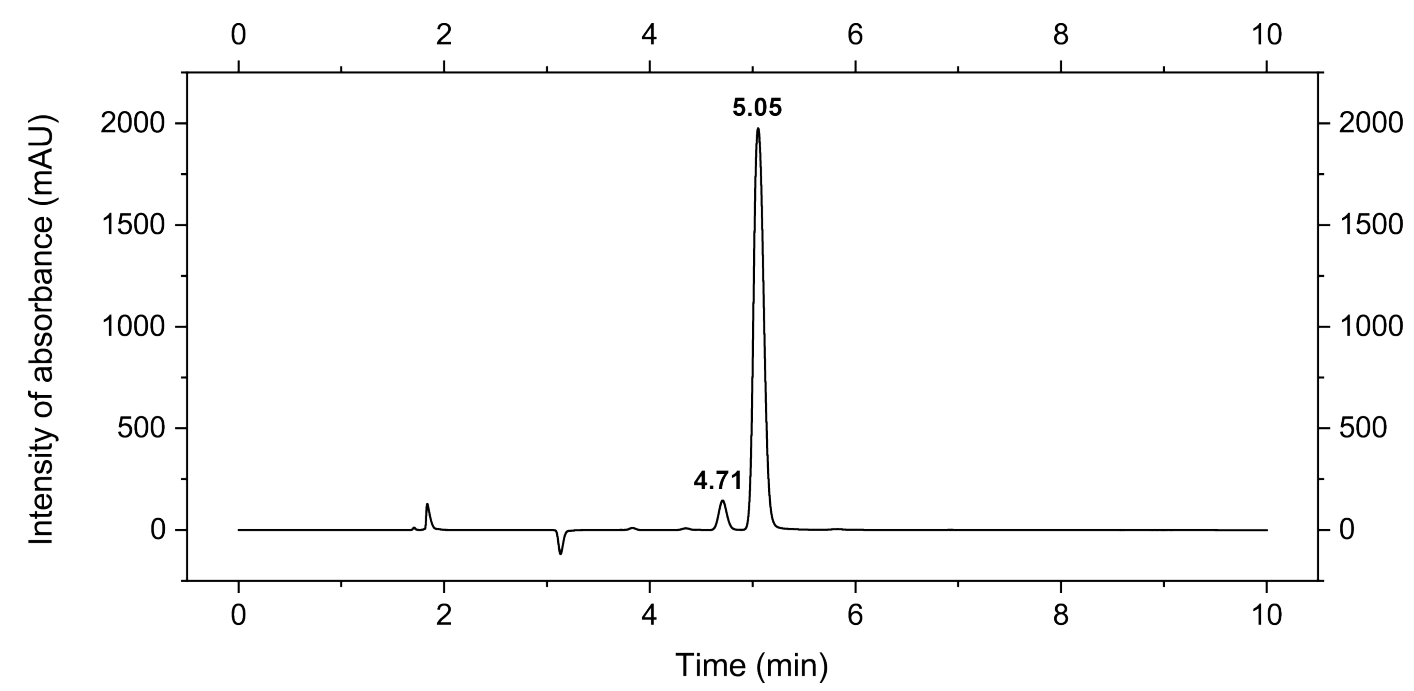

Figure S3.24: HPLC analysis of experiment 1.

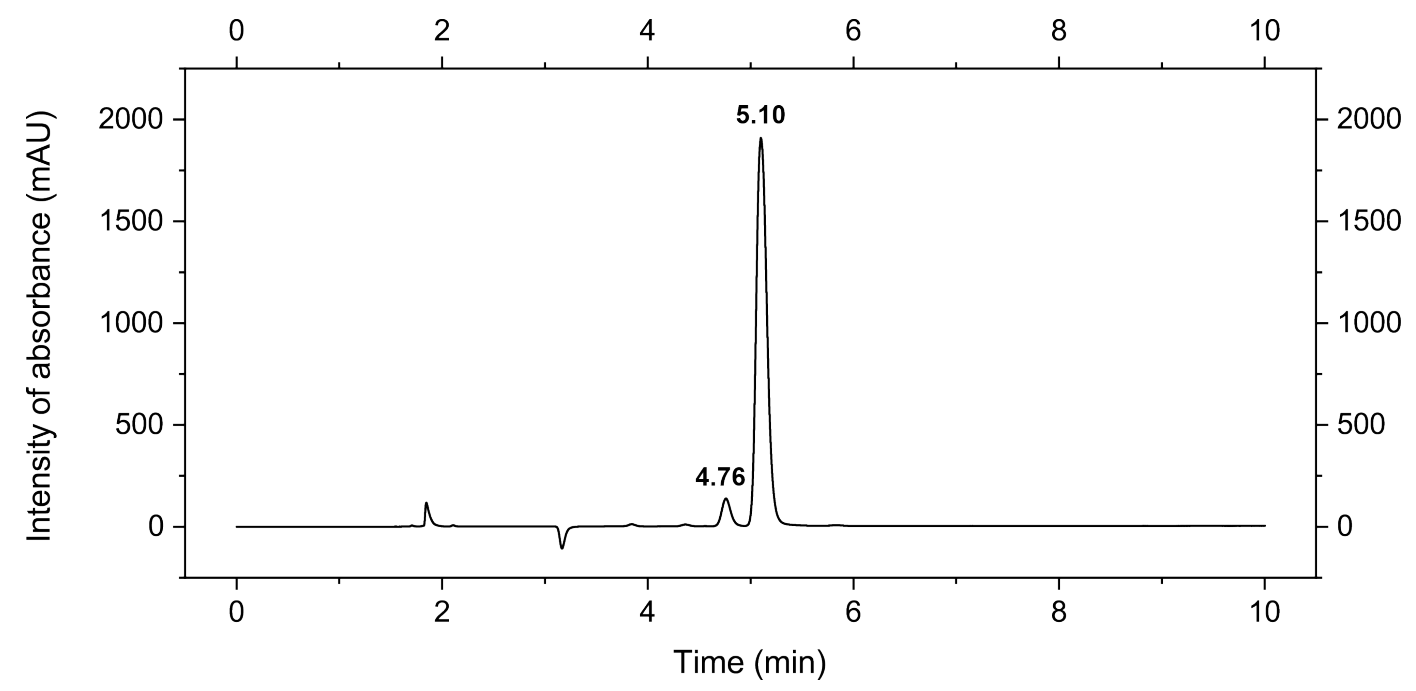

Figure S3.25: HPLC analysis of experiment 2.

Table S3.6: Results of the HPLC analyses.

\begin{tabular}{|c|c|c|c|c|c|c|c|}
\hline Exp. & En. & $t_{\text {ret }}(\min )$ & Height & Width & Area & Area $\%$ & $e e$ \\
\hline \multirow[b]{2}{*}{1} & $R$ & 4.71 & 146.1 & 0.0927 & 812.5 & 5.6 & \multirow{2}{*}{$89 \% S$} \\
\hline & $S$ & 5.05 & 1979.0 & 0.1153 & 13685.3 & 94.4 & \\
\hline \multirow{3}{*}{2} & $R$ & 4.76 & 135.4 & 0.1001 & 813.0 & 5.5 & \multirow{2}{*}{$89 \% S$} \\
\hline & $S$ & 5.10 & 1906.0 & 0.1211 & 13843.2 & 94.5 & \\
\hline & & & & & \multicolumn{2}{|c|}{ Arithmethic mean } & $89 \% S$ \\
\hline
\end{tabular}


$100^{\circ} \mathrm{C}, 100 \mathrm{bar}$
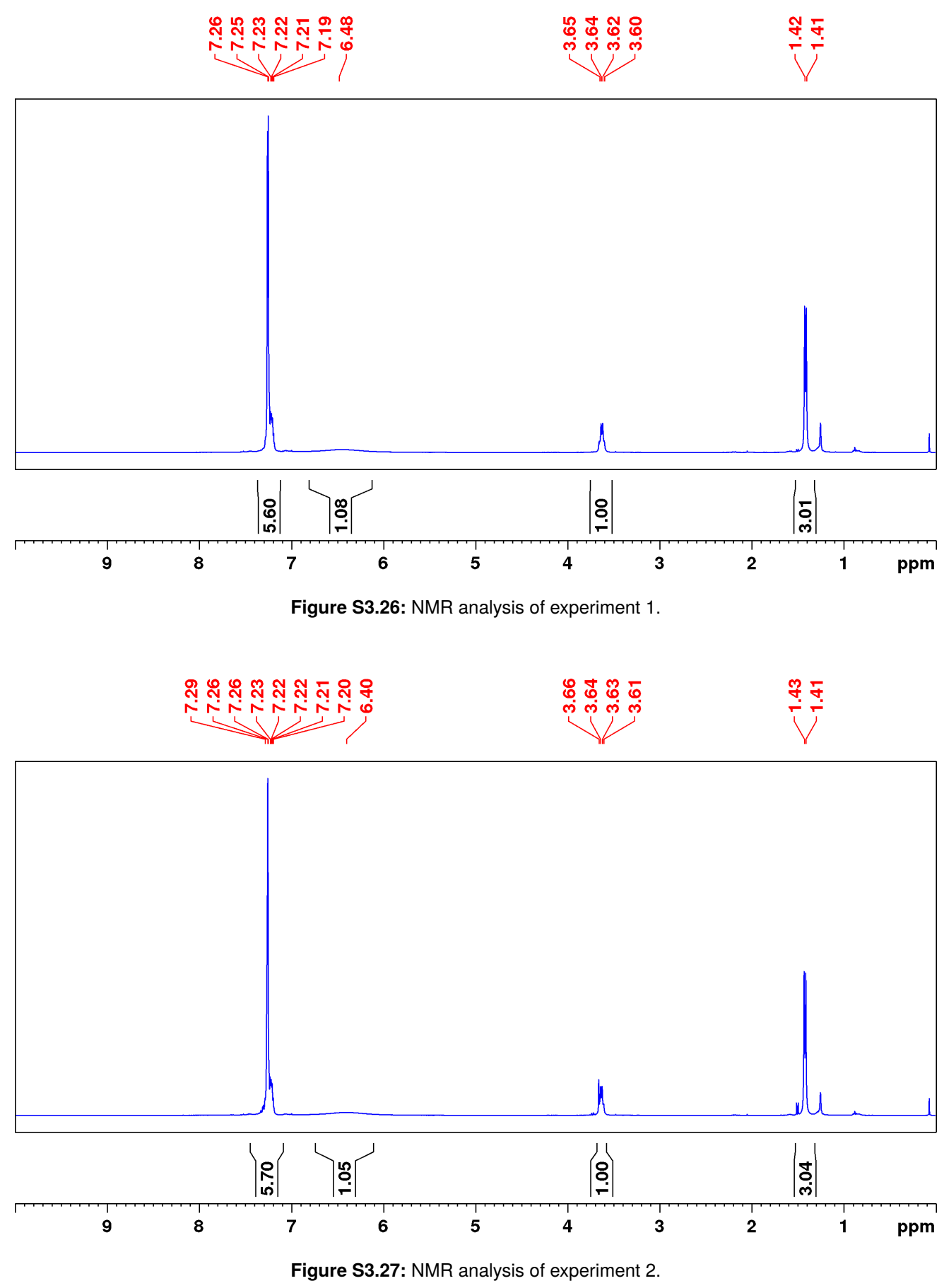


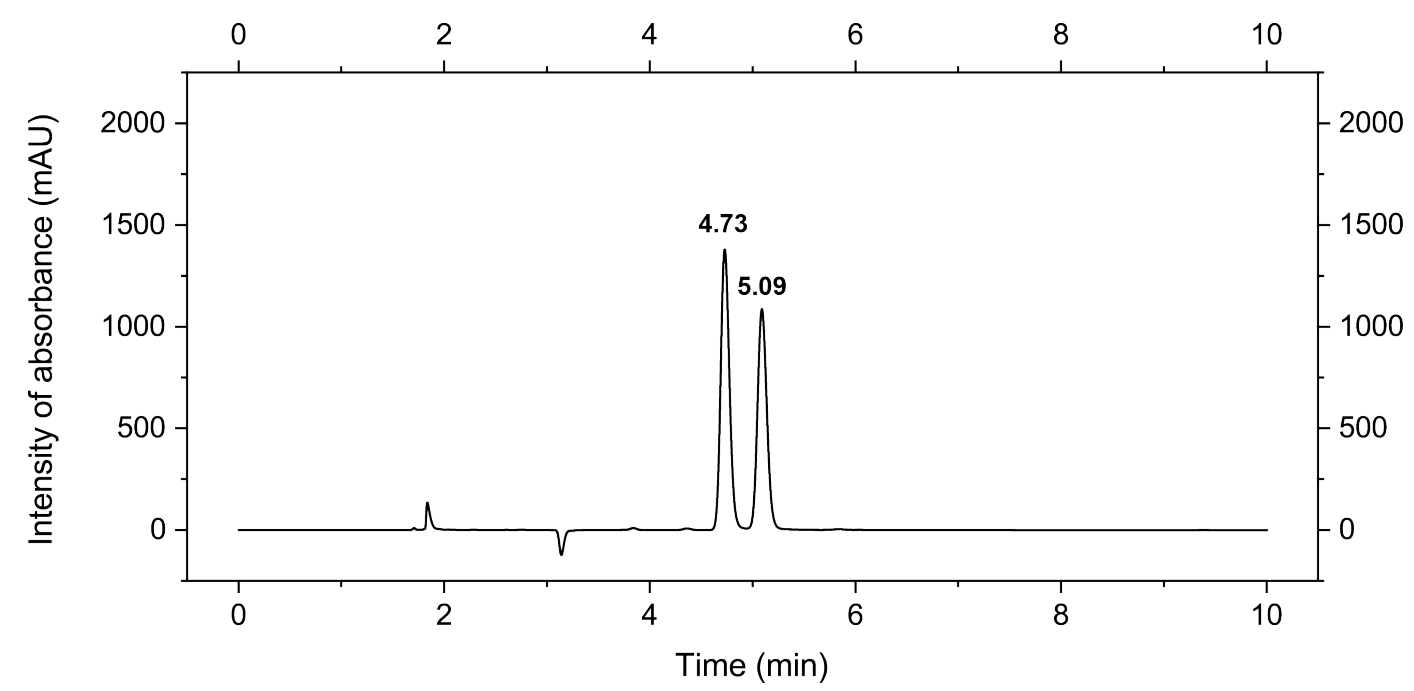

Figure S3.28: HPLC analysis of experiment 1.

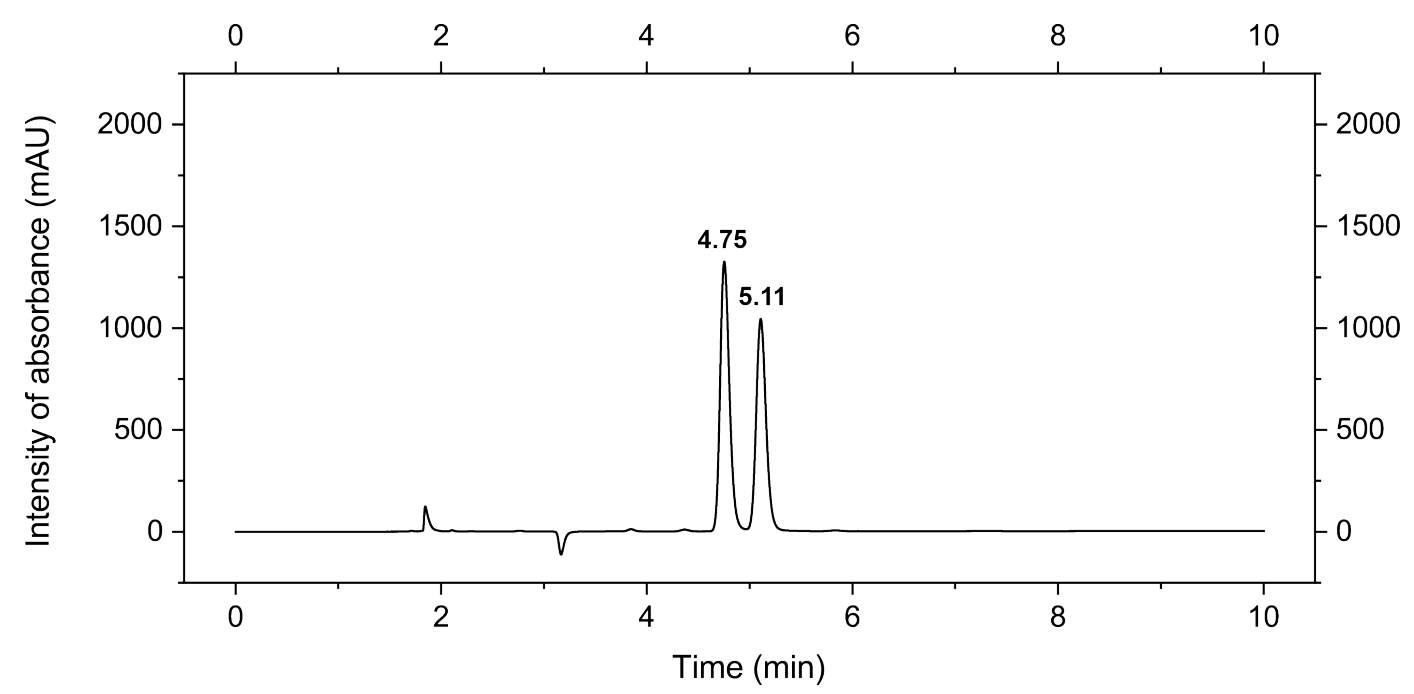

Figure S3.29: HPLC analysis of experiment 2.

Table S3.7: Results of the HPLC analyses.

\begin{tabular}{|c|c|c|c|c|c|c|c|}
\hline Exp. & En. & $t_{\text {ret }}(\min )$ & Height & Width & Area & Area \% & $e e$ \\
\hline \multirow{2}{*}{1} & $R$ & 4.73 & 1381.1 & 0.0992 & 8218.2 & 54.2 & \multirow{2}{*}{$8 \% R$} \\
\hline & $S$ & 5.09 & 1087.8 & 0.1062 & 6931.7 & 45.8 & \\
\hline \multirow{2}{*}{2} & $R$ & 4.75 & 1326.7 & 0.1054 & 8391.7 & 54.4 & \multirow{2}{*}{$9 \% R$} \\
\hline & $S$ & 5.11 & 1045.0 & 0.1123 & 7041.1 & 45.6 & \\
\hline & & & & & \multicolumn{2}{|c|}{ Arithmethic mean } & $9 \% R$ \\
\hline
\end{tabular}




\subsubsection{Hydrogenation of Dehydronaproxen}

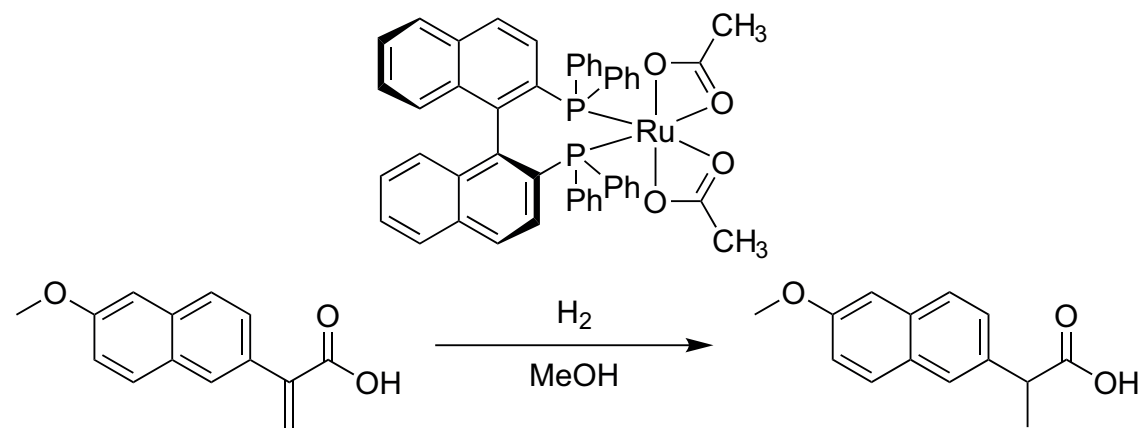

The catalyses were performed according to the procedure elucidated in section 2.1. All catalysis settings were performed twice and the mean value was taken for discussion.

A solution of dehydronaproxen (5.71 mg, $25.0 \mu \mathrm{mol}, 1.00$ eq.) and diacetato[(S)-(-)-2,2'bis(diphenylphosphino)-1,1'-binaphthyl]ruthenium(II) (526 $\mathrm{\mu g}, 625 \mathrm{nmol}, 2.5 \mathrm{~mol} \%$ ) in anhydrous degassed $\mathrm{MeOH}(0.5 \mathrm{~mL})$ was prepared using stock solutions of the substrate and the catalyst.

The catalyses were performed in stainless steel high-pressure autoclaves ( $10 \mathrm{~mL}$ total volume) using an NMR tube as inset and a small stirring bar for mixing. The autoclave was evacuated and flushed with nitrogen three times before the catalysis solution was transferred into the NMR tube inset. The hydrogen gas line was purged with $\mathrm{H}_{2}$ at least seven times. In case of reactions at 25 and $100^{\circ} \mathrm{C}$, the autoclave was directly pressurized with $\mathrm{H}_{2}$. In case of reactions at $0{ }^{\circ} \mathrm{C}$, the autoclave was cooled to $0^{\circ} \mathrm{C}$ using a cold bath for $5 \mathrm{~min}$ before it was pressurized with $\mathrm{H}_{2}$. The reaction mixture was stirred at the respective temperature for $18 \mathrm{~h}$. In case of reactions at 0 and $25^{\circ} \mathrm{C}$, the reaction was terminated by carefully venting the autoclave. In case of reactions at $100^{\circ} \mathrm{C}$, the autoclave was cooled to $0^{\circ} \mathrm{C}$ using a cold bath for $10 \mathrm{~min}$ before it was carefully vented at $25^{\circ} \mathrm{C}$.

The reaction solution was eluted with EtOAc $(15 \mathrm{~mL})$ through a short pad of silica $(\mathrm{ca} .2 \mathrm{~cm})$ to remove metal residues. The volatile compounds were removed in vacuo. The conversion of the reaction was determined by NMR and the enantiomeric excess of the product by enantioselective HPLC analysis. 
The enantioselective HPLC analyses were carried out using:

Chiralpak IC (4.6 mm x $250 \mathrm{~mm}, 5 \mu \mathrm{m}), n$-hexane:IPA:AcOH 95:5:0.1, $1 \mathrm{~mL} \mathrm{~min}^{-1}, 20^{\circ} \mathrm{C}$, $\lambda=230 \mathrm{~nm}$.

Table S3.8: Retention times for the substrate and the hydrogenation products of dehydronaproxen.

\begin{aligned} & \hline Compound Retention Time \\ & \hline substrate 12.64 to $12.65 \mathrm{~min} \\ &(R)$-enantiomer 10.03 to $10.09 \mathrm{~min} \\ &$ (S)-enantiomer 11.56 to $11.62 \mathrm{~min} \\ &$\hline\end{aligned}

In order to assign the configuration of the enantiomers, commercially purchased (S)naproxen and racemized naproxen were analyzed by enantioselective HPLC. In order to ensure separation of the substrate and the resulting enantiomers, the substrate 2-(6methoxynaphthalen-2-yl)acrylic acid was analyzed under the same conditions. 


\section{HPLC Analysis of Reference Compounds}

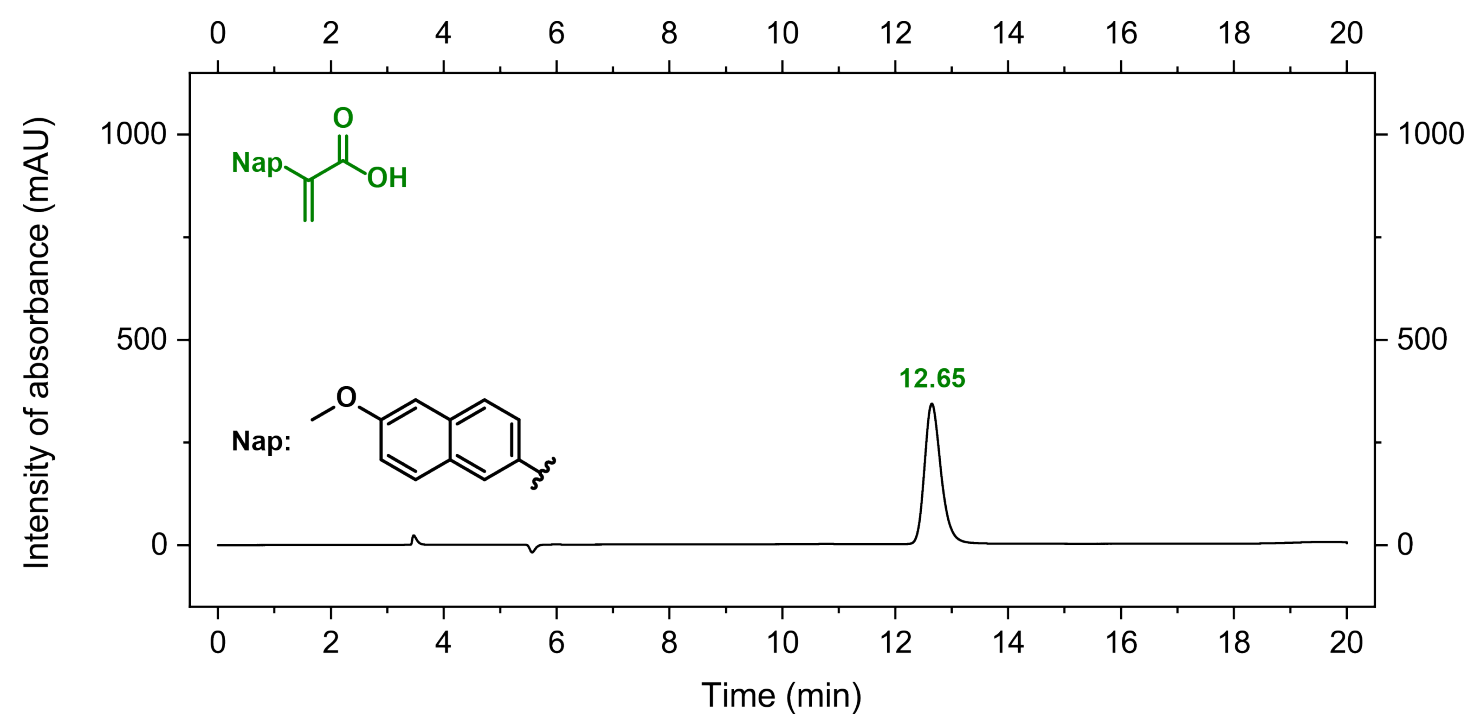

Figure S3.30: Chromatogram of the HPLC analysis of the substrate dehydronaproxen.

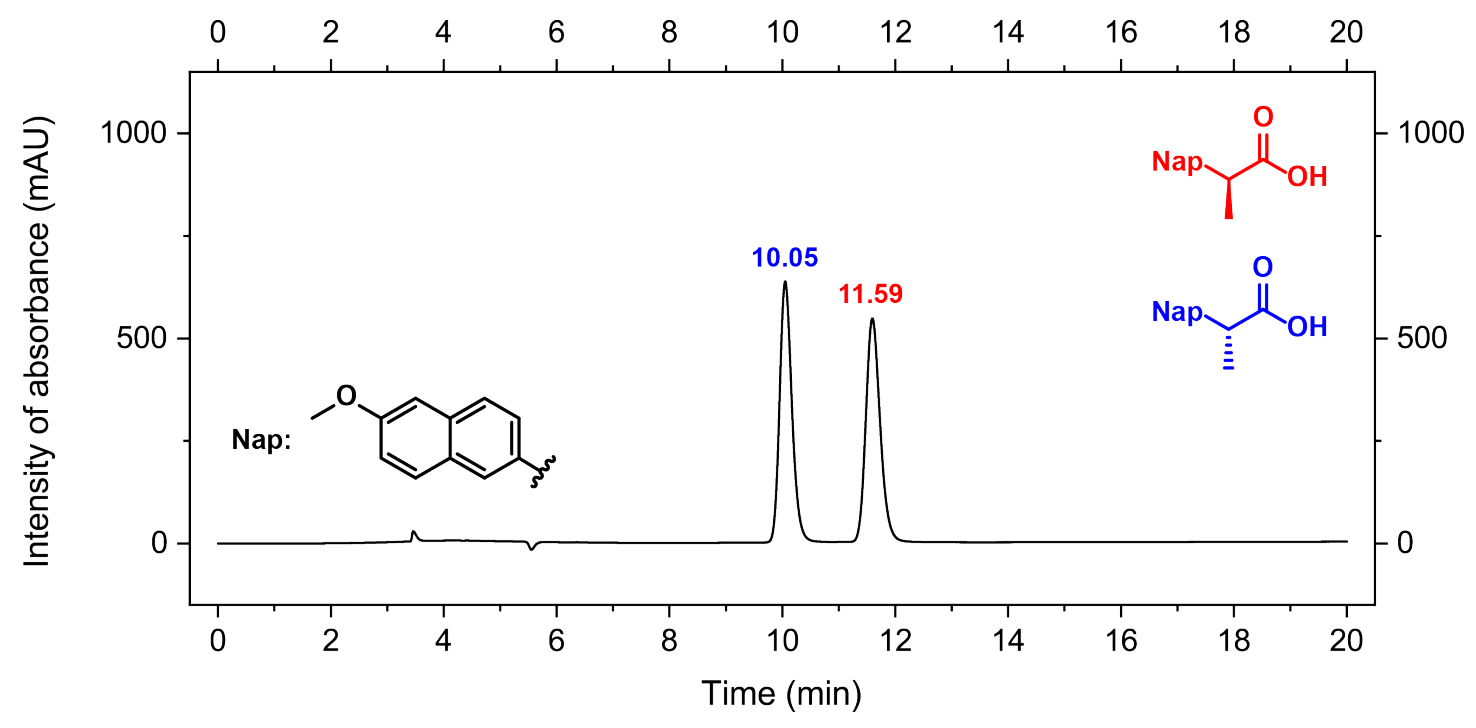

Figure S3.31: Chromatogram of the HPLC analysis of racemic naproxen. 


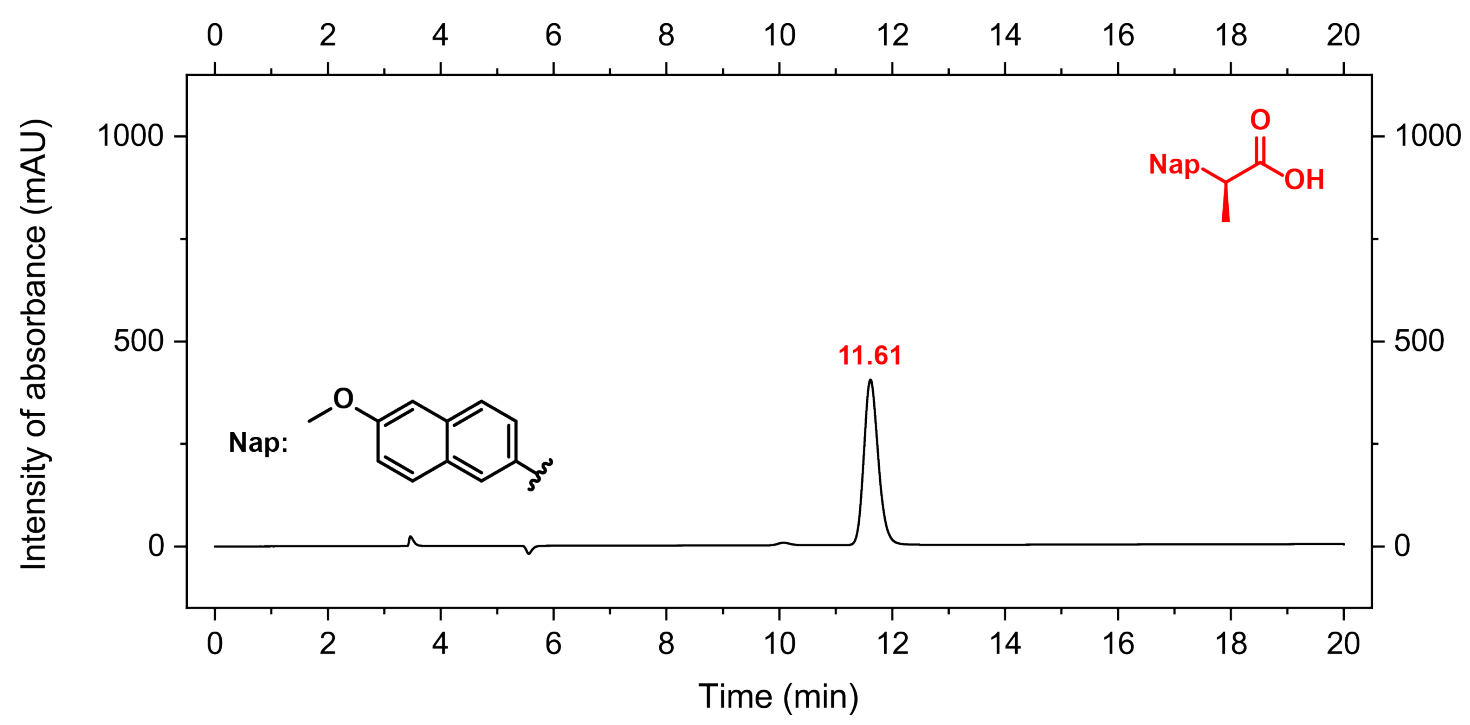

Figure S3.32: Chromatogram of the HPLC analysis of $(S)$-naproxen.

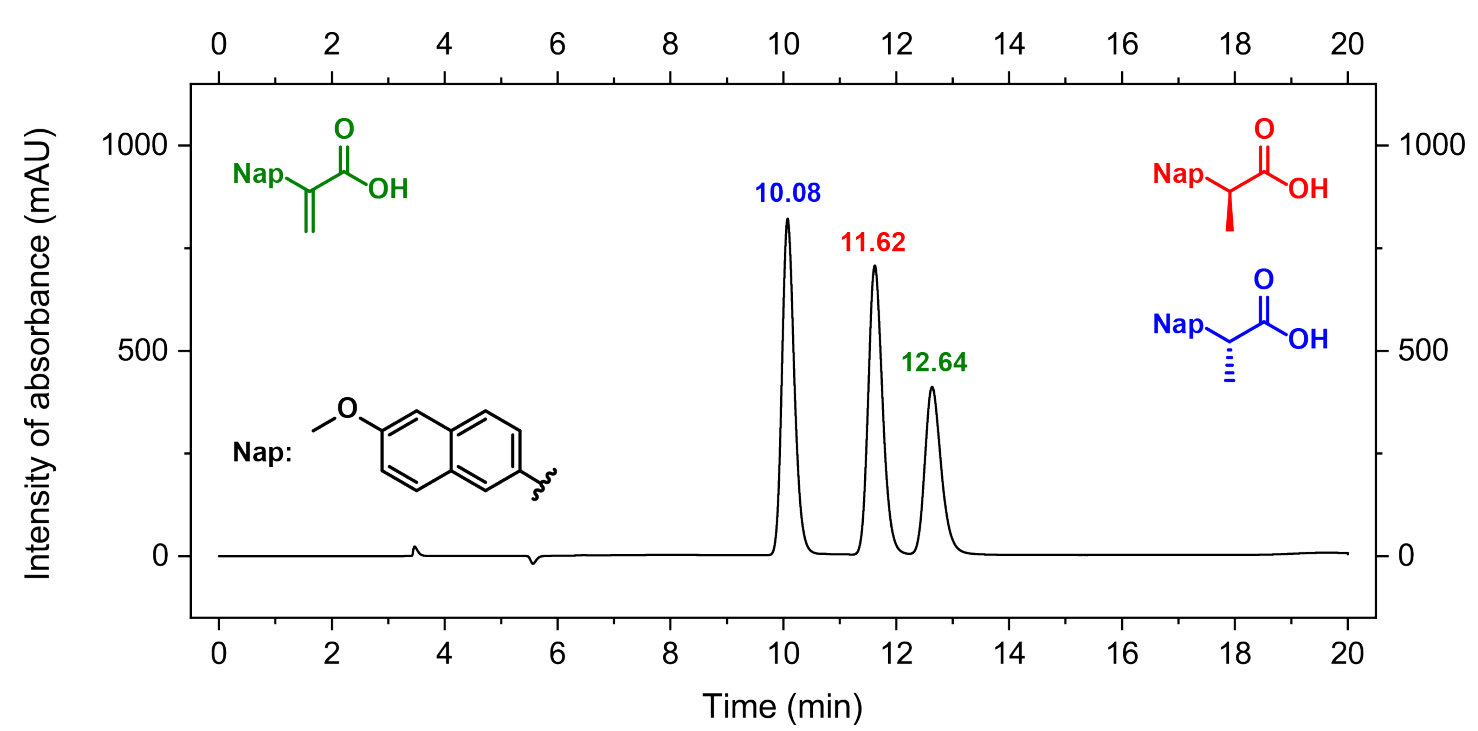

Figure S3.33: Chromatogram of the HPLC analysis of a mixture of the substrate dehydronaproxen and racemic naproxen. 


\section{$25^{\circ} \mathrm{C}, 10$ bar}
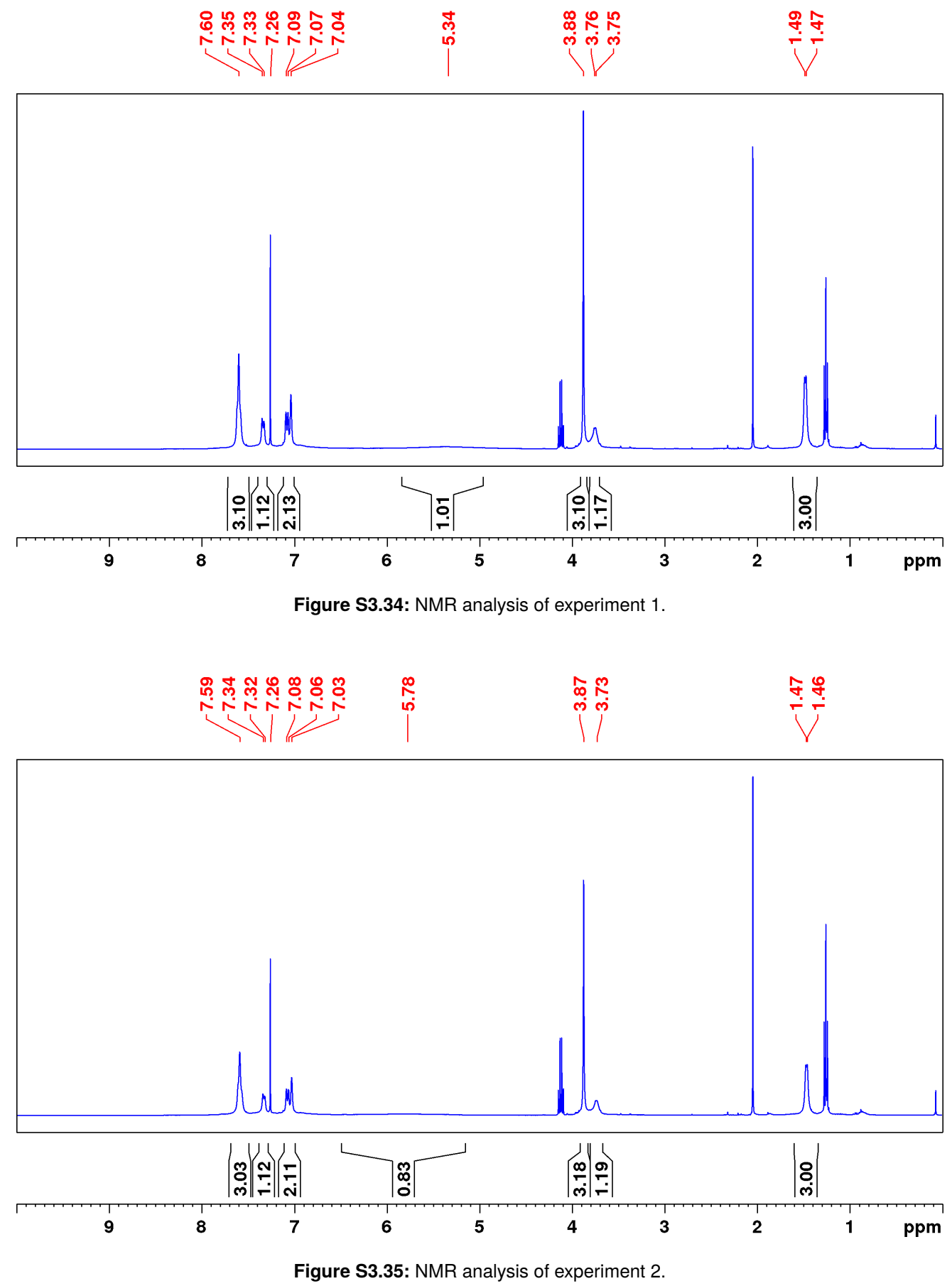


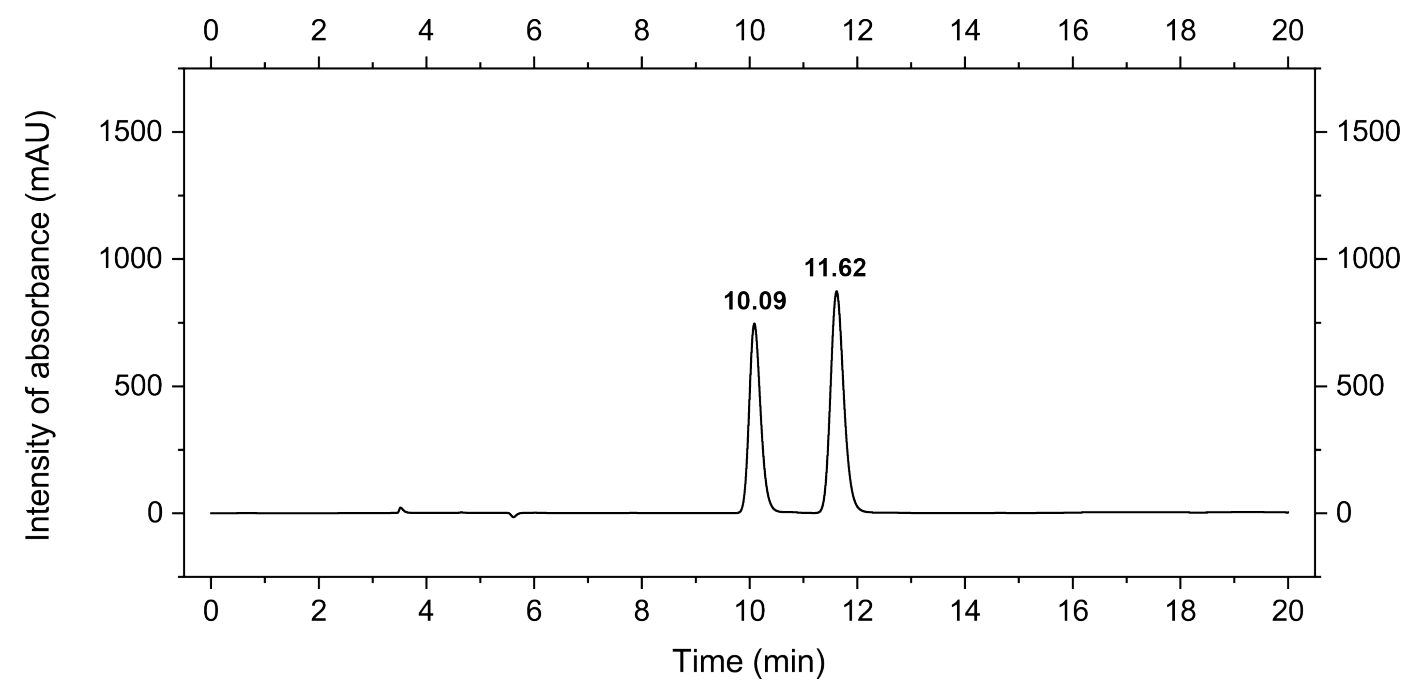

Figure S3.36: HPLC analysis of experiment 1.

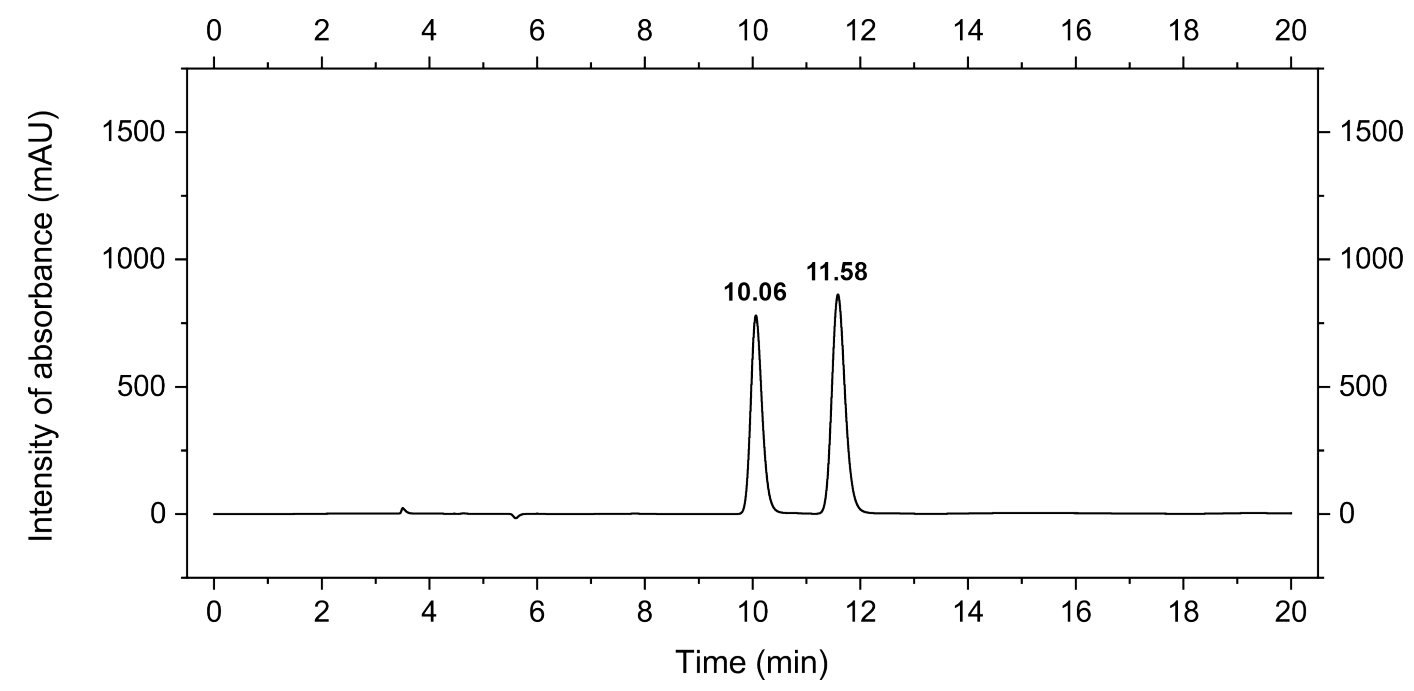

Figure S3.37: HPLC analysis of experiment 2.

Table S3.9: Results of the HPLC analyses.

\begin{tabular}{|c|c|c|c|c|c|c|c|}
\hline Exp. & En. & $t_{\text {ret }}(\min )$ & Height & Width & Area & Area \% & $e e$ \\
\hline \multirow{2}{*}{1} & $R$ & 10.09 & 747.3 & 0.2502 & 11220.2 & 42.5 & \multirow{2}{*}{$15 \% S$} \\
\hline & $S$ & 11.62 & 873.5 & 0.2892 & 15159.0 & 57.5 & \\
\hline \multirow{2}{*}{2} & $R$ & 10.06 & 781.8 & 0.2488 & 11669.2 & 43.7 & \multirow{2}{*}{$13 \% S$} \\
\hline & $S$ & 11.58 & 863.2 & 0.2897 & 15005.4 & 56.3 & \\
\hline & & & & & \multicolumn{2}{|c|}{ Arithmethic mean } & $14 \% S$ \\
\hline
\end{tabular}




\section{$25^{\circ} \mathrm{C}, 20$ bar}
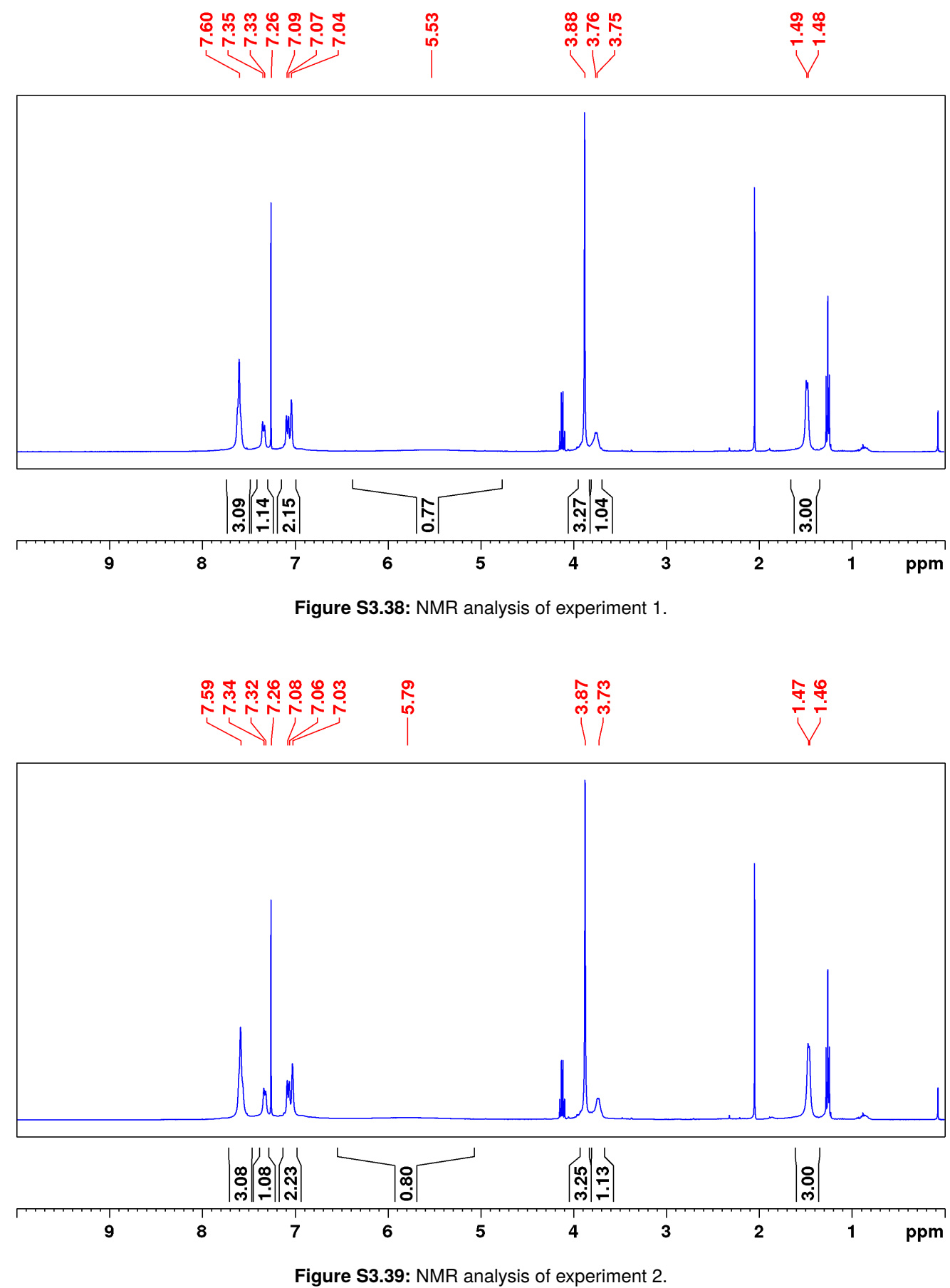


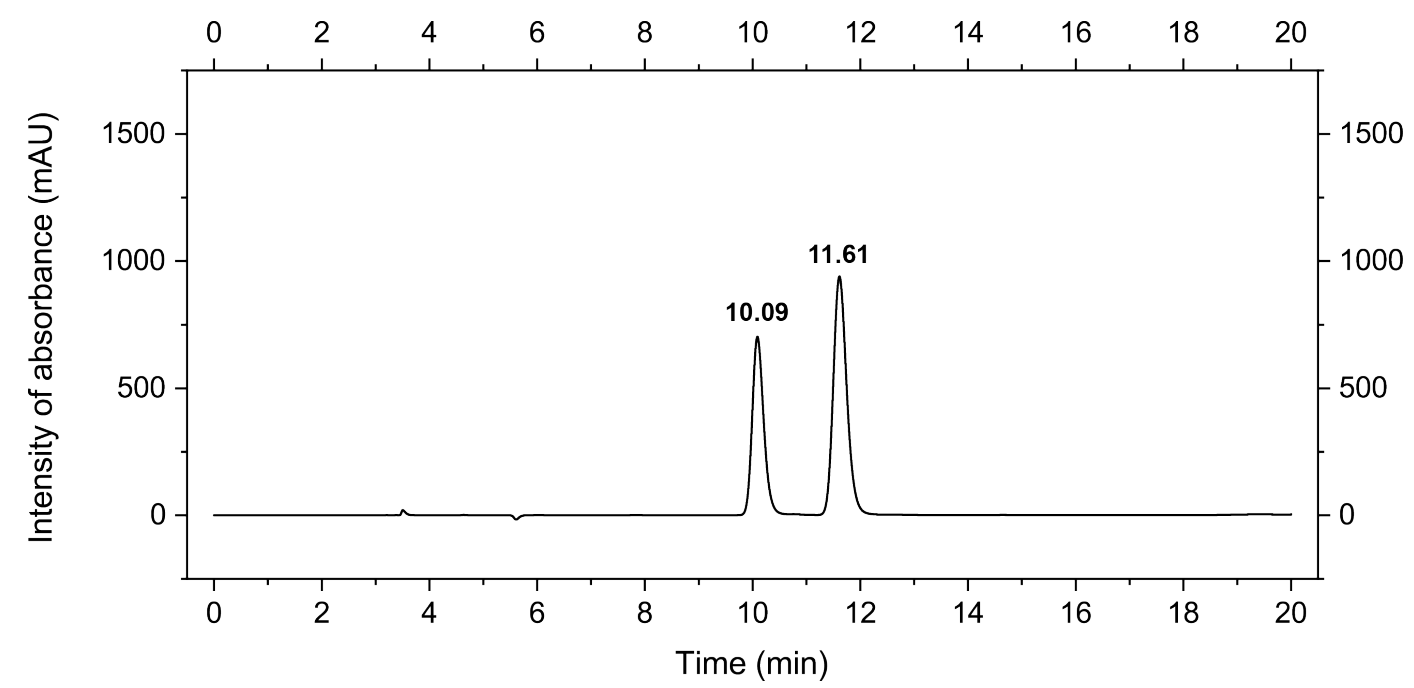

Figure S3.40: HPLC analysis of experiment 1.

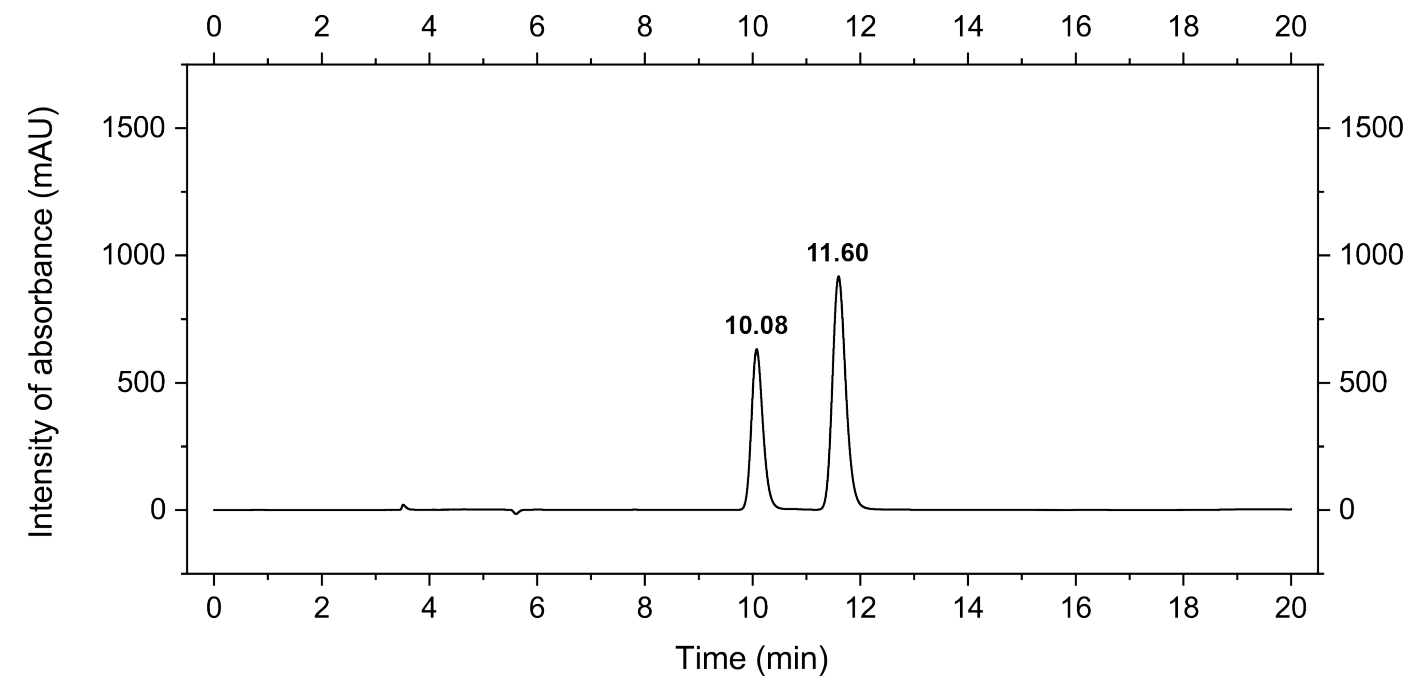

Figure S3.41: HPLC analysis of experiment 2.

Table S3.10: Results of the HPLC analyses.

\begin{tabular}{cccccccc}
\hline Exp. & En. & $t_{\text {ret }}(\min )$ & Height & Width & Area & Area\% & ee \\
\hline \multirow{2}{*}{1} & $R$ & 10.09 & 703.0 & 0.2496 & 10530.7 & 39.0 & \multirow{2}{*}{$22 \% S$} \\
& $S$ & 11.61 & 940.1 & 0.2915 & 16441.0 & 61.0 & \\
\hline \multirow{2}{*}{2} & $R$ & 10.08 & 633.3 & 0.2506 & 9522.0 & 37.4 & \multirow{2}{*}{$25 \% S$} \\
\cline { 5 - 7 } & $S$ & 11.60 & 918.5 & 0.2894 & 15951.5 & 62.6 & \\
\hline
\end{tabular}




\section{$25^{\circ} \mathrm{C}, 100$ bar}
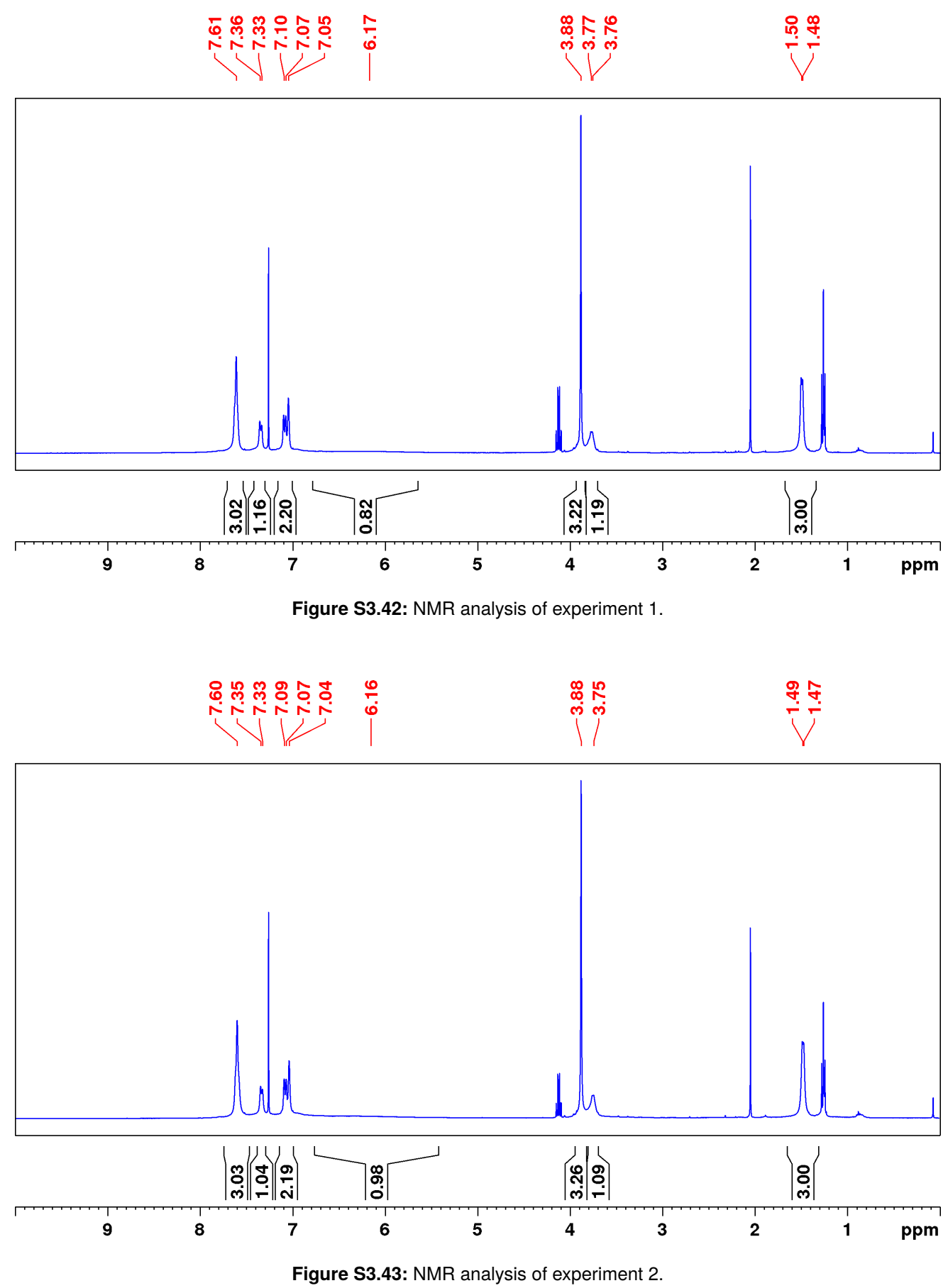


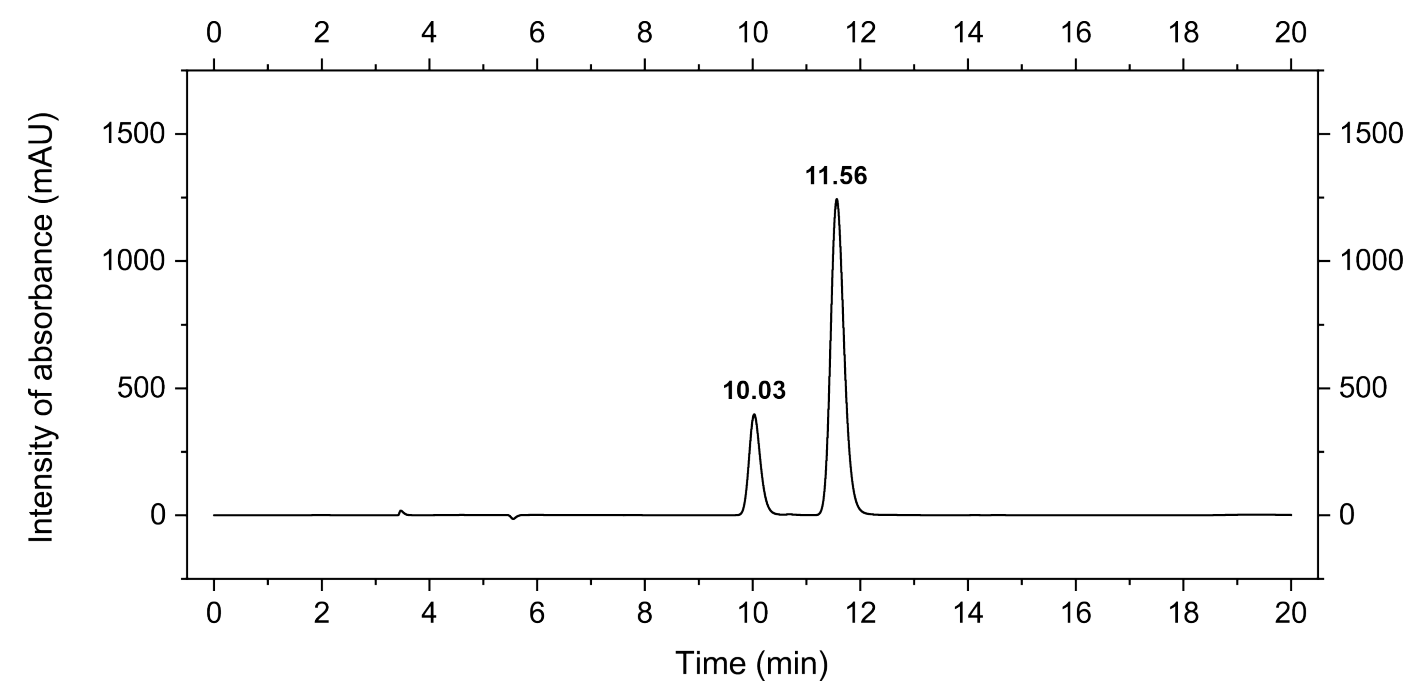

Figure S3.44: HPLC analysis of experiment 1.

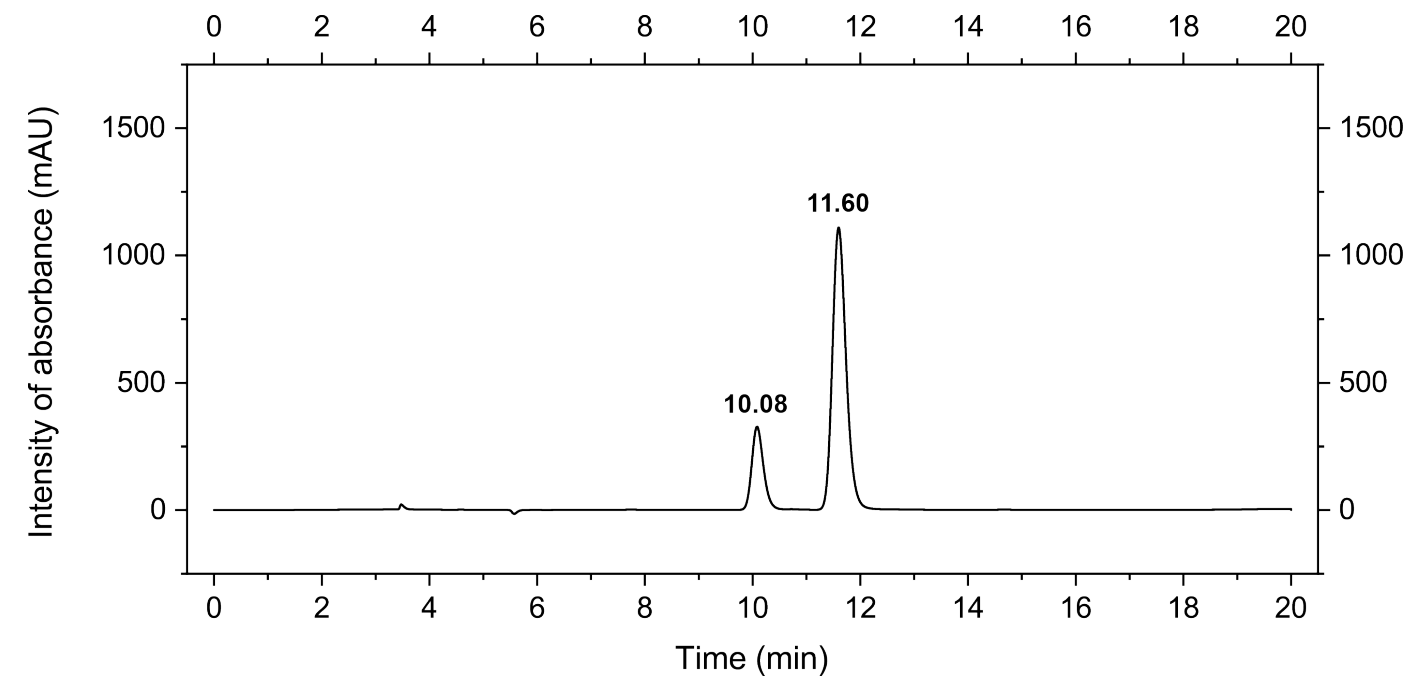

Figure S3.45: HPLC analysis of experiment 2.

Table S3.11: Results of the HPLC analyses.

\begin{tabular}{|c|c|c|c|c|c|c|c|}
\hline Exp. & En. & $t_{\text {ret }}(\min )$ & Height & Width & Area & Area \% & $e e$ \\
\hline \multirow{2}{*}{1} & $R$ & 10.03 & 397.8 & 0.2505 & 5978.4 & 21.4 & \multirow{2}{*}{$57 \% S$} \\
\hline & $S$ & 11.56 & 1245.2 & 0.2942 & 21979.3 & 78.6 & \\
\hline \multirow{2}{*}{2} & $R$ & 10.08 & 331.4 & 0.2571 & 5111.9 & 20.6 & \multirow{2}{*}{$59 \% S$} \\
\hline & $S$ & 11.60 & 1111.6 & 0.2956 & 19715.3 & 79.4 & \\
\hline & & & & & \multicolumn{2}{|c|}{ Arithmethic mean } & $58 \% S$ \\
\hline
\end{tabular}




\section{$0^{\circ} \mathrm{C}, 100 \mathrm{bar}$}
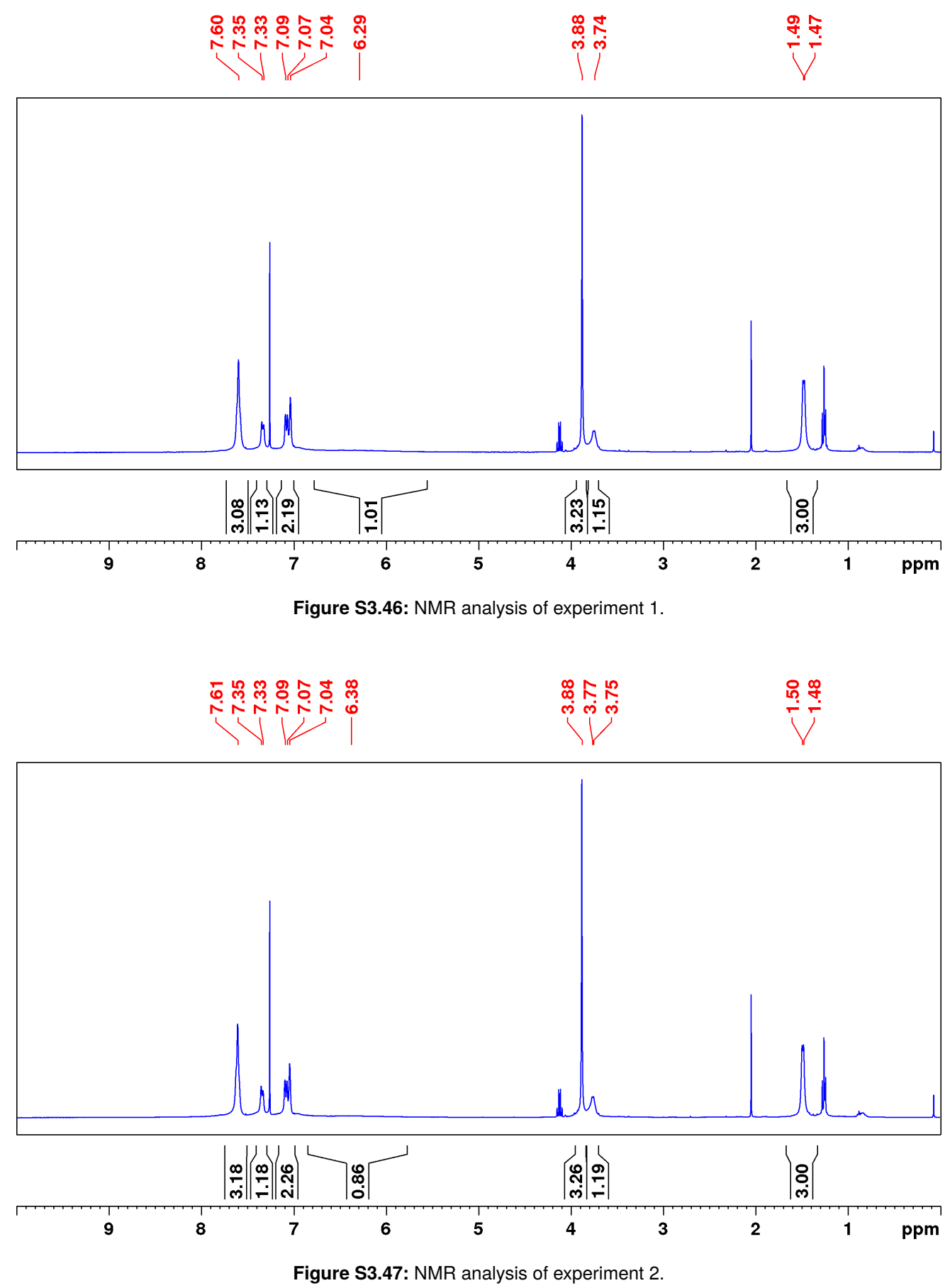


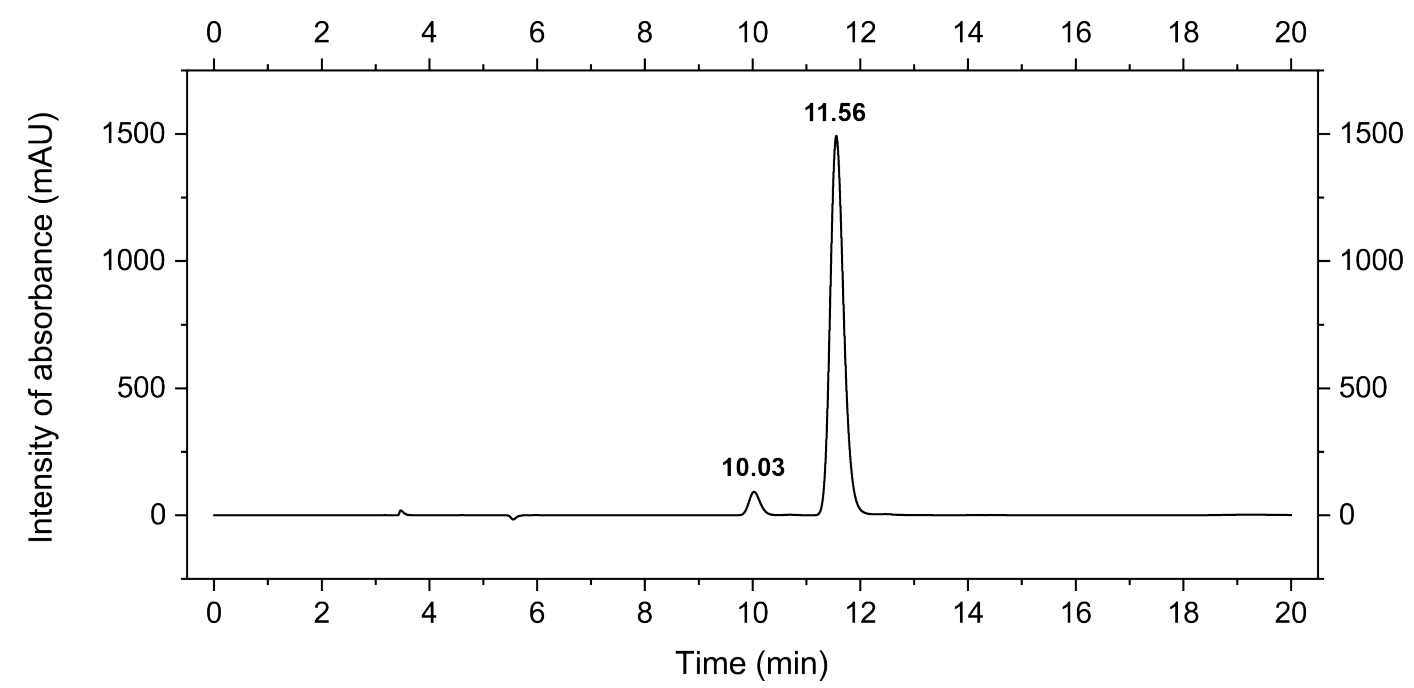

Figure S3.48: HPLC analysis of experiment 1.

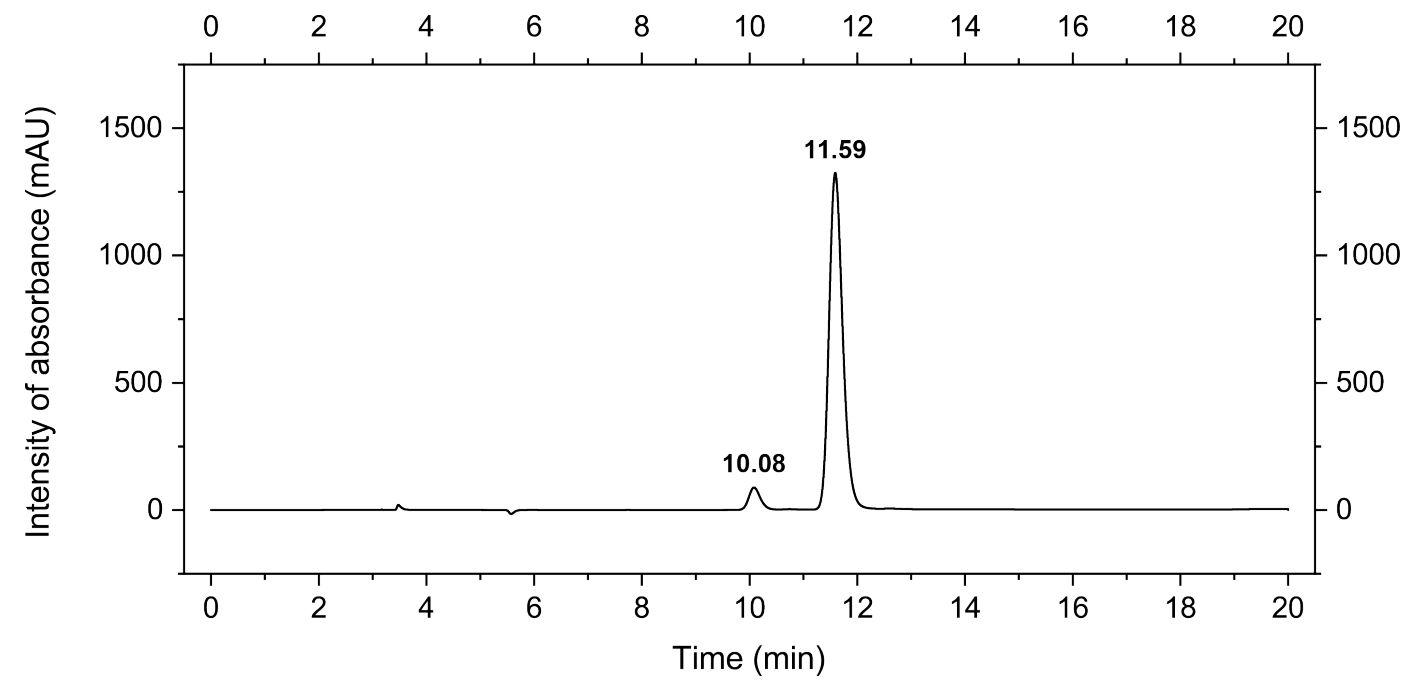

Figure S3.49: HPLC analysis of experiment 2.

Table S3.12: Results of the HPLC analyses.

\begin{tabular}{|c|c|c|c|c|c|c|c|}
\hline Exp. & En. & $t_{\text {ret }}(\min )$ & Height & Width & Area & Area \% & $e e$ \\
\hline \multirow{2}{*}{1} & $R$ & 10.03 & 93.8 & 0.2481 & 1395.7 & 5.0 & \multirow{2}{*}{$90 \% S$} \\
\hline & $S$ & 11.56 & 1494.2 & 0.2948 & 26431.9 & 95.0 & \\
\hline \multirow{2}{*}{2} & $R$ & 10.08 & 87.7 & 0.2239 & 1318.2 & 5.3 & \multirow{2}{*}{$89 \% S$} \\
\hline & $S$ & 11.59 & 1323.0 & 0.2700 & 23422.6 & 94.7 & \\
\hline & & & & & \multicolumn{2}{|c|}{ Arithmethic mean } & $90 \% S$ \\
\hline
\end{tabular}


$100^{\circ} \mathrm{C}, 100 \mathrm{bar}$
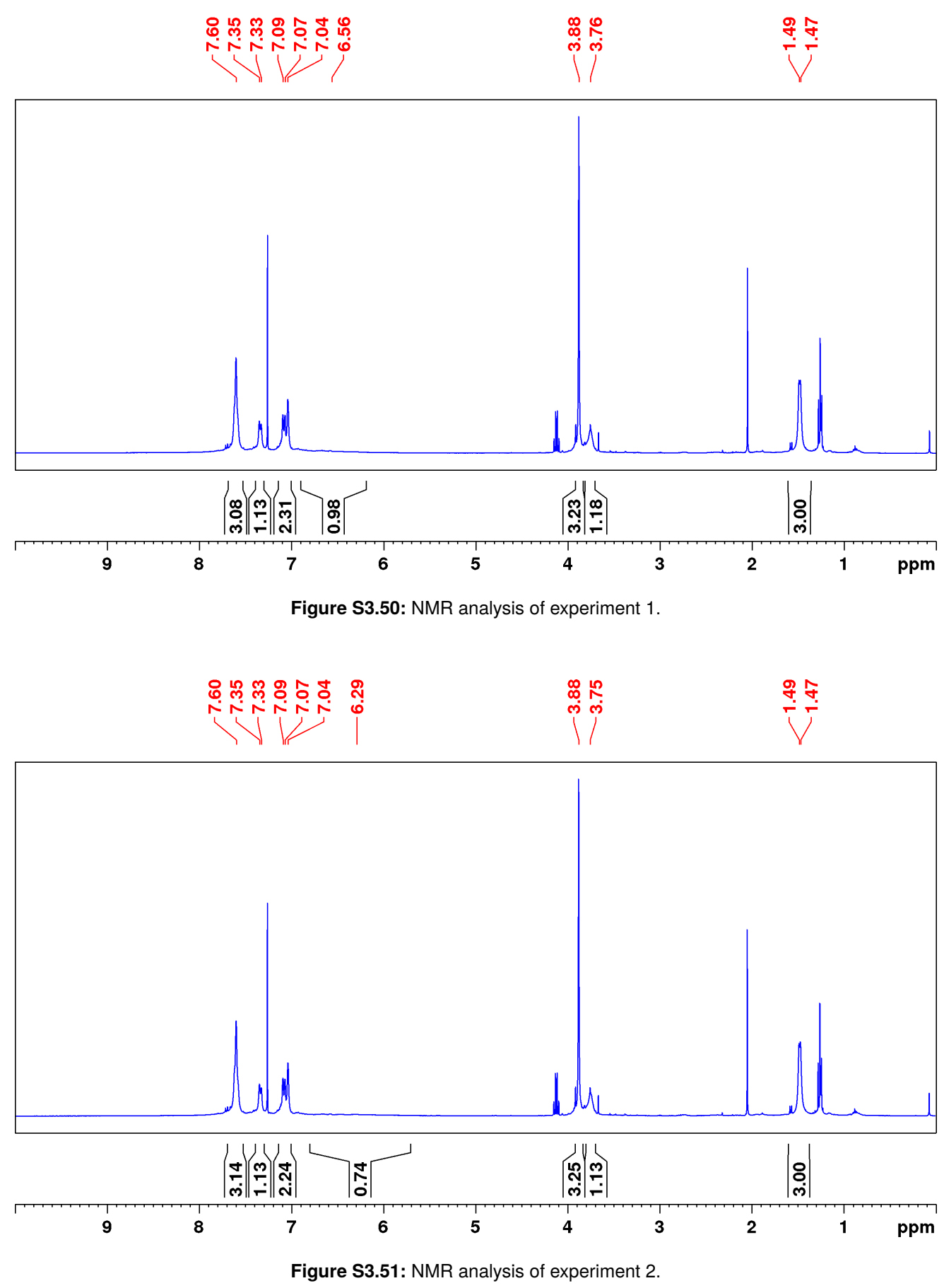


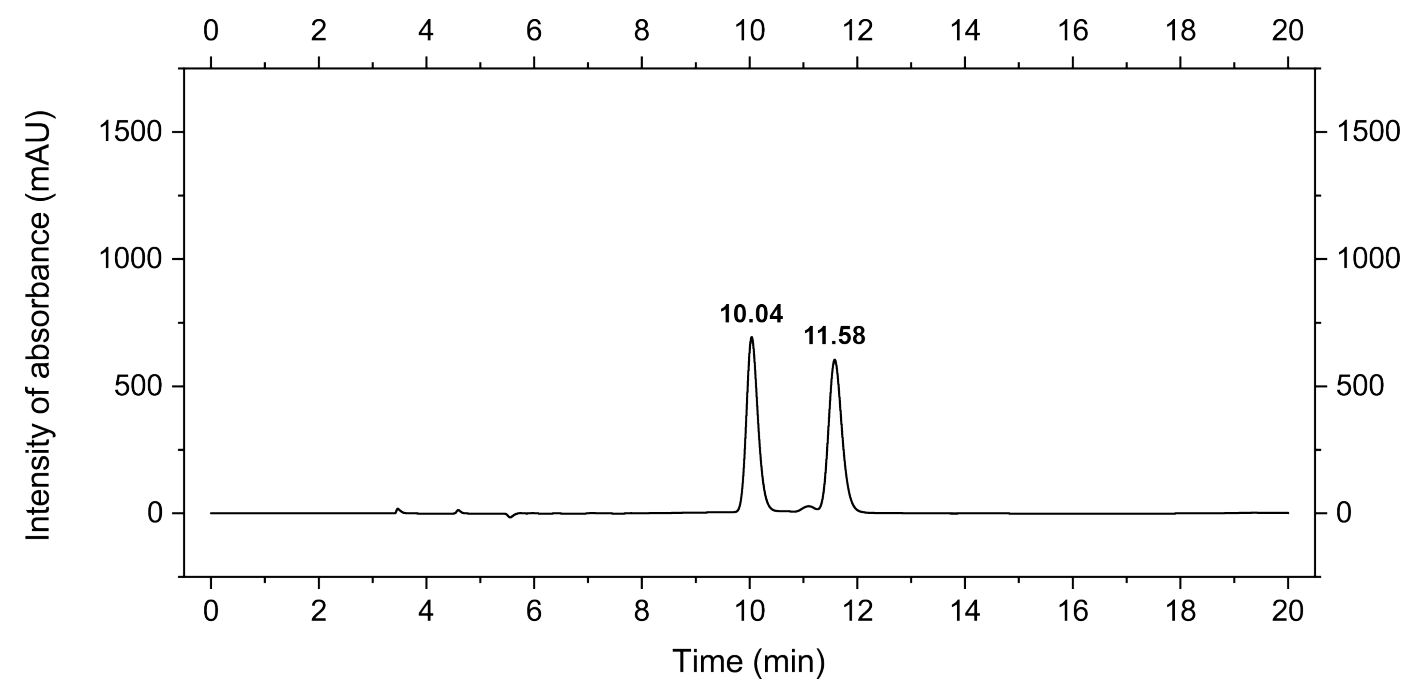

Figure S3.52: HPLC analysis of experiment 1.

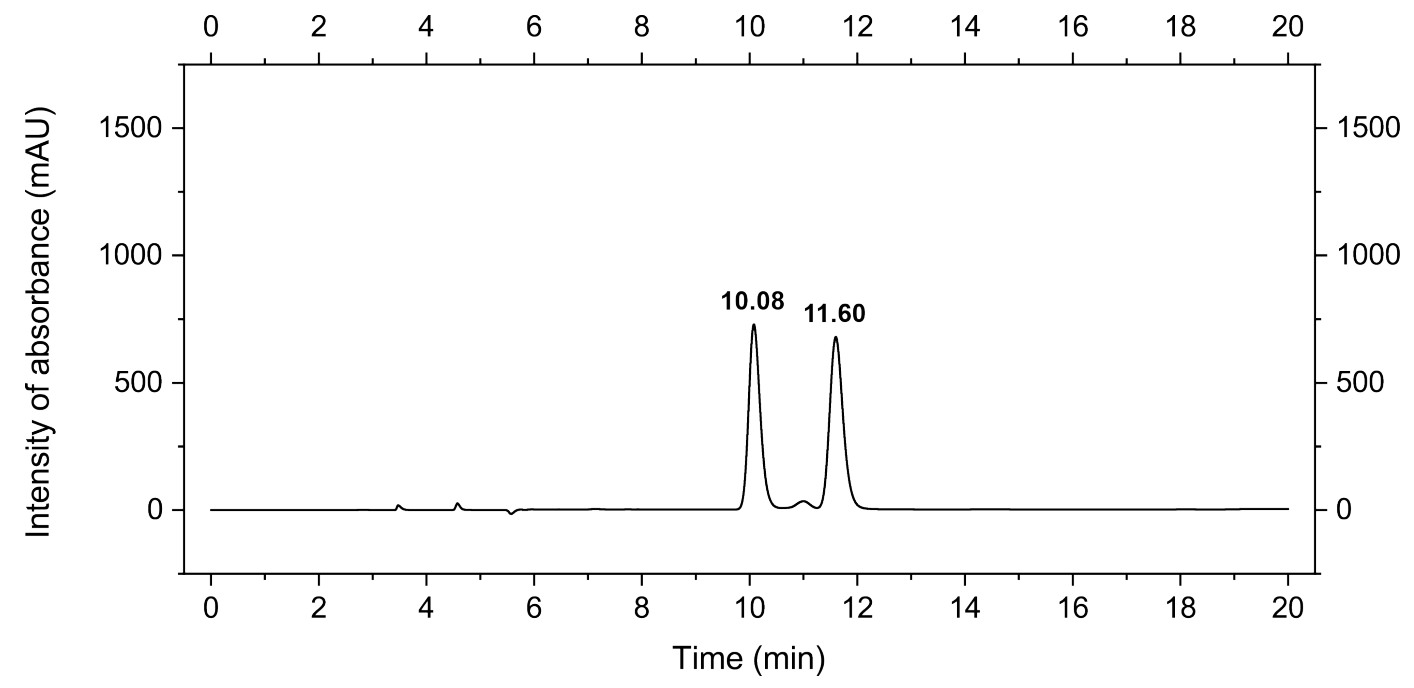

Figure S3.53: HPLC analysis of experiment 2.

Table S3.13: Results of the HPLC analyses.

\begin{tabular}{|c|c|c|c|c|c|c|c|}
\hline Exp. & En. & $t_{\text {ret }}(\min )$ & Height & Width & Area & Area \% & $e e$ \\
\hline \multirow{2}{*}{1} & $R$ & 10.04 & 690.4 & 0.2516 & 10423.8 & 49.8 & \multirow{2}{*}{$0 \%$} \\
\hline & $S$ & 11.58 & 601.1 & 0.2919 & 10528.2 & 50.2 & \\
\hline \multirow{2}{*}{2} & $R$ & 10.08 & 727.9 & 0.2535 & 11072.1 & 48.2 & \multirow{2}{*}{$4 \% S$} \\
\hline & $S$ & 11.60 & 676.7 & 0.2931 & 11900.8 & 51.8 & \\
\hline & & & & & \multicolumn{2}{|c|}{ Arithmethic mean } & $2 \% S$ \\
\hline
\end{tabular}




\section{List of Abbreviations}

\begin{tabular}{cl}
\hline Abbreviation & Full Name \\
\hline $3 V$ & Dreiwegeventil (English translation: three-way valve) \\
Ac & Acetyl \\
BS & British Standards \\
C & Connector \\
CGA & Compressed Gas Association \\
DAD & Diode Array Detector \\
DIN & Deutsches Institut für Normung e.V. (English translation: Ger- \\
& man Institute for Standardization) \\
$e e$ & enantiomeric excess \\
En. & Enantiomer \\
Et & Ethyl \\
Exp. & Experiment \\
FV & Feinventil (English translation: needle valve) \\
HPLC & High-Performance Liquid Chromatography \\
ID & Inner Diameter \\
IP & International Protection \\
IPA & Isopropanol \\
IR & Infrared \\
mAU & Milli Absorbance Unit \\
Me & Methyl \\
$n$ & normal \\
NEMA & National Electrical Manufacturers Association \\
NMR & Nuclear Magnetic Resonance \\
& \\
\hline
\end{tabular}




\begin{tabular}{cl}
\hline Abbreviation & Full Name \\
\hline NPT & National Pipe Taper (full name: American National Standard \\
& Taper Pipe Thread) \\
OD & Outer Diameter \\
PCTFE & Polychlorotrifluoroethylene \\
Ph & Phenyl \\
PTFE & Polytetrafluoroethylene \\
ret & retention \\
rpm & revolutions per minute \\
RV & Regulierventil (English translation: regulating valve)
\end{tabular}




\section{Bibliography}

[1] Storch, G.; Trapp, O. Temperature-Controlled Bidirectional Enantioselectivity in a Dynamic Catalyst for Asymmetric Hydrogenation. Angew. Chem., Int. Ed. 2015, 54, 3580-3586.

[2] Storch, G.; Deberle, L.; Menke, J.-M.; Rominger, F.; Trapp, O. A stereodynamic phosphoramidite ligand derived from 3,3'-functionalized ortho-biphenol and its rhodium(I) complex. Chirality 2016, 28, 744-748.

[3] Storch, G.; Trapp, O. By-design enantioselective self-amplification based on noncovalent product-catalyst interactions. Nat. Chem. 2017, 9, 179-187.

[4] Siebert, M.; Storch, G.; Rominger, F.; Trapp, O. Temperature-Controlled Bidirectional Enantioselectivity in Asymmetric Hydrogenation Reactions Utilizing Stereodynamic Iridium Complexes. Synthesis 2017, 49, 3485-3494.

[5] Storch, G.; Trapp, O. Supramolecular chirality transfer in a stereodynamic catalysts. Chirality 2018, 30, 1150-1160.

[6] Siebert, M.;Seibicke, M.; Siegle, A. F.; Kräh, S.; Trapp,O. Selective Ruthenium-Catalyzed Transformation of Carbon Dioxide: An Alternative Approach toward Formaldehyde. J. Am. Chem. Soc. 2019, 141, 334-341.

[7] Scholtes, J. F.; Trapp, O. Inducing Enantioselectivity in a Dynamic Catalyst by Supramolecular Interlocking. Angew. Chem., Int. Ed. 2019, 58, 6306-6310.

[8] Seibicke, M.; Siebert, M.; Siegle, A. F.; Gutenthaler, S. M.; Trapp, O. Application of Hetero-Triphos Ligands in the Selective Ruthenium-Catalyzed Transformation of Carbon Dioxide to the Formaldehyde Oxidation State. Organometallics 2019, 38 , 1809-1814.

[9] Scholtes, J. F.; Trapp, O. Enantioselectivity Induced by Stereoselective Interlocking: A Novel Core Motif for Tropos Ligands. Chem. Eur. J. 2019, 25, 11707-11714. 
[10] Scholtes, J. F.; Trapp, O. Design and synthesis of a stereodynamic catalyst with reversal of selectivity by enantioselective self-inhibition. Chirality 2019, 31, 1028-1042.

[11] Siebert, M.; Krennrich, G.; Seibicke, M.; Siegle, A. F.; Trapp, O. Identifying highperformance catalytic conditions for carbon dioxide reduction to dimethoxymethane by multivariate modelling. Chem. Sci. 2019, 10, 10466-10474.

[12] Fulmer, G. R.; Miller, A. J. M.; Sherden, N. H.; Gottlieb, H. E.; Nudelman, A.; Stoltz, B. M.; Bercaw, J. E.; Goldberg, K. I. NMR Chemical Shifts of Trace Impurities: Common Laboratory Solvents, Organics, and Gases in Deuterated Solvents Relevant to the Organometallic Chemist. Organometallics 2010, 29, 2176-2179. 